\title{
The sensitivity of Lick indices to abundance variations ${ }^{\star}$
}

\author{
A. J. Korn ${ }^{\star \star}$, C. Maraston ${ }^{\star \star \star}$, and D. Thomas ${ }^{\star \star \star}$ \\ Max-Planck-Institut für extraterrestrische Physik (MPE), Giessenbachstraße, 85748 Garching, Germany \\ e-mail: akorn@mpe.mpg.de
}

Received 6 October 2004 / Accepted 17 April 2005

\begin{abstract}
We present results of model atmosphere/line formation calculations which quantitatively test how the 21 classical and four higher-order Balmer-line Lick/IDS indices (Worthey et al. 1994, ApJS, 94, 687; Worthey \& Ottaviani 1997, ApJS, 111,377 ) depend on individual elemental abundances (of carbon, nitrogen, oxygen, magnesium, iron, calcium, sodium, silicon, chromium, titanium) and overall metallicity in various stellar evolutionary stages and at various metallicities. At low metallicities the effects of an overall enhancement of $\alpha$-elements are also investigated. The general results obtained by Tripicco \& Bell $(1995$, ApJ, 110, 3035) at solar metallicity are confirmed, while details do differ. Tables are given detailing to which element every index reacts significantly, as a function of evolutionary stage and composition.

This work validates a number of assumptions implicitly made in the stellar population models of Thomas et al. (2003a, MNRAS, $339,897)$, which utilized the results of Tripicco \& Bell (1995) to include the effects of element abundance ratios variations. In particular, these computations confirm that fractional changes to index strengths computed at solar metallicity (and solar age) can be applied over a wide range of abundances and ages, also to model old stellar populations with non-solar abundance ratios. The use of metallicity-dependent response functions not only leads to a higher degree of self-consistency in the stellar population models, but is even required for the proper modelling of the Balmer-line indices. We find that the latter become increasingly sensitive to element abundances with increasing metallicity and decreasing wavelength. While $\mathrm{H} \beta$ still responds only moderately to abundance ratio variations, the higher-order Balmer-line indices $\mathrm{H} \gamma$ and $\mathrm{H} \delta$ display very strong dependencies at high metallicities. As shown in Thomas et al. (2004, MNRAS, 351, L19), this result allows to remove systematic effects in age determinations based on different Balmer-line indices.
\end{abstract}

Key words. radiative transfer - line: formation - stars: late-type - galaxies: abundances - galaxies: evolution galaxies: fundamental parameters

\section{Introduction}

In order to constrain galaxy formation models, and with it the cosmological evolution of the baryonic Universe, the analysis of stellar populations is of primary importance, because it provides the unique way of measuring the metal enrichment and the epoch(s) of star formation. Furthermore, if it was possible to measure the relative abundances of individual elements in integrated spectra, in the same way one does for single stars (e.g. magnesium, iron, calcium, oxygen), this would provide further important information on the detailed chemical enrichment. In massive galaxies the situation is, however, more complicated. The dispersion of the velocity distribution significantly reduces the intrinsic spectral resolution, in other words single absorption lines are not resolved. Typical galaxy spectra exhibit

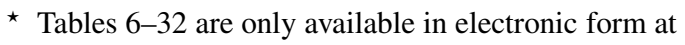
http://www.edpsciences.org and at

http://www-astro.physics.ox.ac.uk/ dthomas

$\star \star$ Leopoldina fellow at Uppsala Astronomical Observatory, Box 515, 75120 Uppsala, Sweden.

$\star \star \star$ Present address: University of Oxford, Denys Wilkinson Building, Keble Road, Oxford OX1 3RH, UK.
}

relatively broad absorption features, that contain a huge number of lines from a large variety of chemical elements. This obviously complicates the chemical abundance analysis.

Substantial progress in exploiting galaxy spectra has been made by the Lick group who defined a set of so-called absorption-line indices in the visual region $(4000 \AA \lessgtr \lambda \lesssim$ $6400 \AA)$ with relatively wide band-passes on the feature $(\Delta \lambda \sim$ 20-40 $\AA$ ) and two windows blue- and redward of the band-pass defining pseudo-continua (Burstein et al. 1984). The various indices were measured on a large sample of Milky Way stars, mostly located in the solar vicinity, and were related with the stellar parameters, effective temperature $\left(T_{\text {eff }}\right)$, surface gravity $(g)$, total metallicity $(Z)$, by analytical relations, known as the Lick fitting functions (Gorgas et al. 1993; Worthey et al. 1994). The latter are then plugged into an evolutionary synthesis code which produces integrated Lick indices for stellar population models (Worthey 1994). The comparison of galaxy data with these models allows one in principle to quantify the metallicity of the galaxy.

It had been realized from the very start, that the interpretation of the Lick indices would not be as simple as the naming of the indices suggests. The modelled Lick indices fail to match 
the data of elliptical galaxies (Worthey et al. 1994; Davies et al. 1993; Carollo \& Danziger 1994), more specifically magnesium indices were found to be much stronger than predicted by the models at a given iron index. The calibration of the models with globular cluster (GC) data having abundance patterns known from high-resolution spectroscopy have secured the conclusion that the mismatch is indeed caused by an elemental abundance effect, in particular an enhanced $[\alpha / \mathrm{Fe}]$ ratio (Maraston et al. 2003). There are several astrophysical environments that have non-solar elemental proportions, which urges the computation of models for a variety of chemical mixtures. This task is difficult to accomplish empirically by using observed spectra, because these are bound to trace the specific chemical history of the portion of Universe the stars were born in (cf. efforts of Borges et al. 1995; Idiart et al. 1997; Lejeune et al. 1997; and LeBorgne et al. 2004).

The theoretical approach has the undoubted advantage of allowing a much larger variety of chemical mixtures and ages, and was the way embarked on by the seminal study of Tripicco \& Bell (1995, hereafter TB95). The authors investigated how the 21 original indices depend upon individual abundance variations for representative positions along a solar-metallicity 5 Gyr isochrone. On the whole, their calculations succeeded in reproducing many of the observed index strengths, while some deficits were uncovered.

Thomas et al. (2003a, hereafter TMB03) have implemented the results by TB95 for the individual stars in a theoretical scheme, using an extension of the method introduced by Trager et al. (2000). This allows the computation of a complete stellar population model, thereby providing integrated Lick indices for a variety of chemical mixtures. In first applications, $\alpha / \mathrm{Fe}$ and $\mathrm{Ca} / \mathrm{Fe}$ ratios of early-type galaxies have been derived (Thomas et al. 2003b, 2004).

Although the models have been carefully calibrated to reproduce the absorption lines of globular clusters with known element abundance ratios, a number of approximations have entered their modelling, due to the limited range of results published by TB95.

Firstly, TB95 measured the index variations for solar metallicity only, while the corresponding partial derivatives have been applied by TMB03 to a large range of chemical compositions. Although the calibrating GCs span a wide range in metallicities, super-solar metallicities are not covered, while they are very important for many applications. Also, the very low metallicities encountered in Halo GCs $([\mathrm{Z} / \mathrm{H}] \sim-2)$ remain to be calibrated.

Secondly, TB95 selected the three representative stars, a main-sequence dwarf, a turnoff and a giant star on a 5 Gyr isochrone (shown to match the colour-magnitude diagram of the open cluster M 67), while TMB03 used the results for these stars to compute models for a wide range of ages from 1 to $15 \mathrm{Gyr}$ (and thus a range of stellar parameters as well).

Thirdly, TB95 analysed the classical Lick indices, while absorption indices in other wavelength ranges are nowadays in wide use, and especially for high-redshift galaxies bluer wavelength settings are required.

The principle goal of the present paper is to verify and extend the work of TB95, the prior by using an independent model atmosphere code, the latter by investigating how all 25 Lick indices react to abundance variations at different metallicities. That is, we extend the computations to include the four higher-order Balmer-line indices $\mathrm{H} \gamma_{\mathrm{A}}, \mathrm{H} \gamma_{\mathrm{F}}, \mathrm{H} \delta_{\mathrm{A}}, \mathrm{H} \delta_{\mathrm{F}}$ defined by Worthey \& Ottaviani (1997) and the modification of the Fe5270 index by the SAURON collaboration (Davies et al. 2001; Falcon-Barroso et al. 2004; H. Kuntschner, private communication).

Section 2 describes the computations we have performed and confronts the synthetic spectra with high-resolution spectra of the Sun and Arcturus. In Sect. 3 the derived index values are compared with the computations by TB95 and the empirical fitting functions (relating line index strengths and stellar parameters, hereafter referred to as FFs) of Worthey et al. (1994). The behaviour of every index to abundance variations is subsequently discussed individually. Section 4 puts the new computations in the context of stellar population models, while Sect. 5 summarizes our results.

\section{Computations}

\subsection{Model atmospheres}

All spectra and indices presented below are based on the model atmosphere code originally written by Gehren (Gehren 1975a,b) and later named MAFAGS. Just like e.g. ATLAS (Kurucz 1993a) or MARCS (Gustafsson et al. 1975), this code produces model temperature structures for the photospheres of cool stars assuming a plane-parallel geometry in hydrostatic equilibrium and LTE. The models are flux-conserving and line blanketed by means of Opacity Distribution Functions (ODFs, Kurucz 1993b). As these ODFs were computed assuming $^{1} \log \varepsilon(\mathrm{Fe})=7.67$, we rescale them by -0.16 dex to account for the low solar iron abundance of $\log \varepsilon(\mathrm{Fe})=7.50 \pm 0.05$ as given by Grevesse \& Sauval (1998). For all models of all metallicities ODFs with a microturbulence of $1 \mathrm{~km} \mathrm{~s}^{-1}$ were used, while the microturbulence entering the line formation calculation was allowed to vary between $1 \mathrm{~km} \mathrm{~s}^{-1}$ and $2.5 \mathrm{~km} \mathrm{~s}^{-1}$.

Convection is approximated by mixing-length theory (Böhm-Vitense 1958). No overshooting is considered. Unlike in the other codes mentioned above, a mixing length $\alpha_{\text {conv }}=$ $l / H_{\mathrm{p}}=0.5$ is used in order to simultaneously model $\mathrm{H} \alpha$ and the higher Balmer lines (cf. Fuhrmann et al. 1993; van't Veer-Menneret \& Mégessier 1996). This choice has little effect on metal lines, as they, in contrast to $\mathrm{H} \beta$ and higher members of the Balmer series, form at optical depths in which the flux is predominantly carried by radiation. A low convective efficiency leads to a steeper temperature gradient at high optical depths which alters the line formation of $\mathrm{H} \beta$ and the higher-order Balmer lines (see below and Sect. 3).

It is worth noticing that in the framework of a refined theory of convection (Canuto \& Mazzitelli 1992) a single value of $\alpha_{\text {conv }}$ is capable of fulfilling the constraints of stellar evolution (i.e., reproducing the solar radius at the solar age) and Balmer profile fitting (Bernkopf 1998).

Following TB95, we have calculated model atmospheres with solar abundance ratios and ones with the abundances of

\footnotetext{
${ }^{1} \log \varepsilon(\mathrm{Fe})=\log \left(n_{\mathrm{Fe}} / n_{\mathrm{H}}\right)+12$.
} 
carbon, nitrogen, oxygen, magnesium, iron, calcium, sodium, silicon, chromium and titanium each doubled in turn. In addition, we have also increased the overall metallicity $[\mathrm{Z} / \mathrm{H}]$ of the model by +0.3 dex from each base metallicity ${ }^{2}[\mathrm{Fe} / \mathrm{H}]$ of $\{+0.67,+0.35,0.0,-0.35,-1.35,-2.25\}$. Only in the latter case the ODF was changed according to the modified metallicity isolating the abundance effect whenever a single elemental abundance was varied. This assumes that the element whose abundance is varied behaves like a trace element and its variation has no effect on the temperature structure of the atmosphere. For most of the elements considered here, this is a valid assumption. It is not in two cases: iron and carbon. As iron is responsible for more than half of all line blanketing effects, the true index change due to varying the iron abundance will be somewhere between what is tabulated as "Fe" and " $[\mathrm{Z} / \mathrm{H}]$ ".

Carbon is an even more complicated case. Enhancing $\mathrm{C}$ by 0.3 dex brings the $\mathrm{C} / \mathrm{O}$ ratio so close to unity that a carbon star is produced. While the according changes to the molecular equilibria of $\mathrm{C}_{2}, \mathrm{CH}, \mathrm{CO}$ and $\mathrm{CN}$ are properly accounted for in the line formation, the feedback of the significantly modified line blanketing of carbon-star spectra on the underlying atmospheric structure cannot be modelled in an ODF approach to calculating model atmospheres. This can lead to dramatically overestimated (or underestimated) index strengths. Worthey (2005) argues that the excess of carbon (the fraction not locked up in CO) in the C-enhanced models of TB95 overestimates the true sensitivity of certain indices to carbon, as the Swan bands of $\mathrm{C}_{2}$ react quadratically to the carbon abundance. This is correct, but not the main cause for a potential overestimation of the sensitivity. Rather, we believe it is caused by the shortcomings inherent to the ODF approach (also adopted by TB95) when applied to carbon stars.

To guide the reader in an attempt to assess the reliability of the index variations due to carbon, we have computed additional sequences for the solar-metallicity stars tabulated in Tables 12-14: carbon was enhanced by 0.15 dex only (Col. 15). This smaller increase will not produce a carbon star and reflects the approach taken by Houdashelt et al. (2002). Another attempt was performed by increasing both carbon and oxygen by $0.3 \mathrm{dex}$, thus preventing the formation of a carbon star. The "C0.15" sequence ought to correctly predict the sensitivity to an increase of carbon by $40 \%$. "C+O0.3" - "O" (Col. 16-Col. 6) is deemed a better proxy to the actual $\mathrm{C}$ variation that what is tabulated in Col. 4. As carbon was not varied in TMB03, this whole problem has no impact on the scientific results published so far.

For solar metallicity, three representative models along a $1 \mathrm{Gyr}$ isochrone were also computed. They allow an assessment of the overall influence the parameter "age" has on the index strengths, mainly via increased turnoff temperatures.

For the two lowest metallicities additional sequences were computed in which a global enhancement of the $\alpha$ elements by a factor of two was assumed. This change in abundance was assumed not to influence the stellar parameters, to be able to isolate the effect of $\alpha$ enhancement. To be consistent with previous assumptions (TMB03), $\alpha$ elements were chosen to

\footnotetext{
${ }^{2}[\mathrm{Fe} / \mathrm{H}]=\log \varepsilon(\mathrm{Fe})_{\star}-\log \varepsilon(\mathrm{Fe})_{\odot}$.
}

include $\mathrm{O}, \mathrm{Ne}, \mathrm{Mg}, \mathrm{Si}, \mathrm{S}, \mathrm{Ar}, \mathrm{Ca}$, Ti (particles that are build up with $\alpha$-particle nuclei) plus the elements $\mathrm{N}$ and $\mathrm{Na}$. The abundance of $\mathrm{C}$ was kept fixed at the base metallicity, such that the $\alpha$ enhancement is compensated for by a deficit of iron-group elements. For more details on this point, see TMB03.

\subsection{Synthetic spectra}

For computing the emergent spectral energy distribution we utilize the line formation code LINFOR which is derived from MAFAGS. It has to be realized that the traditional two-step approach to calculating spectra (step 1: determining the temperature structure and partial pressures, step 2: calculating the spectrum) is a convenient, but artificial, separation of the one task of solving the radiative transfer equation with boundary conditions. It is convenient, as (in codes like ATLAS or MAFAGS) a resolution of $20 \AA$ (the resolution of the ODFs) is enough to compute realistically blanketed model temperature structures in step 1, while the use of a line formation code (like SYNTHE for ATLAS, SSG for MARCS or LINFOR for MAFAGS) in principle allows one to compute spectra at arbitrary resolutions.

LINFOR considers the formation of lines for 37 elements and 14 diatomic molecules: $\mathrm{H}_{2}, \mathrm{CH}, \mathrm{NH}, \mathrm{OH}, \mathrm{C}_{2}, \mathrm{CN}, \mathrm{CO}$, $\mathrm{N}_{2}, \mathrm{NO}, \mathrm{O}_{2}, \mathrm{MgH}, \mathrm{SiH}, \mathrm{CaH}$ and TiO. Triatomic molecules are currently not included. All important external broadening mechanisms are considered, i.e. Doppler, van-der-Waals, resonance and Stark broadening. In the specific case of Fe I, $\log \mathrm{C}_{6}$ values were determined to be 0.15 dex smaller than those proposed by Anstee \& O'Mara (1995) and changed accordingly (see Gehren et al. 2001 for more details). For most of the other elements, $\log \mathrm{C}_{6}$ values according to Unsöld (1968) or Kurucz (1992) are used.

The line list serving as input to LINFOR is not, strictly speaking, fully consistent with the ODFs used in the model atmosphere computation. This is because the atomic data of individual lines has been modified over the years based on constraints arising from the reproduction of the solar spectrum. However, the vast majority of lines still has unaltered atomic data most of which taken from Kurucz \& Peytremann (1975), Kurucz (1992) and Kurucz \& Bell (1995). Our line list does not contain TiO (Kurucz (2002) quotes his list to contain close to 40 million lines due to this molecule alone), therefore we refrain from discussing the two TiO indices in Sect. 3 at great length.

\subsection{The Sun and Arcturus}

The Sun clearly constitutes the most important point of reference for our calculations. We have therefore compared our synthetic spectra with the most commonly used solar flux atlas, the Kitt Peak atlas (Kurucz et al. 1984), in two ways. Firstly, we can compare the spectra by eye. This way individual lines obviously missing from our line list were identified and added utilizing online compilations for atomic data like those of the National (American) Institute of Standards and Technology, NIST. We, however, refrained from adding 


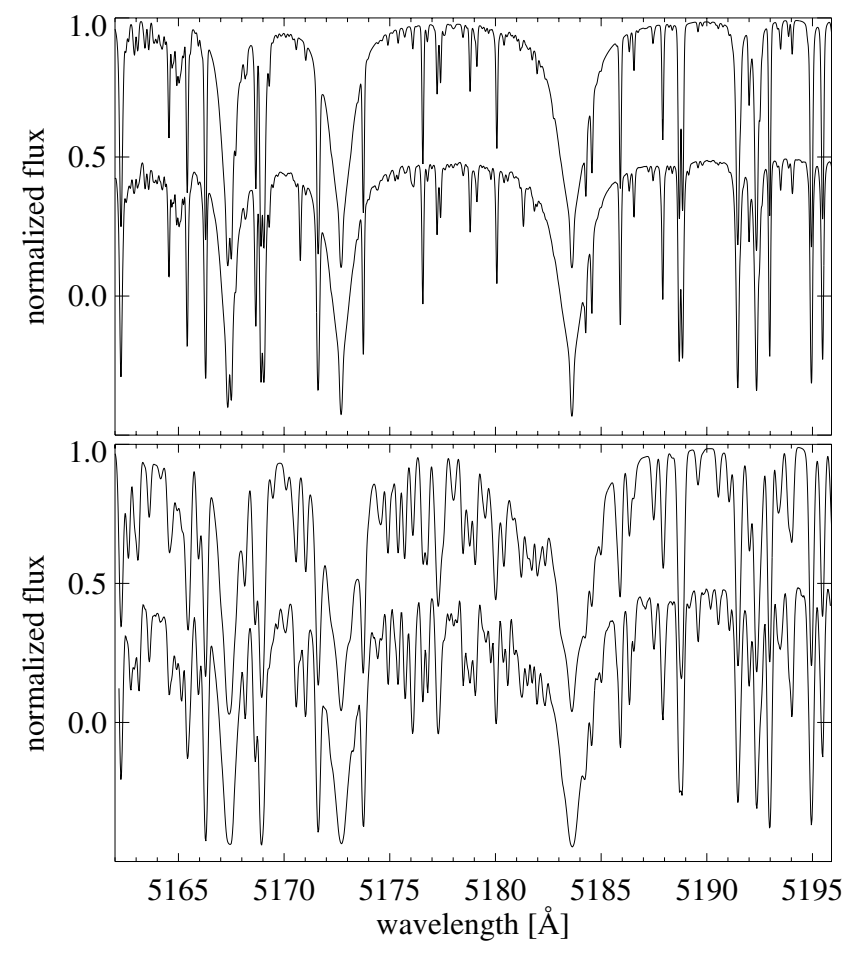

Fig. 1. A comparison between observed and computed spectra around the $\mathrm{Mg} \mathrm{I} b$ lines. Upper panel: the Sun, lower panel: Arcturus. In both panels the observations are offset by -0.5 units.

artificial lines as substitutes for unidentified lines in the Sun of which there are still thousands in the optical (a good example is the line at $5170.76 \AA$, cf. Fig. 1). Figures 1 and 2 give a qualitative indication of how well our modelling performs. These figures can be directly compared to Figs. 1 and 2 of TB95 and show that the performance of the two independent codes is quite comparable.

Secondly, since the position of the continuum is known in both the observed and the theoretical spectrum of the Sun, we can directly compare the equivalent widths $W_{\lambda}$ of the band-passes of the 25 Lick indices without the use of the pseudo-continua. This comparison was done after folding the theoretical spectra with a projected rotational velocity $v \sin i$ of $1.8 \mathrm{~km} \mathrm{~s}^{-1}$ and a macroturbulence $\Xi_{\mathrm{rt}}$ of $3.5 \mathrm{~km} \mathrm{~s}^{-1}$ in the radial-tangential approximation (Gray 1977) to account for the observed solar line broadening. The results are given in Table 1 with the last column indicating that there is a general absorption deficit in our modelling of $(15 \pm 5) \%$. Some indices deviate markedly from this mean value: $\mathrm{C}_{2} 4668, \mathrm{NaD}$ and the two TiO indices have significantly higher $\Delta W_{\lambda}{ }^{3}, \mathrm{G} 4300, \mathrm{H} \beta$, $\mathrm{Mg}_{2}, \mathrm{Mg} b$ and $\mathrm{H} \gamma \mathrm{F}$ perform better than average. There is no clear trend with wavelength. We note that using $\alpha_{\text {conv }}=$ 1.5 would result in a $\Delta W_{\lambda}$ twice as large for $\mathrm{H} \beta(14.1 \%)$ and 4-8\% larger for the higher-order Balmer-line indices.

\footnotetext{
3 The spectral regions around Fe5709 and Fe5782 were re-rectified by +1.0 respectively $+1.8 \%$ to account for an unmodelled global suppression of the observed continuum in the Kitt Peak atlas. This procedure reduces the $\Delta W_{\lambda}$ values for these two indices.
}

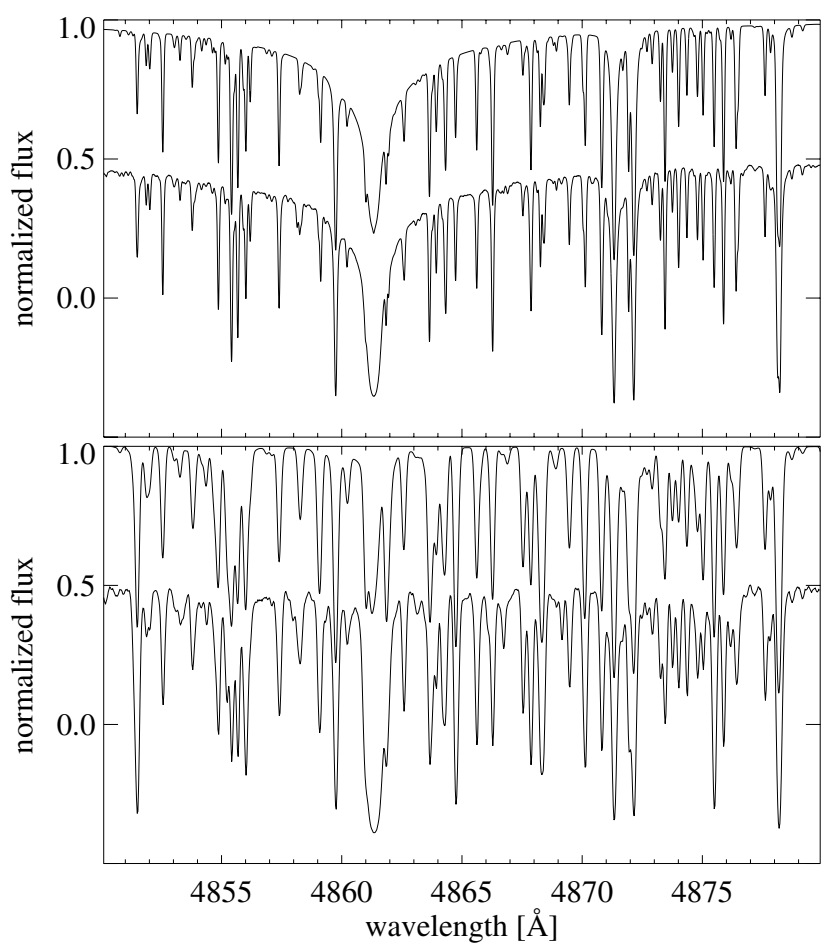

Fig. 2. A comparison between observed and computed spectra around $\mathrm{H} \beta$. Upper panel: the Sun, lower panel: Arcturus. In both panels the observations are offset by -0.5 units. Due to unmodelled physics, the line strength of $\mathrm{H} \beta$ comes out too low in Arcturus.

The cause of this absorption deficit is not to be found primarily in individual strong lines that are missing in our line list; rather is has to be attributed to many unmodelled lines of low oscillator strength and small equivalent width. To make progress in this context significantly larger line lists would have to be implemented (cf. efforts by Kurucz 2002) which is beyond the scope of this project.

The lower panels of Figs. 1 and 2 compare theory and observation for the thick-disk standard star Arcturus, a first-ascent red giant. The spectrum was obtained with the FOCES spectrograph (Pfeiffer et al. 1998) on the Calar Alto $2.2 \mathrm{~m}$ telescope in May 2000 (kindly made available by K. Fuhrmann). The spectrum covers $4200 \AA<\lambda<9000 \AA$ and has a resolving power of $R=60000$. The signal-to-noise ratio $(S / N)$ varies between 70 in the bluest part of the spectrum and 430 in the near-IR; at the wavelengths presented here it is around $230(\mathrm{Mg}$ Ib lines) and $200(\mathrm{H} \beta)$, respectively.

For the modelling we take stellar parameters from the literature: $T_{\mathrm{eff}}=4300 \mathrm{~K}$ (Peterson et al. 1993), $\log g=$ 1.6 (between Peterson et al. 1993; and Decin et al. 1997), $[\mathrm{Fe} / \mathrm{H}]=-0.5, \xi_{\text {mic }}=1.7 \mathrm{~km} \mathrm{~s}^{-1}$. The abundances of $\mathrm{O}, \mathrm{Mg}$, $\mathrm{Si}$ and $\mathrm{Ca}$ were enhanced by 0.3 dex to account for Arcturus' $\alpha$ enhancement.

As can be appreciated from the lower panels of Figs. 1 and 2, our model for Arcturus is, within its limitations, an appropriate representation of the conditions in this cool red giant. One marked exception is the $\mathrm{H} \beta$ line itself with obvious modelling deficits that have to be attributed to unmodelled physics 
Table 1. Direct integration of the Lick index band-passes, both on the observed spectrum of the Sun (Kitt Peak National Observatory, KPNO) and on the theoretical spectrum computed using the MAFAGS atmosphere code $\left(T_{\text {eff }}=5780, \log g=4.44,[\mathrm{Fe} / \mathrm{H}]=0, \xi_{\text {mic }}=\right.$ $\left.1.0 \mathrm{~km} \mathrm{~s}^{-1}, \alpha_{\text {conv }}=0.5\right)$. The final column gives the absorption deficit $\Delta W_{\lambda}=100\left(W_{\lambda}(\mathrm{KPNO})-W_{\lambda}(\mathrm{MAFAGS})\right) / W_{\lambda}(\mathrm{KPNO})$. All numbers are rounded to the first decimal place.

\begin{tabular}{|c|c|c|c|}
\hline Lick index & $\begin{array}{r}W_{\lambda}(\mathrm{KPNO}) \\
[\AA]]\end{array}$ & $\begin{array}{c}W_{\lambda}(\text { MAFAGS }) \\
{[\AA ̊ \AA]}\end{array}$ & $\begin{array}{r}\Delta W_{\lambda} \\
{[\%]}\end{array}$ \\
\hline $\mathrm{CN}_{1}, \mathrm{CN}_{2}$ & 9.1 & 7.4 & 18.0 \\
\hline $\mathrm{Ca} 4227$ & 4.0 & 3.7 & 9.4 \\
\hline G4300 & 14.1 & 13.2 & 6.5 \\
\hline $\mathrm{Fe} 4383$ & 12.7 & 11.3 & 11.2 \\
\hline $\mathrm{Ca} 4455$ & 4.4 & 3.9 & 11.5 \\
\hline $\mathrm{Fe} 4531$ & 6.8 & 5.6 & 17.9 \\
\hline $\mathrm{C}_{2} 4668$ & 11.2 & 7.6 & 31.9 \\
\hline $\mathrm{H} \beta$ & 5.9 & 5.5 & 7.1 \\
\hline $\mathrm{Fe} 5015$ & 10.0 & 8.6 & 14.2 \\
\hline $\mathrm{Mg}_{1}$ & 6.7 & 5.7 & 13.8 \\
\hline $\mathrm{Mg}_{2}$ & 7.7 & 7.3 & 5.0 \\
\hline $\operatorname{Mg} b$ & 6.7 & 6.4 & 4.5 \\
\hline $\mathrm{Fe} 5270$ & 5.0 & 4.3 & 13.9 \\
\hline Fe5335 & 3.5 & 3.0 & 13.6 \\
\hline Fe5406 & 2.8 & 2.4 & 12.7 \\
\hline Fe5709 & 1.5 & 1.3 & 13.5 \\
\hline $\mathrm{Fe} 5782$ & 1.0 & 0.8 & 21.0 \\
\hline $\mathrm{NaD}$ & 2.5 & 1.9 & 25.6 \\
\hline $\mathrm{TiO}_{1}$ & 1.7 & 0.7 & 57.4 \\
\hline $\mathrm{TiO}_{2}$ & 3.0 & 1.9 & 37.2 \\
\hline $\mathrm{H} \gamma \mathrm{A}$ & 11.9 & 10.5 & 11.9 \\
\hline $\mathrm{H} \gamma \mathrm{F}$ & 6.1 & 5.7 & 6.8 \\
\hline $\mathrm{H} \delta \mathrm{A}$ & 10.3 & 9.3 & 10.3 \\
\hline $\mathrm{H} \delta \mathrm{F}$ & 6.5 & 5.9 & 9.3 \\
\hline
\end{tabular}

(non-LTE and/or chromospheric contributions, see Przybilla \& Butler 2004). The overall good correspondence between theory and observation shows that the choices for transition probabilities and damping constants made for the Sun are essentially correct. Absorption deficits of similar magnitude as in the solar case are, however, also encountered for Arcturus.

\subsection{Spectral indices}

The output spectra are normalized and have a flux point spacing of $0.1 \AA$, just like those of TB95. To put them onto the Lick/IDS system, they were convolved with Gaussians of variable FWHM interpolated among the values given in Table 8 of Worthey \& Ottaviani (1997). This ought to not have a significant influence on the comparison with TB95 (see below). The final flux point spacing is typically $0.5 \AA$, a factor of two higher than that of the IDS spectrograph.
Table 2. Stellar parameters used in the computation of the synthetic Lick indices.

\begin{tabular}{|c|c|c|c|c|c|}
\hline$[Z / \mathrm{H}]$ & Age [Gyr] & Stage & $T_{\text {eff }}$ & $\log g$ & {$[\alpha / \mathrm{Fe}]$} \\
\hline \multirow[t]{3}{*}{+0.67} & 5 & MS & 4667 & 4.59 & 0.0 \\
\hline & & TO & 5694 & 4.16 & \\
\hline & & RG & 4590 & 3.42 & \\
\hline \multirow[t]{3}{*}{+0.35} & 5 & MS & 4543 & 4.58 & 0.0 \\
\hline & & TO & 5969 & 4.18 & \\
\hline & & RG & 4236 & 2.00 & \\
\hline \multirow[t]{3}{*}{+0.00} & 5 & MS & 4575 & 4.60 & 0.0 \\
\hline & & TO & 6200 & 4.10 & \\
\hline & & RG & 4255 & 1.90 & \\
\hline \multirow[t]{3}{*}{+0.00} & 1 & MS & 5297 & 4.56 & 0.0 \\
\hline & & TO & 8048 & 3.91 & \\
\hline & & RG & 4336 & 1.83 & \\
\hline \multirow[t]{3}{*}{-0.35} & 13 & MS & 4466 & 4.60 & 0.0 \\
\hline & & TO & 5822 & 4.22 & \\
\hline & & RG & 4414 & 1.77 & \\
\hline \multirow[t]{3}{*}{-1.35} & 13 & MS & 4385 & 4.83 & $0.0 /+0.3$ \\
\hline & & TO & 6383 & 4.16 & \\
\hline & & RG & 4662 & 1.83 & \\
\hline \multirow[t]{3}{*}{-2.25} & 13 & MS & 5124 & 4.70 & $0.0 /+0.3$ \\
\hline & & TO & 6724 & 4.15 & \\
\hline & & RG & 4822 & 1.83 & \\
\hline
\end{tabular}

We did not run calculations testing the influence of microturbulence, offsets, FWHM, continuum and resolution on the index values. The reader is referred to Tables $1-3$ of TB95 for a thorough evaluation of these aspects. Note, however, that the dependence on FWHM, continuum and resolution was found to be below the $2 \sigma$ (twice the observed standard error) level in all cases. This leaves microturbulence and potential wavelengths distortions/offsets as additional sources of systematic error.

936 Lick indices were computed at each base metallicity making it 8424 spectral indices in total.

\section{Results}

\subsection{Comparison with TB95}

Tables 12-14 give the Lick index name (Col. 1), the computed index strength (Col. 2), the standard error taken from TB95 (Col. 3) and the absolute variation of the index strengths upon increasing the abundance of the element given at the top of the column by 0.3 dex. $[\mathrm{Z} / \mathrm{H}](\mathrm{Col}$. 14) refers to an overall increase in metallicity by 0.3 dex. The Tables can be compared with Tables 4-6 of TB95. Note, however, that we chose to tabulate the absolute index changes, i.e., not the ones normalized to the assumed standard error.

Common and disparate features of the two data sets are discussed below, first globally, then index by index.

In comparing the computed index values given in Col. 2 to those of TB95, one notices agreement at the $2 \sigma$ level in $2 / 3$ of all cases (42 out of 63 ). 
Table 3. Sensitivity of individual indices to abundance variations in the dwarf phase of evolution. Only the significant (>one standard error) top three elements are given. For Fe5270(Sauron), the standard error of Fe5270(Lick) was assumed to be applicable.

\begin{tabular}{|c|c|c|c|c|c|c|c|c|}
\hline Index & +0.67 & +0.35 & 0.00 & -0.35 & -1.35 & $\begin{array}{l}-1.35 \\
\alpha \text {-enh. }\end{array}$ & -2.25 & $\begin{array}{l}-2.25 \\
\alpha \text {-enh. }\end{array}$ \\
\hline $\mathrm{CN}_{1}$ & $\mathrm{C}, \mathrm{O}, \mathrm{N}$ & $\mathrm{C}, \mathrm{O}, \mathrm{N}$ & $\mathrm{C}, \mathrm{N}, \mathrm{O}$ & $\mathrm{C}, \mathrm{N}$ & & & & \\
\hline $\mathrm{CN}_{2}$ & $\mathrm{C}, \mathrm{O}, \mathrm{N}$ & $\mathrm{C}, \mathrm{O}, \mathrm{N}$ & $\mathrm{C}, \mathrm{N}, \mathrm{O}$ & $\mathrm{C}, \mathrm{N}$ & & & & \\
\hline $\mathrm{Ca} 4227$ & $\mathrm{Ca},[\mathrm{Z} / \mathrm{H}], \mathrm{C}$ & $\mathrm{Ca},[\mathrm{Z} / \mathrm{H}], \mathrm{C}$ & $\mathrm{Ca}, \mathrm{C},[\mathrm{Z} / \mathrm{H}]$ & $\mathrm{Ca},[\mathrm{Z} / \mathrm{H}], \mathrm{C}$ & $\mathrm{Ca},[\mathrm{Z} / \mathrm{H}], \mathrm{C}$ & $\mathrm{Ca},[\mathrm{Z} / \mathrm{H}], \mathrm{C}$ & & \\
\hline G4300 & $\mathrm{C}, \mathrm{O}, \mathrm{Ti}$ & $\mathrm{C}, \mathrm{O}, \mathrm{Ti}$ & $\mathrm{C}, \mathrm{O}, \mathrm{Fe}$ & $\mathrm{C}, \mathrm{O}, \mathrm{Ti}$ & $\mathrm{C}, \mathrm{O}$ & $\mathrm{C}, \mathrm{O}$ & $\mathrm{C},[\mathrm{Z} / \mathrm{H}], \mathrm{O}$ & $\mathrm{C},[\mathrm{Z} / \mathrm{H}], \mathrm{O}$ \\
\hline $\mathrm{Fe} 4383$ & $\mathrm{Fe}, \mathrm{Mg},[\mathrm{Z} / \mathrm{H}]$ & $\mathrm{Fe}, \mathrm{Mg},[\mathrm{Z} / \mathrm{H}]$ & $\mathrm{Fe}, \mathrm{Mg},[\mathrm{Z} / \mathrm{H}]$ & $\mathrm{Fe}, \mathrm{Mg},[\mathrm{Z} / \mathrm{H}]$ & $\mathrm{Fe},[\mathrm{Z} / \mathrm{H}]$ & $\mathrm{Fe},[\mathrm{Z} / \mathrm{H}]$ & {$[\mathrm{Z} / \mathrm{H}], \mathrm{Fe}$} & \\
\hline \multicolumn{9}{|l|}{$\mathrm{Ca} 4455$} \\
\hline $\mathrm{Fe} 4531$ & $\mathrm{Ti},[\mathrm{Z} / \mathrm{H}], \mathrm{Mg}$ & $\mathrm{Ti},[\mathrm{Z} / \mathrm{H}], \mathrm{Mg}$ & $\mathrm{Ti},[\mathrm{Z} / \mathrm{H}]$ & $\mathrm{Ti},[Z / \mathrm{H}]$ & {$[Z / \mathrm{H}], \mathrm{Ti}$} & {$[Z / \mathrm{H}], \mathrm{Ti}$} & & \\
\hline $\mathrm{C}_{2} 4668$ & $\mathrm{C}, \mathrm{O}$ & $\mathrm{C}$ & $\mathrm{C}$ & $\mathrm{C}$ & & & & \\
\hline \multicolumn{9}{|l|}{$\mathrm{H} \beta$} \\
\hline Fe5015 & $\mathrm{Ti},[Z / \mathrm{H}], \mathrm{Mg}$ & $\mathrm{Ti},[Z / \mathrm{H}], \mathrm{Mg}$ & $\mathrm{Ti},[Z / \mathrm{H}], \mathrm{Mg}$ & $\mathrm{Ti},[Z / \mathrm{H}], \mathrm{Mg}$ & $\mathrm{Ti}, \mathrm{Mg},[\mathrm{Z} / \mathrm{H}]$ & $\mathrm{Ti}, \mathrm{Mg},[Z / \mathrm{H}]$ & & \\
\hline $\mathrm{Mg}_{1}$ & $\mathrm{C}, \mathrm{Mg}, \mathrm{Fe}$ & $\mathrm{C}, \mathrm{Mg},[\mathrm{Z} / \mathrm{H}]$ & $\mathrm{C}, \mathrm{Mg}, \mathrm{Fe}$ & $\mathrm{Mg}, \mathrm{C}, \mathrm{Fe}$ & $\mathrm{Mg},[\mathrm{Z} / \mathrm{H}], \mathrm{Fe}$ & $\mathrm{Mg},[\mathrm{Z} / \mathrm{H}]$ & & \\
\hline $\mathrm{Mg}_{2}$ & $\mathrm{Mg},[Z / \mathrm{H}], \mathrm{Fe}$ & $\mathrm{Mg},[Z / \mathrm{H}], \mathrm{Fe}$ & $\mathrm{Mg},[Z / \mathrm{H}], \mathrm{Fe}$ & $\mathrm{Mg},[Z / \mathrm{H}], \mathrm{Fe}$ & $\mathrm{Mg},[Z / \mathrm{H}], \mathrm{Fe}$ & $\mathrm{Mg},[Z / \mathrm{H}], \mathrm{Fe}$ & $\mathrm{Mg},[Z / \mathrm{H}]$ & $\mathrm{Mg},[Z / \mathrm{H}]$ \\
\hline $\operatorname{Mg} b$ & $\mathrm{Mg}, \mathrm{Fe},[\mathrm{Z} / \mathrm{H}]$ & $\mathrm{Mg}, \mathrm{Fe}, \mathrm{Cr}$ & $\mathrm{Mg}, \mathrm{Fe}, \mathrm{Cr}$ & $\mathrm{Mg}, \mathrm{Fe}, \mathrm{Cr}$ & $\mathrm{Mg},[Z / \mathrm{H}], \mathrm{Cr}$ & $\mathrm{Mg},[\mathrm{Z} / \mathrm{H}], \mathrm{Cr}$ & $\mathrm{Mg},[Z / \mathrm{H}]$ & $\mathrm{Mg},[Z / \mathrm{H}]$ \\
\hline $\mathrm{Fe} 5270$ & $\mathrm{Fe},[\mathrm{Z} / \mathrm{H}], \mathrm{Mg}$ & $\mathrm{Fe},[\mathrm{Z} / \mathrm{H}], \mathrm{Mg}$ & $\mathrm{Fe},[Z / \mathrm{H}], \mathrm{Mg}$ & $\mathrm{Fe},[Z / \mathrm{H}], \mathrm{Mg}$ & {$[Z / \mathrm{H}], \mathrm{Fe}$} & {$[Z / \mathrm{H}], \mathrm{Fe}$} & & \\
\hline Fe5270(Sauron) & $\mathrm{Fe},[\mathrm{Z} / \mathrm{H}], \mathrm{Mg}$ & $\mathrm{Fe},[\mathrm{Z} / \mathrm{H}], \mathrm{Mg}$ & $\mathrm{Fe},[Z / \mathrm{H}], \mathrm{Mg}$ & $\mathrm{Fe},[\mathrm{Z} / \mathrm{H}], \mathrm{Mg}$ & {$[Z / \mathrm{H}], \mathrm{Fe}$} & {$[\mathrm{Z} / \mathrm{H}], \mathrm{Fe}$} & & \\
\hline Fe5335 & $\mathrm{Fe},[\mathrm{Z} / \mathrm{H}], \mathrm{Mg}$ & $\mathrm{Fe},[\mathrm{Z} / \mathrm{H}], \mathrm{Mg}$ & $\mathrm{Fe},[\mathrm{Z} / \mathrm{H}], \mathrm{Mg}$ & $\mathrm{Fe},[\mathrm{Z} / \mathrm{H}], \mathrm{Mg}$ & $\mathrm{Fe},[\mathrm{Z} / \mathrm{H}]$ & $\mathrm{Fe},[\mathrm{Z} / \mathrm{H}]$ & & \\
\hline $\mathrm{Fe} 5406$ & $\mathrm{Fe},[\mathrm{Z} / \mathrm{H}], \mathrm{Mg}$ & $\mathrm{Fe},[\mathrm{Z} / \mathrm{H}], \mathrm{Mg}$ & $\mathrm{Fe},[\mathrm{Z} / \mathrm{H}], \mathrm{Mg}$ & $\mathrm{Fe},[\mathrm{Z} / \mathrm{H}], \mathrm{Mg}$ & $\mathrm{Fe},[\mathrm{Z} / \mathrm{H}]$ & $\mathrm{Fe},[\mathrm{Z} / \mathrm{H}]$ & & \\
\hline $\mathrm{Fe} 5709$ & {$[\mathrm{Z} / \mathrm{H}]$} & {$[Z / H]$} & {$[\mathrm{Z} / \mathrm{H}]$} & {$[\mathrm{Z} / \mathrm{H}]$} & & & & \\
\hline Fe5782 & $\mathrm{Cr}$ & $\mathrm{Cr}$ & $\mathrm{Cr}$ & $\mathrm{Cr}$ & & & & \\
\hline $\mathrm{Na} \mathrm{D}$ & $\mathrm{Na},[\mathrm{Z} / \mathrm{H}], \mathrm{Mg}$ & $\mathrm{Na},[\mathrm{Z} / \mathrm{H}], \mathrm{Mg}$ & $\mathrm{Na},[\mathrm{Z} / \mathrm{H}], \mathrm{Mg}$ & $\mathrm{Na},[\mathrm{Z} / \mathrm{H}], \mathrm{Mg}$ & $\mathrm{Na},[Z / \mathrm{H}]$ & $\mathrm{Na},[Z / \mathrm{H}]$ & & \\
\hline \multicolumn{9}{|l|}{$\mathrm{TiO}_{1}$} \\
\hline \multicolumn{9}{|l|}{$\mathrm{TiO}_{2}$} \\
\hline $\mathrm{H} \gamma \mathrm{A}$ & $\mathrm{Fe}, \mathrm{Mg},[\mathrm{Z} / \mathrm{H}]$ & $\mathrm{Fe}, \mathrm{Mg},[\mathrm{Z} / \mathrm{H}]$ & $\mathrm{Fe}, \mathrm{Mg},[\mathrm{Z} / \mathrm{H}]$ & $\mathrm{Fe}, \mathrm{Mg}, \mathrm{C}$ & $\mathrm{C},[\mathrm{Z} / \mathrm{H}], \mathrm{Fe}$ & $\mathrm{C},[\mathrm{Z} / \mathrm{H}], \mathrm{Fe}$ & $\mathrm{C},[\mathrm{Z} / \mathrm{H}]$ & $\mathrm{C},[\mathrm{Z} / \mathrm{H}]$ \\
\hline $\mathrm{H} \gamma \mathrm{F}$ & $\mathrm{Fe}, \mathrm{C}, \mathrm{Mg}$ & $\mathrm{Fe}, \mathrm{C}, \mathrm{Mg}$ & $\mathrm{Fe}, \mathrm{C}, \mathrm{Mg}$ & $\mathrm{Fe}, \mathrm{C}, \mathrm{Mg}$ & $\mathrm{C}, \mathrm{Fe}, \mathrm{O}$ & $\mathrm{C}, \mathrm{O}, \mathrm{Fe}$ & $\mathrm{C},[\mathrm{Z} / \mathrm{H}]$ & $\mathrm{C}$ \\
\hline $\mathrm{H} \delta \mathrm{A}$ & $\mathrm{Fe}, \mathrm{Mg},[\mathrm{Z} / \mathrm{H}]$ & $\mathrm{Fe}, \mathrm{Mg},[\mathrm{Z} / \mathrm{H}]$ & $\mathrm{Fe}, \mathrm{Mg},[\mathrm{Z} / \mathrm{H}]$ & $\mathrm{Fe}, \mathrm{C}, \mathrm{Mg}$ & $\mathrm{Fe},[\mathrm{Z} / \mathrm{H}], \mathrm{C}$ & $\mathrm{Fe},[\mathrm{Z} / \mathrm{H}], \mathrm{C}$ & & \\
\hline $\mathrm{H} \delta \mathrm{F}$ & $\mathrm{Fe},[\mathrm{Z} / \mathrm{H}], \mathrm{Mg}$ & $\mathrm{Fe},[\mathrm{Z} / \mathrm{H}], \mathrm{Mg}$ & $\mathrm{Fe},[\mathrm{Z} / \mathrm{H}], \mathrm{Mg}$ & $\mathrm{Fe},[\mathrm{Z} / \mathrm{H}], \mathrm{Mg}$ & $\mathrm{Fe},[\mathrm{Z} / \mathrm{H}]$ & $\mathrm{Fe},[\mathrm{Z} / \mathrm{H}]$ & & \\
\hline
\end{tabular}

For the turnoff star (6200/4.1, Table 13), the agreement is always within $2 \sigma$, in $2 / 3$ of all cases (14 out of 21 ) even within $1 \sigma$. It was expected that the turnoff star would show the highest degree of consistency as $a$ ) the temperature structure and electron pressure is robust to small changes in the assumed composition and $b$ ) molecules play a significantly reduces rôle in computing the spectra. Therefore, it does not come as a surprise either that the fractional changes show a similar overall behaviour: in 17 out of the 21 cases the sensitivity is found to be highest for the same particular element. The seemingly discrepant cases are $\mathrm{Ca} 4227, \mathrm{Fe} 5335, \mathrm{NaD}$ an $\mathrm{TiO}_{2}$. We find $\mathrm{Ca} 4227$ and $\mathrm{NaD}$ to depend more strongly on the name-giving element than on metallicity (TB95 vice versa), in the case of Fe5335 it is the other way around. The two TiO indices do not significantly depend on any of the 12 elements, neither in this study nor in TB95 (in the M-star regime, they would naturally depend on $\mathrm{Ti}$ and $\mathrm{O}$ ).

Turning to the main sequence star (4575/4.6), there are two indices which turn out more than $2 \sigma$ stronger than their TB95 counterparts: $\mathrm{H} \beta$ and Fe5015. In both cases, this strengthening turns out to bring these indices into much better agreement with both the observational data on M67 and the Worthey et al. FFs. The index strength of Fe5015 is still $1 \AA$ short of the FF for the dwarf, but the scatter among the M 67 dwarfs is of the same order (cf. Fig. 13 of TB95).

Seven indices have $I_{0}$ values smaller by more than $2 \sigma$ : $\mathrm{CN}_{1}, \mathrm{CN}_{2}, \mathrm{Ca} 4227, \mathrm{G} 4300, \mathrm{Ca} 4455, \mathrm{C}_{2} 4668$ and $\mathrm{NaD}$. In two cases (Ca4227 and $\mathrm{NaD})$, the new values lie closer to the corresponding FF and the M67 data. Two other cases (the two $\mathrm{CN}$ indices) are now in better agreement with M 67, but move away from the FF. The remaining three cases (G4300, Ca4455 and $C_{2} 4668$ ) perform worse with respect to both references.

Comparing the sensitivity to particular abundance variations, agreement is found on the element causing the largest index change in 16 cases. In two cases ( $\mathrm{Fe} 5015$ and $\mathrm{Mg}_{1}$ ) the element in first and second place trade places, and we find Ca4455 to (insignificantly) react more strongly to $\mathrm{Ca}$ itself than to metallicity, $\mathrm{Cr}$ or Fe. Furthermore, no sensitivity to $\mathrm{C}$ is found in the two $\mathrm{TiO}$ indices (as claimed by TB95). In fact, no significant sensitivity is found at all for any of these indices, neither for $\mathrm{Ca} 4455$ and $\mathrm{H} \beta$ (cf. the red giant). 
Table 4. Sensitivity of individual indices to abundance variations in the turnoff phase of evolution. Only the significant (>one standard error) top three elements are given. For Fe5270(Sauron), the standard error of Fe5270(Lick) was assumed to be applicable.

\begin{tabular}{|c|c|c|c|c|c|c|c|c|}
\hline Index & +0.67 & +0.35 & 0.00 & -0.35 & -1.35 & $\begin{array}{l}-1.35 \\
\alpha \text {-enh. }\end{array}$ & -2.25 & $\begin{array}{l}-2.25 \\
\alpha \text {-enh. }\end{array}$ \\
\hline $\mathrm{CN}_{1}$ & $\mathrm{~N}, \mathrm{C},[\mathrm{Z} / \mathrm{H}]$ & $\mathrm{N},[Z / \mathrm{H}], \mathrm{C}$ & & & & & & \\
\hline $\mathrm{CN}_{2}$ & $\mathrm{~N}, \mathrm{C},[\mathrm{Z} / \mathrm{H}]$ & $\mathrm{N},[Z / \mathrm{H}], \mathrm{C}$ & & & & & & \\
\hline $\mathrm{Ca} 4227$ & $\mathrm{C}, \mathrm{Ca}, \mathrm{N}$ & $\mathrm{Ca}$ & & & & & & \\
\hline G4300 & $\mathrm{C}, \mathrm{Fe}$ & $\mathrm{C}, \mathrm{Fe}$ & $\mathrm{C},[\mathrm{Z} / \mathrm{H}]$ & $\mathrm{C}$ & & {$[Z / H]$} & & \\
\hline $\mathrm{Fe} 4383$ & $\mathrm{Fe},[\mathrm{Z} / \mathrm{H}]$ & $\mathrm{Fe}$ & & {$[\mathrm{Z} / \mathrm{H}]$} & & & & \\
\hline \multicolumn{9}{|l|}{ Ca4455 } \\
\hline $\mathrm{Fe} 4531$ & {$[Z / H]$} & {$[Z / H]$} & {$[\mathrm{Z} / \mathrm{H}]$} & {$[\mathrm{Z} / \mathrm{H}]$} & & & & \\
\hline $\mathrm{C}_{2} 4668$ & $\mathrm{C},[\mathrm{Z} / \mathrm{H}], \mathrm{O}$ & $\mathrm{C},[\mathrm{Z} / \mathrm{H}]$ & $\mathrm{C}$ & $\mathrm{C}$ & & & & \\
\hline $\mathrm{H} \beta$ & {$[\mathrm{Z} / \mathrm{H}]$} & {$[Z / \mathrm{H}]$} & {$[\mathrm{Z} / \mathrm{H}]$} & & & & & \\
\hline Fe5015 & {$[Z / H]$} & {$[Z / \mathrm{H}]$} & {$[Z / H]$} & {$[Z / \mathrm{H}]$} & & & & \\
\hline $\mathrm{Mg}_{1}$ & $\mathrm{C},[\mathrm{Z} / \mathrm{H}], \mathrm{O}$ & $\mathrm{C},[\mathrm{Z} / \mathrm{H}], \mathrm{Fe}$ & $\mathrm{C}$ & $\mathrm{C}$ & & & & \\
\hline $\mathrm{Mg}_{2}$ & $\mathrm{Mg},[Z / \mathrm{H}], \mathrm{C}$ & {$[Z / \mathrm{H}], \mathrm{Mg}, \mathrm{C}$} & $\mathrm{Mg},[Z / \mathrm{H}]$ & $\mathrm{Mg},[Z / \mathrm{H}], \mathrm{C}$ & & & & \\
\hline $\operatorname{Mg} b$ & $\mathrm{Mg},[Z / \mathrm{H}], \mathrm{C}$ & $\mathrm{Mg},[Z / \mathrm{H}]$ & $\mathrm{Mg},[Z / \mathrm{H}]$ & $\mathrm{Mg},[Z / \mathrm{H}]$ & & & & \\
\hline Fe5270 & {$[\mathrm{Z} / \mathrm{H}], \mathrm{Fe}$} & {$[Z / H], F e$} & {$[\mathrm{Z} / \mathrm{H}]$} & {$[\mathrm{Z} / \mathrm{H}]$} & & & & \\
\hline Fe5270(Sauron) & {$[\mathrm{Z} / \mathrm{H}], \mathrm{Fe}, \mathrm{Ca}$} & {$[\mathrm{Z} / \mathrm{H}], \mathrm{Fe}, \mathrm{Ca}$} & {$[\mathrm{Z} / \mathrm{H}], \mathrm{Fe}, \mathrm{Ca}$} & {$[\mathrm{Z} / \mathrm{H}], \mathrm{Fe}, \mathrm{Ca}$} & {$[\mathrm{Z} / \mathrm{H}], \mathrm{Ca}, \mathrm{Fe}$} & {$[\mathrm{Z} / \mathrm{H}], \mathrm{Ca}, \mathrm{Fe}$} & {$[\mathrm{Z} / \mathrm{H}], \mathrm{Fe}, \mathrm{Ca}$} & {$[\mathrm{Z} / \mathrm{H}], \mathrm{Fe}, \mathrm{Ca}$} \\
\hline $\mathrm{Fe} 5335$ & $\mathrm{Fe},[\mathrm{Z} / \mathrm{H}]$ & {$[Z / \mathrm{H}], \mathrm{Fe}$} & {$[\mathrm{Z} / \mathrm{H}]$} & {$[\mathrm{Z} / \mathrm{H}]$} & & & & \\
\hline Fe5406 & $\mathrm{Fe},[\mathrm{Z} / \mathrm{H}]$ & & & & & & & \\
\hline $\mathrm{Fe} 5709$ & {$[\mathrm{Z} / \mathrm{H}]$} & {$[Z / \mathrm{H}]$} & & & & & & \\
\hline \multicolumn{9}{|l|}{$\mathrm{Fe} 5782$} \\
\hline $\mathrm{Na} \mathrm{D}$ & $\mathrm{Na},[\mathrm{Z} / \mathrm{H}]$ & $\mathrm{Na},[\mathrm{Z} / \mathrm{H}]$ & $\mathrm{Na}$ & $\mathrm{Na}$ & & & & \\
\hline \multicolumn{9}{|l|}{$\mathrm{TiO}_{1}$} \\
\hline \multicolumn{9}{|l|}{$\mathrm{TiO}_{2}$} \\
\hline $\mathrm{H} \gamma \mathrm{A}$ & $\mathrm{C}, \mathrm{Fe}, \mathrm{Mg}$ & $\mathrm{C}$ & $\mathrm{C}$ & $\mathrm{C},[\mathrm{Z} / \mathrm{H}]$ & & & & \\
\hline $\mathrm{H} \gamma \mathrm{F}$ & $\mathrm{C}$ & $\mathrm{C}$ & $\mathrm{C}$ & $\mathrm{C}$ & & & & \\
\hline $\mathrm{H} \delta \mathrm{A}$ & $\mathrm{Fe}$ & & & & & & & \\
\hline $\mathrm{H} \delta \mathrm{F}$ & $\mathrm{Fe}$ & & & & & & & \\
\hline
\end{tabular}

In the red giant (4255/1.9), four indices are significantly stronger: $\mathrm{Fe} 4531, \mathrm{H} \beta, \mathrm{Fe} 5015$ and Fe5335. Just like in the case of the main sequence star, $\mathrm{H} \beta$ and Fe 5015 are now in excellent agreement with the M67 fiducials of TB95. Fe4531 and Fe5335 are $2 \AA$ respectively $1 \AA$ too large to be in accord with M 67 and the FF.

The same seven indices that were found to be more than $2 \sigma$ weaker in the dwarf are also weaker in the giant; $\mathrm{TiO}_{2}$ has to be added to this list. Four indices $\left(\mathrm{CN}_{1}, \mathrm{Ca} 4455\right.$, $\mathrm{C}_{2} 4668$ and $\mathrm{TiO}_{2}$ ) clearly perform worse, the new strength of $\mathrm{NaD}$ places it on the opposite side of the distribution of giants in M 67 from TB95 and about equally close to the FF, and three indices $\left(\mathrm{CN}_{2}, \mathrm{Ca} 4227\right.$ and $\left.\mathrm{G} 4300\right)$ fare better using MAFAGS.

Turning to the abundance variations, the dominant rôle of a particular element found by TB95 is recovered for 11 indices. In a further 5 cases (Fe5015, Fe5270, Fe5335, Fe5406 and Fe5782) the order of the first two element is reversed (sometimes making them most sensitive to $\mathrm{Fe}$, sometimes to $[\mathrm{Z} / \mathrm{H}])$, in one case $(\mathrm{Ca} 4227)$ that of the dominant three. In four cases $\left(\mathrm{Ca} 4455, \mathrm{H} \beta, \mathrm{TiO}_{1}\right.$ and $\left.\mathrm{TiO}_{2}\right)$ we find no significant sensitivity to any of the elements studied. For $\mathrm{H} \beta$ this is confirmation of the TB95 result.

Overall, the one-by-one comparison shows that the computations presented here are on par with those published by TB95. Irrespective of whether improvements were found or not, understanding the cause of disparate results would bring on progress. Since we do not have access to R. Bell's version of the MARCS code nor to the line-formation code SSG and the line list used, this is unfortunately not possible. Taken at face value, the differences certainly tell us something about the uncertainties involved in the modelling of Lick indices. As a rule of thumb, we conclude that the bluest classical indices except Fe4383 ${ }^{4}$ (that is, $\mathrm{CN}_{1}, \mathrm{CN}_{2}, \mathrm{Ca} 4227, \mathrm{G} 4300, \mathrm{Ca} 4455$, $\mathrm{Fe} 4531$ and $\mathrm{C}_{2} 4668$ ) bear higher modelling uncertainties than the other 13 indices. Together with the wavelength independence of $\Delta W_{\lambda}$ (see Table 1), this indicates that line-list differences are largest in regions of high line density, as one might have expected.

${ }^{4}$ Fe4383 can be considered an exception. We agree with TB95 that this index is best suited for the determination of the iron abundance. 
Table 5. Sensitivity of individual indices to abundance variations in the giant phase of evolution. Only the significant (>one standard error) top three elements are given. For Fe5270(Sauron), the standard error of Fe5270(Lick) was assumed to be applicable.

\begin{tabular}{|c|c|c|c|c|c|c|c|c|}
\hline Index & +0.67 & +0.35 & 0.00 & -0.35 & -1.35 & $\begin{array}{l}-1.35 \\
\alpha \text {-enh. }\end{array}$ & -2.25 & $\begin{array}{l}-2.25 \\
\alpha \text {-enh. }\end{array}$ \\
\hline $\mathrm{CN}_{1}$ & $\mathrm{C}, \mathrm{O}, \mathrm{N}$ & $\mathrm{C}, \mathrm{O}, \mathrm{N}$ & $\mathrm{C}, \mathrm{O}, \mathrm{N}$ & $\mathrm{C}, \mathrm{N}, \mathrm{O}$ & $\mathrm{N}, \mathrm{C}$ & $\mathrm{N}, \mathrm{C},[\mathrm{Z} / \mathrm{H}]$ & & \\
\hline $\mathrm{CN}_{2}$ & $\mathrm{C}, \mathrm{O}, \mathrm{N}$ & $\mathrm{C}, \mathrm{O}, \mathrm{N}$ & $\mathrm{C}, \mathrm{O}, \mathrm{N}$ & $\mathrm{C}, \mathrm{N}, \mathrm{O}$ & $\mathrm{N},[Z / \mathrm{H}], \mathrm{C}$ & $\mathrm{N},[\mathrm{Z} / \mathrm{H}], \mathrm{C}$ & & \\
\hline $\mathrm{Ca} 4227$ & $\mathrm{Ca},[\mathrm{Z} / \mathrm{H}], \mathrm{C}$ & $\mathrm{Ca},[\mathrm{Z} / \mathrm{H}], \mathrm{C}$ & $\mathrm{Ca},[\mathrm{Z} / \mathrm{H}], \mathrm{C}$ & $\mathrm{C}, \mathrm{Ca},[\mathrm{Z} / \mathrm{H}]$ & $\mathrm{C}$ & $\mathrm{C}$ & & \\
\hline G4300 & $\mathrm{C}, \mathrm{O}, \mathrm{Fe}$ & $\mathrm{C}, \mathrm{O}, \mathrm{Fe}$ & $\mathrm{C}, \mathrm{O}$ & $\mathrm{C}, \mathrm{O}$ & $\mathrm{C}$ & & $\mathrm{C},[\mathrm{Z} / \mathrm{H}]$ & $\mathrm{C},[Z / \mathrm{H}]$ \\
\hline $\mathrm{Fe} 4383$ & $\mathrm{Fe}, \mathrm{Mg},[\mathrm{Z} / \mathrm{H}]$ & $\mathrm{Fe},[\mathrm{Z} / \mathrm{H}], \mathrm{Mg}$ & $\mathrm{Fe},[\mathrm{Z} / \mathrm{H}], \mathrm{Mg}$ & $\mathrm{Fe},[\mathrm{Z} / \mathrm{H}]$ & {$[\mathrm{Z} / \mathrm{H}], \mathrm{C}$} & $\mathrm{C},[\mathrm{Z} / \mathrm{H}]$ & & \\
\hline \multicolumn{9}{|l|}{$\mathrm{Ca} 4455$} \\
\hline $\mathrm{Fe} 4531$ & {$[Z / \mathrm{H}], \mathrm{Ti}$} & {$[Z / \mathrm{H}], \mathrm{Ti}$} & {$[Z / \mathrm{H}], \mathrm{Ti}$} & {$[Z / \mathrm{H}]$} & {$[Z / \mathrm{H}]$} & {$[Z / \mathrm{H}]$} & {$[Z / \mathrm{H}]$} & \\
\hline$C_{2} 4668$ & $\mathrm{C}, \mathrm{O},[\mathrm{Z} / \mathrm{H}]$ & $\mathrm{C}, \mathrm{O},[\mathrm{Z} / \mathrm{H}]$ & $\mathrm{C}, \mathrm{O},[\mathrm{Z} / \mathrm{H}]$ & $\mathrm{C},[\mathrm{Z} / \mathrm{H}], \mathrm{O}$ & $\mathrm{C}$ & $\mathrm{C}$ & & \\
\hline \multicolumn{9}{|l|}{$\mathrm{H} \beta$} \\
\hline Fe5015 & {$[\mathrm{Z} / \mathrm{H}], \mathrm{Ti}, \mathrm{Mg}$} & {$[\mathrm{Z} / \mathrm{H}], \mathrm{Ti}, \mathrm{Mg}$} & {$[\mathrm{Z} / \mathrm{H}], \mathrm{Ti}, \mathrm{Mg}$} & {$[\mathrm{Z} / \mathrm{H}], \mathrm{Fe}, \mathrm{Mg}$} & {$[Z / \mathrm{H}]$} & {$[Z / \mathrm{H}]$} & {$[Z / H]$} & {$[Z / \mathrm{H}]$} \\
\hline $\mathrm{Mg}_{1}$ & $\mathrm{C}, \mathrm{Mg},[\mathrm{Z} / \mathrm{H}]$ & $\mathrm{C}, \mathrm{Mg},[\mathrm{Z} / \mathrm{H}]$ & $\mathrm{C},[\mathrm{Z} / \mathrm{H}], \mathrm{Mg}$ & $\mathrm{C},[\mathrm{Z} / \mathrm{H}], \mathrm{Mg}$ & $\mathrm{C},[\mathrm{Z} / \mathrm{H}]$ & $\mathrm{C},[\mathrm{Z} / \mathrm{H}]$ & & \\
\hline $\mathrm{Mg}_{2}$ & $\mathrm{Mg},[\mathrm{Z} / \mathrm{H}], \mathrm{C}$ & $\mathrm{Mg},[\mathrm{Z} / \mathrm{H}], \mathrm{C}$ & $\mathrm{Mg},[\mathrm{Z} / \mathrm{H}], \mathrm{C}$ & $\mathrm{Mg},[\mathrm{Z} / \mathrm{H}], \mathrm{C}$ & {$[Z / H], C$} & {$[\mathrm{Z} / \mathrm{H}], \mathrm{Mg}, \mathrm{C}$} & & \\
\hline $\operatorname{Mg} b$ & $\mathrm{Mg}, \mathrm{Fe},[\mathrm{Z} / \mathrm{H}]$ & $\mathrm{Mg},[Z / \mathrm{H}], \mathrm{Fe}$ & $\mathrm{Mg},[\mathrm{Z} / \mathrm{H}], \mathrm{Fe}$ & $\mathrm{Mg},[\mathrm{Z} / \mathrm{H}], \mathrm{C}$ & & $\mathrm{Mg}$ & & \\
\hline $\mathrm{Fe} 5270$ & $\mathrm{Fe},[\mathrm{Z} / \mathrm{H}]$ & $\mathrm{Fe},[\mathrm{Z} / \mathrm{H}]$ & $\mathrm{Fe},[\mathrm{Z} / \mathrm{H}]$ & {$[\mathrm{Z} / \mathrm{H}], \mathrm{Fe}$} & {$[\mathrm{Z} / \mathrm{H}]$} & {$[\mathrm{Z} / \mathrm{H}]$} & & \\
\hline Fe5270(Sauron) & $\mathrm{Fe},[\mathrm{Z} / \mathrm{H}], \mathrm{Mg}$ & $\mathrm{Fe},[\mathrm{Z} / \mathrm{H}], \mathrm{Mg}$ & $\mathrm{Fe},[\mathrm{Z} / \mathrm{H}], \mathrm{Mg}$ & {$[\mathrm{Z} / \mathrm{H}], \mathrm{Fe}, \mathrm{Mg}$} & {$[\mathrm{Z} / \mathrm{H}], \mathrm{Fe}, \mathrm{Ca}$} & {$[\mathrm{Z} / \mathrm{H}], \mathrm{Fe}, \mathrm{Ca}$} & {$[\mathrm{Z} / \mathrm{H}], \mathrm{Fe}, \mathrm{Ca}$} & {$[\mathrm{Z} / \mathrm{H}], \mathrm{Ca}, \mathrm{Fe}$} \\
\hline $\mathrm{Fe} 5335$ & {$[\mathrm{Z} / \mathrm{H}], \mathrm{Fe}, \mathrm{Mg}$} & {$[\mathrm{Z} / \mathrm{H}], \mathrm{Fe}$} & {$[\mathrm{Z} / \mathrm{H}], \mathrm{Fe}$} & {$[\mathrm{Z} / \mathrm{H}], \mathrm{Fe}$} & {$[\mathrm{Z} / \mathrm{H}]$} & & & \\
\hline $\mathrm{Fe} 5406$ & {$[Z / \mathrm{H}], \mathrm{Fe}$} & {$[\mathrm{Z} / \mathrm{H}], \mathrm{Fe}$} & {$[Z / \mathrm{H}], \mathrm{Fe}$} & {$[\mathrm{Z} / \mathrm{H}], \mathrm{Fe}$} & {$[\mathrm{Z} / \mathrm{H}]$} & & & \\
\hline $\mathrm{Fe} 5709$ & {$[Z / \mathrm{H}]$} & {$[Z / H]$} & {$[Z / \mathrm{H}]$} & {$[Z / \mathrm{H}]$} & {$[\mathrm{Z} / \mathrm{H}]$} & & & \\
\hline $\mathrm{Fe} 5782$ & $\mathrm{Cr},[\mathrm{Z} / \mathrm{H}]$ & $\mathrm{Cr}$ & $\mathrm{Cr},[\mathrm{Z} / \mathrm{H}]$ & $\mathrm{Cr},[\mathrm{Z} / \mathrm{H}]$ & & & & \\
\hline $\mathrm{NaD}$ & $\mathrm{Na},[Z / \mathrm{H}], \mathrm{Mg}$ & $\mathrm{Na},[\mathrm{Z} / \mathrm{H}]$ & $\mathrm{Na},[Z / \mathrm{H}]$ & $\mathrm{Na},[\mathrm{Z} / \mathrm{H}]$ & & & & \\
\hline \multicolumn{9}{|l|}{$\mathrm{TiO}_{1}$} \\
\hline \multicolumn{9}{|l|}{$\mathrm{TiO}_{2}$} \\
\hline $\mathrm{H} \gamma \mathrm{A}$ & $\mathrm{Fe},[\mathrm{Z} / \mathrm{H}], \mathrm{Mg}$ & $\mathrm{Fe},[Z / \mathrm{H}], \mathrm{Mg}$ & $\mathrm{Fe},[\mathrm{Z} / \mathrm{H}], \mathrm{Mg}$ & {$[\mathrm{Z} / \mathrm{H}], \mathrm{Fe}$} & {$[Z / H]$} & {$[Z / \mathrm{H}]$} & {$[\mathrm{Z} / \mathrm{H}], \mathrm{C}$} & {$[Z / H], C$} \\
\hline $\mathrm{H} \gamma \mathrm{F}$ & $\mathrm{Fe}, \mathrm{C}$ & {$[\mathrm{Z} / \mathrm{H}], \mathrm{Fe}, \mathrm{C}$} & $\mathrm{Fe},[\mathrm{Z} / \mathrm{H}]$ & & & & $\mathrm{C},[\mathrm{Z} / \mathrm{H}]$ & $\mathrm{C},[\mathrm{Z} / \mathrm{H}]$ \\
\hline $\mathrm{H} \delta \mathrm{A}$ & $\mathrm{Fe},[Z / \mathrm{H}], \mathrm{Mg}$ & $\mathrm{Fe},[\mathrm{Z} / \mathrm{H}]$ & $\mathrm{Fe},[\mathrm{Z} / \mathrm{H}]$ & $\mathrm{Fe},[\mathrm{Z} / \mathrm{H}]$ & $\mathrm{C}$ & $\mathrm{C}$ & & \\
\hline $\mathrm{H} \delta \mathrm{F}$ & $\mathrm{Fe},[\mathrm{Z} / \mathrm{H}], \mathrm{Mg}$ & {$[Z / \mathrm{H}], \mathrm{Fe}, \mathrm{Mg}$} & {$[\mathrm{Z} / \mathrm{H}], \mathrm{Fe}$} & {$[\mathrm{Z} / \mathrm{H}], \mathrm{Fe}$} & & & & \\
\hline
\end{tabular}

\subsection{Comparison with Fitting Functions at various metallicities}

Table 2 gives details of the stellar parameters used for the computation of the synthetic Lick indices. The data pairs $\left\{T_{\text {eff }}\right.$, $\log g\}$ were read off from isochrones of the given metallicity and age (from Cassisi et al. 1997; and Salasnich et al. 2000 for the highest metallicity, see Maraston 1998, 2005 for details) for dwarf and turnoff stars. For the giants, they represent average locations in which the fuel consumption on the Red Giant Branch is maximum (see Maraston 2005).

Tables 6-32 give the index values and index variations for representative dwarfs (MS), turnoff stars (TO) and red giants $(\mathrm{RG})$ for metallicities ranging from +0.67 to -2.25 . At solar metallicity Tables 15-17 give additional values for objects of age 1 Gyr. At metallicities -1.35 and -2.25 Tables $24-26$ and 30-32 contain additional data sets computed under the assumption of a general enhancement of $\alpha$ elements. Tables 3-5 give an overview of the sensitivity of Lick indices to abundance variations (including sensitivity to $[\mathrm{Z} / \mathrm{H}]$ ).
Figures 4-8 are a graphical representation of the metallicity dependence of the index and the corresponding FF values. They may serve as an at-a-glance source of information on where modelling deficits are practically absent or dominating. Modelled index strengths are denoted by the (coloured) boxes, the bullets are the corresponding FF values with IDS standard errors of Worthey et al. (1994). The diamonds indicate the absolute index change that results from a 0.3 dex increase of the element producing the highest index change. This dominant element was sometimes found to vary with evolutionary phase, see e.g. $\mathrm{H} \beta$.

Offsets between our results and the FFs beyond $1 \sigma$ are found in 2/3 of all cases (cf. Figs. 4-8). Note that it is practically impossible to name the cause for a mismatch between theory and observation. This is because a high index strength can be caused by too few absorbers in the continuum bandpasses or too many in the band-pass itself. A mismatch can also result from ill-determined stellar parameters in the sample of stars defining the FFs such that one is not comparing like with like. There certainly is room for the latter at the 
low-metallicity end where absolute effective temperatures are still uncertain at the $200 \mathrm{~K}$ level (see e.g. Barklem et al. 2002) and where the FFs are poorly constrained owing to the lack of stars in the Lick library.

In what follows the 25 indices are discussed individually.

\section{$\mathrm{CN}_{1}$ and $\mathrm{CN}_{2}$ (Fig. 4)}

The index is most sensitive to the abundances of $\mathrm{C}$ and $\mathrm{N}$. It is also sensitive to $\mathrm{O}$ via the preferred formation of $\mathrm{CO}$. Metallicity plays some rôle in the turnoff phase.

Contrary to TB95, our computations underpredict the index strengths at high metallicity, in particular for the dwarfs and the giants. Interestingly, this behaviour is reversed in the low-metallicity dwarfs making the dependence on metallicity rather weak. The FFs do show such a weak trend for the turnoff stars where our modelling is in good agreement with them. The metallicity trend for the giants is more or less recovered with an offset of $0.1 \mathrm{mag}$. An increase of $0.2 \mathrm{dex}$ in $\mathrm{C}$ would be sufficient to account for this offset at high metallicities. However, as mixing with $\mathrm{CN}$-cycled material on the giant branch would lower the $\mathrm{C}$ abundance, this can not serve as an explanation for the low index values predicted here.

\section{Ca4227 (Fig. 4)}

$\mathrm{Ca}, \mathrm{C}$ and $[\mathrm{Z} / \mathrm{H}]$ dominate the overall index strength, $\alpha$-enhancement has no effect on it.

The index strengths for the dwarfs rise steeper than the FFs and do not saturate. At solar metallicity, the agreement is acceptable (within the 0.3 dex variation of $\mathrm{Ca}$ ), somewhat better than in TB95. In the giants, a steeper rise with metallicity is also predicted which starts at higher metallicities only.

\section{G4300 (Fig. 4)}

This index is very sensitive to the $\mathrm{C}$ abundance, $\mathrm{O}$ and $\mathrm{Fe}$ are important contributors as well. The sensitivity to $\alpha$-enhancement is generally low.

The turnoff stars and dwarfs are compatible with the FFs within a 0.3 dex variation of the $\mathrm{C}$ abundance. The highmetallicity giants are also consistent and are in fact in better agreement with the FFs than in the study of TB95. Yet the index strengths are significantly overestimated at low metallicities. The saturation in index strength takes place at much lower metallicities than what is deduced from the FFs.

\section{Fe4383 (Fig. 4)}

This index is particularly sensitive to the iron abundance itself which is no surprise given the intrinsic strength of Fe I 4383 and Fe I 4404 (both multiplet 41). Metallicity $[\mathrm{Z} / \mathrm{H}]$ and the $\mathrm{Mg}$ abundance also influence the index strength, the latter one via its influence on the continuous opacity arising from $\mathrm{H}^{-}$.

There is a very slight tendency for the index strength to be too high in the turnoff stars and giants, a clear one in the case of the dwarfs. Here, the dynamic response to $\alpha$-enhancement is also overestimated, whereas it is well reproduced in the evolved stages of evolution.

\section{Ca4455 (Fig. 5)}

This index is not very sensitive to any of the elements studied, at all times below the level of $1 \sigma$. The highest variations are due to $\mathrm{Ca}$ (dwarf phase), $[\mathrm{Z} / \mathrm{H}]$ (turnoff phase) and $\mathrm{Fe}$ and $\mathrm{Cr}$ (giant phase).

In the absence of a significant response to varying elemental abundances it is particularly troublesome to see the index perform increasingly badly towards high metallicities, in all stages of evolution. TB95 note the strong dependence on bandpass placement, the highest found for any of the 21 classical Lick indices. The size of the variation (between 4 and $8 \sigma$ for a $-3 \AA$ wavelength shift in the giant and dwarf, respectively) is in principle fully sufficient to account for the offsets found. This might or might not be the sole source of the discrepancy; in any case, it tells us that one has to be careful in using this index, as also noted from the comparison with globular cluster data (Maraston et al. 2003, TMB03).

\section{Fe4531 (Fig. 5)}

For this index, variations of $\mathrm{Ti}$ and $[\mathrm{Z} / \mathrm{H}]$ are important. All other elements cause an index response at or below the $1 \sigma$ level.

The agreement between our model predictions and the FFs is good in the case of the dwarfs, excellent for the turnoff stars, but mediocre for the giants. Here, the index strengths are overpredicted at high metallicities, which goes into the opposite direction from TB95.

\section{$\mathrm{C}_{2} 4668$ (formerly Fe4668) (Fig. 5)}

This index is almost exclusively a measure of the carbon abundance. It shows practically no dependence on $\alpha$-enhancement.

The dwarfs do not follow the FFs at all: values too high at low metallicity, values too low at high metallicity. At $[\mathrm{Z} / \mathrm{H}]=$ $0, \mathrm{C}_{2} 4668$ (TB95) is at $2 \AA$ rather than $1 \AA$ as here, whereas the FF is close to $5 \AA$. The turnoff stars, on the other hand, are wellmatched. A variation of $\mathrm{C}$ by $0.2 \mathrm{dex}$ is enough to bring the giants into concordance with the FF values. Yet, it is quite obvious that the metallicity dependence is not properly accounted for. TB95 succeed remarkably well in reproducing the FFs and the data on giants in M 67. Just like in the case of Fe4531, our respective baseline values fall on opposite sides of the FFs.

\section{$\mathrm{H} \beta$ (Fig. 5)}

This index is hardly changed by any of the studied elemental variations, $\alpha$-enhancement has no effect, either (see Thomas et al. 2004). The dominant variations presented in Fig. 5 are at or below $1 / 3 \sigma$ and therefore hard to trace observationally.

The expected behaviour of the index is reproduced well for all evolutionary stages, even at low temperatures where TB95 
found systematic offsets of around $1 \AA$. We have no explanation for the $1 \AA$ offset encountered in the $Z=0.05 Z_{\odot}$ dwarf.

The seemingly non-monotonic behaviour of the $\mathrm{H} \beta$ index (most apparent in the turnoff stars) is a direct consequence of our choice of representative stars: they are non-monotonic in $T_{\text {eff }}$ causing the temperature sensitivity of the $\mathrm{H} \beta$ line to carry through to the index strength.

\section{Fe5015 (Fig. 5)}

In the turnoff stars, this index is only sensitive to $[\mathrm{Z} / \mathrm{H}]$, in the cooler stars also to Ti and $\mathrm{Mg}$. This supports the findings of TB95. $\alpha$-enhancement has some effect on the overall index strength, in good agreement with the FFs.

This index was considered to be the overall poorest fit by TB95. On the contrary, the FFs of all stages of evolution are reasonably well-matched by our computations. All discrepancies can be removed by a 0.3 dex increase in Ti alone. This is, however, not to say that all stars defining the FFs show super-solar $[\mathrm{Ti} / \mathrm{Fe}]$ abundance ratios (which is unlikely at or above solar metallicity). We note that the high sensitivity to offsets in wavelength found in the TB95 dwarf (5 standard errors per $-3 \AA$ ) cannot explain the residual discrepancies.

\section{$\mathrm{Mg}_{1}$ (Fig. 6)}

$\mathrm{C}, \mathrm{Mg},[\mathrm{Z} / \mathrm{H}]$ and $\mathrm{Fe}$ dominate the behaviour of this index in decreasing order of importance. It is interesting to see how the relative sensitivity to $\mathrm{Mg}(\mathrm{MgH})$ wins over that to $\mathrm{C}\left(\mathrm{C}_{2}\right)$ towards lower metallicities in the dwarf phase.

The overall correspondence between FFs and theoretical index strengths is good, except for two areas: the $I_{0}$ values are systematically too low in the metal-poor dwarfs and systematically too high in the metal-rich giants. The latter was also found by TB95.

\section{$\mathrm{Mg}_{2}$ (Fig. 6)}

As the $\mathrm{Mg}_{2}$ band-pass covers the $\mathrm{Mg} b$ lines, the sensitivity to $\mathrm{Mg}$ is higher than in the case of $\mathrm{Mg}_{1}$. It is also influenced by $[\mathrm{Z} / \mathrm{H}], \mathrm{C}$ and $\mathrm{Fe}$.

The behaviour of $\mathrm{Mg}_{2}$ as a function of metallicity is very similar to $\mathrm{Mg}_{1}$. Among the dwarfs, only the most metal-poor star shows a significant discrepancy, among the giants it is once more the solar and super-solar ones. In this case, no offset was reported by TB95 at solar metallicity.

\section{$\operatorname{Mg} b$ (Fig. 6)}

The most dominant species are $\mathrm{Mg},[\mathrm{Z} / \mathrm{H}]$ and $\mathrm{Fe}$ (plus $\mathrm{Cr}$ in the dwarfs). $\alpha$ enhancement has an effect on the $Z=0.005 Z_{\odot}$ dwarfs and giants which is well-modelled.

The turnoff and red giant stars are well accounted for, in this index the dwarfs are off the FFs. This is then a feature common to all three $\mathrm{Mg}$ indices. At the lowest metallicity, our calculation predict values far below the FFs, which is due to the FFs largely overestimating the index strengths with respect to real stars (see Fig. 3 in Maraston et al. 2003). At high metallicities, the behaviour of all three $\mathrm{Mg}$ indices is also similar ( $\mathrm{Mg} b$ performs best) and - in contrast to the low-metallicity cases in the dwarf phase - stays within a 0.3 dex variation of $\mathrm{Mg}$.

\section{Fe5270 (Fig. 6)}

This index is most sensitive to $\mathrm{Fe},[\mathrm{Z} / \mathrm{H}]$ and $\mathrm{Mg}$. A response to $\alpha$-enhancement is practically only visible in the dwarfs where its dynamic range are predicted correctly.

The fit is overall acceptable, displaying the same shortcomings as in TB95: the index strengths is predicted to be somewhat too high at low effective temperatures, both in the dwarfs and giants (the TB95 values for giants come closer to the FFs).

\section{Fe5335 (Fig. 6)}

This index behaves very much like Fe5270. Its response is dominated by $[\mathrm{Z} / \mathrm{H}], \mathrm{Fe}$ and $\mathrm{Mg}$. The effect of $\alpha$-enhancement is more pronounced in the computations than what is encoded in the FFs.

Just like in Fe5270, the theoretical indices for highmetallicity dwarfs and giants are too strong by typically $1 \AA$. Again, the results of TB95 are closer to the FFs.

\section{Fe5406 (Fig. 7)}

The response of this index is practically identical to that of Fe5335 (see above). For a direct comparison, Fe5270, Fe5335 and Fe5406 are all plotted on the same scale in Figs. 6 and 7.

This index performs best of the three above-mentioned iron indices. Deficits only exist in the high-metallicity giants where the index strengths of the FFs are overpredicted by $0.5 \AA$. Considering that the overall index strength is smaller than in the case of Fe5270 and Fe5335, the fractional deficits are all of the same size. It is then observationally easier to use Fe5270 or Fe5335.

\section{Fe5709 (Fig. 7)}

Another iron index quite similar to Fe5406, but with lower sensitivity to Fe. Interestingly, in the high-metallicity giants it is more sensitive to Ti than to Fe itself. All variations cease to be significant at $Z=0.005 Z_{\odot}$. The dependence on $\alpha$-enhancement is well-modelled.

The high-metallicity giants are once again predicted to have index strengths some $0.5 \AA$ larger than what is observed. This finding is not shared by TB95, although their prediction keeps rising towards cooler temperatures while the FF level off and decline at around $4200 \mathrm{~K}$.

\section{Fe5782 (Fig. 7)}

As already noted by TB95, this index measures $\mathrm{Cr}$ rather than $\mathrm{Fe},[\mathrm{Z} / \mathrm{H}]$ plays some rôle as well. 
The predictions are too low at high metallicity and vice versa making the metallicity trends generally flatter than in the FFs. Except for the lowest-metallicity dwarfs and giants, all indices are compatible with the $\mathrm{FF}$ within the dynamic range of a 0.3 dex variation in $\mathrm{Cr}$.

\section{$\mathrm{NaD}$ (Fig. 8)}

This index depends strongly on $\mathrm{Na}$, other than that most significantly on $[Z / \mathrm{H}] . \alpha$-enhancement has little effect whatsoever.

The reproduction of the FFs presented here is quite good overall, in the case of the dwarfs (where deficits are clearly present) better than by TB95. Except for the lowest-metallicity point, all deficits are confined to a \pm 0.3 dex variation in $\mathrm{Na}$.

\section{$\mathrm{TiO}_{1}$ and $\mathrm{TiO}_{2}$ (Fig. 7)}

In the absence of $\mathrm{TiO}$ lines from our line list, the results we get are quite comparable to those of TB95. However, we do not find a pronounced sensitivity to $\mathrm{C}$.

While $\mathrm{TiO}_{2}$ is well-reproduced in the turnoff stars, there is a general deficit of $\approx 0.01$ mag in $\mathrm{TiO} 1$ for all evolutionary phases rising to $\approx 0.03 \mathrm{mag}$ in the super-solar giant. Presumably, this rise is entirely due to the increased importance of $\mathrm{TiO}$ at low effective temperatures.

\section{$\mathrm{H} \gamma \mathrm{A}$ (Fig. 8)}

The most crucial elements for this index are Fe, C, Mg and metallicity $[Z / \mathrm{H}]$. Some dependence on $\alpha$-enhancement is predicted (e.g. $1.3 \AA$ difference between the two $Z=0.005 Z_{\odot}$ dwarfs).

When it comes to stellar populations, this index is dominated by the contribution of the turnoff (by the horizontal branch where applicable). It is therefore reassuring to see that indices for the turnoff stars are predicted correctly (within the 0.3 dex variation of the element dominating the index strength). Both the dwarfs and giants fall short of the FFs by several $\AA$.

\section{$\mathrm{H} \gamma \mathrm{F}$ (Fig. 8)}

Overall, $\mathrm{H} \gamma \mathrm{F}$ behaves quite similar to $\mathrm{H} \gamma \mathrm{A}$. The dependence on $\mathrm{C}$ is, however, more pronounced.

The turnoff stars are well-matched (on par with $\mathrm{H} \gamma \mathrm{A}$ ), the deficits in the dwarfs and giants are smaller here (in relative terms). On the other hand, the difference in index strengths between dwarfs/giants and turnoff stars (as read off from the FFs) is not as large as in $\mathrm{H} \gamma \mathrm{A}$. Taking these two competing properties into account, it is not easy to decide which index is to be preferred.

\section{$\mathrm{H} \delta$ A (Fig. 8)}

The three elements to which this pair of indices is most sensitive are $\mathrm{Fe},[\mathrm{Z} / \mathrm{H}]$ and $\mathrm{Mg}$.

What was said about the behaviour of dwarfs and giants in $\mathrm{H} \gamma$ also holds true here. The theoretical sequence for the giants is in better agreement with the FF at high metallicities, but does not come close to the FFs for the metal-poor objects. At the lowest metallicities, the FFs predict the indices of the giants to compete with those of the turnoff stars, a finding not supported by our calculations.

\section{$\mathrm{H} \delta \mathrm{F}$ (Fig. 8)}

This index is less sensitive to $\mathrm{Fe}$ than $\mathrm{H} \delta \mathrm{A}$. Additionally, the difference in index strengths between dwarfs/giants and turnoff stars is not as large as in $\mathrm{H} \delta \mathrm{A}$. Therefore, $\mathrm{H} \delta \mathrm{A}$ is to be preferred, if one wants to use this band-pass.

\section{Stellar population models}

The index responses presented a here are the key ingredient for the stellar population models with variable element abundance ratios presented in TMB03. In these models the index response functions of TB95 have been used, which have, as mentioned in the Introduction, the major shortcoming to be calculated only for a 5 Gyr isochrone with solar metallicity. The main motivation for this work was to improve on these simplifications. In this section, we discuss the impact of the present paper on stellar population models, and compare stellar population models using the new response functions of this work with the models presented in TMB03 based on TB95.

\subsection{Inclusion of the response functions}

Before, we briefly summarize, how the calculations of this paper are included in stellar population models. For details we refer to TMB03.

\subsubsection{The evolutionary phases}

Like TB95, we have measured on each model star - dwarfs, turnoff, giants - the absolute Lick index value $I_{0}$. Doubling in turn the abundances $X_{i}$ of the dominant elements $\mathrm{C}, \mathrm{N}, \mathrm{O}, \mathrm{Mg}$, $\mathrm{Fe}, \mathrm{Ca}, \mathrm{Na}, \mathrm{Si}, \mathrm{Cr}$, and $\mathrm{Ti}$, we determine the index changes $\delta I(i)$. The abundance effects are therefore isolated at a given temperature and surface gravity. In this way, we obtain the first partial derivative $\partial I / \partial\left[X_{i}\right]$ of the index $I_{0}$ for the logarithmic element abundance increment $\delta\left[X_{i}\right] \equiv \log X_{i}^{1} / X_{i}^{0}=\log 2=0.3$ dex.

As discussed in the previous sections, the $I_{0}$ values of our calculations (like in TB95) do not always match the ones derived from the (purely empirical) FFs. In TMB03, it was therefore decided to rely on the values in a differential sense, and adopt only the index variations $\left(\left(\partial I / \partial\left[X_{i}\right]\right) \times 0.3\right.$. The absolute $I_{0}$ values for the three evolutionary phases, instead, are taken from our underlying $5 \mathrm{Gyr}, Z_{\odot}$ SSP model.

The model index is computed by splitting the basic SSP model in the three evolutionary phases, dwarfs, turnoff stars and giants. We compute the Lick indices of the base model for each phase separately, and modify them using the fractional responses $\delta I / I_{0}$. 


\subsubsection{Negative indices}

As extensively discussed in TMB03, this approach assumes that the index approaches asymptotically the value zero for very low element abundances, i.e. $I \rightarrow 0$ for $X_{i} \rightarrow 0$ or $\left[X_{i}\right] \rightarrow-\infty$. This condition, however, is not generally fulfilled for Lick indices. They can become negative, depending on the definition of line and pseudo-continuum windows. This typically happens at young ages and/or low abundances, and must be corrected before applying fractional index responses. In TMB03 this problem is solved by shifting negative index values such that they approach zero at zero element abundances. After applying the response functions, the index is scaled back (see TMB03 for details). Indices with positive values were assumed to reach the value zero at zero abundances and therefore did not require any correction. This approach seems a bit approximative, but turns out to work very well.

The fact that we have response functions at every metallicity allows us now to improve on this method. We now apply the fractional responses to the flux in the absorption line directly, as the latter is always positive. The absorption index $I$ (measured in $\AA$ ) is linked with the fluxes in line $F_{1}$ and continuum $F_{\mathrm{c}}$ through the following equation ( $\Delta$ is the bandwidth, see Maraston et al. (2003) for more details and for the equivalent definition for indices measured in magnitudes):

$I=\Delta \cdot\left(1-F_{1} / F_{\mathrm{c}}\right)$.

The index variations tabulated in Tables 6-32 are converted to variations in $F_{1}$ with the following equation which can be derived from Eq. (1):

$\frac{\delta F_{1}}{F_{1}^{0}}=\frac{\delta I}{I_{0}-\Delta}$.

Equivalent to Eq. (7) in TMB03, the fractional responses of the flux in the line are then multiplied as follows:

$F_{1}^{\text {new }}=F_{1} \prod_{i=1}^{n} \exp \left\{\frac{1}{F_{1}^{0}} \frac{\partial F_{1}}{\partial\left[X_{i}\right]} 0.3\right\}^{\left(\Delta\left[X_{i}\right] / 0.3\right)}$.

The new index is then computed from $F_{1}^{\text {new }}$ with Eq. (1). We have verified that the resulting stellar population models are not significantly affected when compared to models based on the method used in TMB03. This consistency can be taken as further evidence that the approximation originally used in TMB03 has been successful at dealing with negative absorption line indices.

\subsection{Metallicity dependence}

In TMB03, it had to be assumed that the fractional responses $\delta I / I_{0}$ are independent of metallicity. This approximation is sensible in the linear part of the growth curve, in which equivalent width of the absorption line and element abundance are linearly related. In particular at metallicities well above solar, it is not clear whether this assumption is still valid. The calculations of this paper allow to test the validity of this simplification, as we have now at hand response function in the whole metallicity range $-2.25 \leq[\mathrm{Z} / \mathrm{H}] \leq 0.67$.

\subsection{Age dependence}

TB95 calculated the index response functions for stellar parameter pairs that correspond to an isochrone of $5 \mathrm{Gyr}$, and in TMB03 it is assumed that this age restriction does not significantly impact on the resulting SSP model. In this paper we have now the tools available to check the validity of this assumption. For this purpose, we have additionally computed index response functions for a $1 \mathrm{Gyr}$ isochrone at solar metallicity (Tables 15-17). The resulting $\alpha /$ Fe enhanced SSP model (age $1 \mathrm{Gyr}$ ) is in perfect agreement with the $1 \mathrm{Gyr}$ model based on the response functions from the $5 \mathrm{Gyr}$ isochrone (Tables 12-14). Deviations are about 1 per cent for G4300 and $\mathrm{Fe} 4383$, significantly below that value for all other indices.

\subsection{Symmetry}

TB95 computed index variations upon enhancing the abundance of an individual element by 0.3 dex. We also performed test calculations in which the abundance was diminished instead. No significant changes were found in the absolute index changes. This means that the index variations can be used to trace element abundances both above and below the base abundance.

\subsection{Classical Lick indices}

The resulting stellar population models calibrated with galactic globular clusters are shown in Fig. 3, which is the equivalent of Fig. 2 in TMB03. We plot models for constant age (12 Gyr) and constant $\alpha / \mathrm{Fe}$ ratios in the metallicity range $-2.25 \leq$ $[Z / \mathrm{H}] \leq 0.67$. Three models with $[\alpha / \mathrm{Fe}]=0.0,0.3,0.5$ are shown in blue, green, and red, respectively (see labels). Models with solar abundance ratios $([\alpha / \mathrm{Fe}]=0.0)$ and models with $[\alpha / \mathrm{Fe}]=0.5$ are those with the lowest and highest $\mathrm{Mg} b$ indices, respectively. Solid lines are the TMB03 models using the new response functions of this paper, dotted lines are the models of TMB03 based on the TB95 response functions. Filled squares are globular cluster data, the open square is the integrated Bulge light (both from Puzia et al. 2002), small grey dots are the Lick data of giant elliptical galaxies from Trager et al. (1998).

We recall here that the Galactic globular clusters are $\alpha / \mathrm{Fe}$ enhanced by about a factor 2 , hence the model can be considered well calibrated when the model with $[\alpha / \mathrm{Fe}]=0.3$ (middle green line) fits the observational data (squares). As discussed in detail in TMB03, not all of the Lick absorption line indices show a satisfactory calibration and can be considered adequate for stellar population studies. For the aim of this paper, we are more interested in the direct comparison with the TMB03 models based on the TB95 response functions.

The main conclusion is the following: the assumption of TMB03 that the fractional response is independent of metallicity is generally confirmed for the whole metallicity range considered. The convergence to minimal index variations at the lowest metallicities and the corresponding expansion of the models with different $\alpha / \mathrm{Fe}$ ratios at high metallicities is present also in the models with the metallicity-dependent 


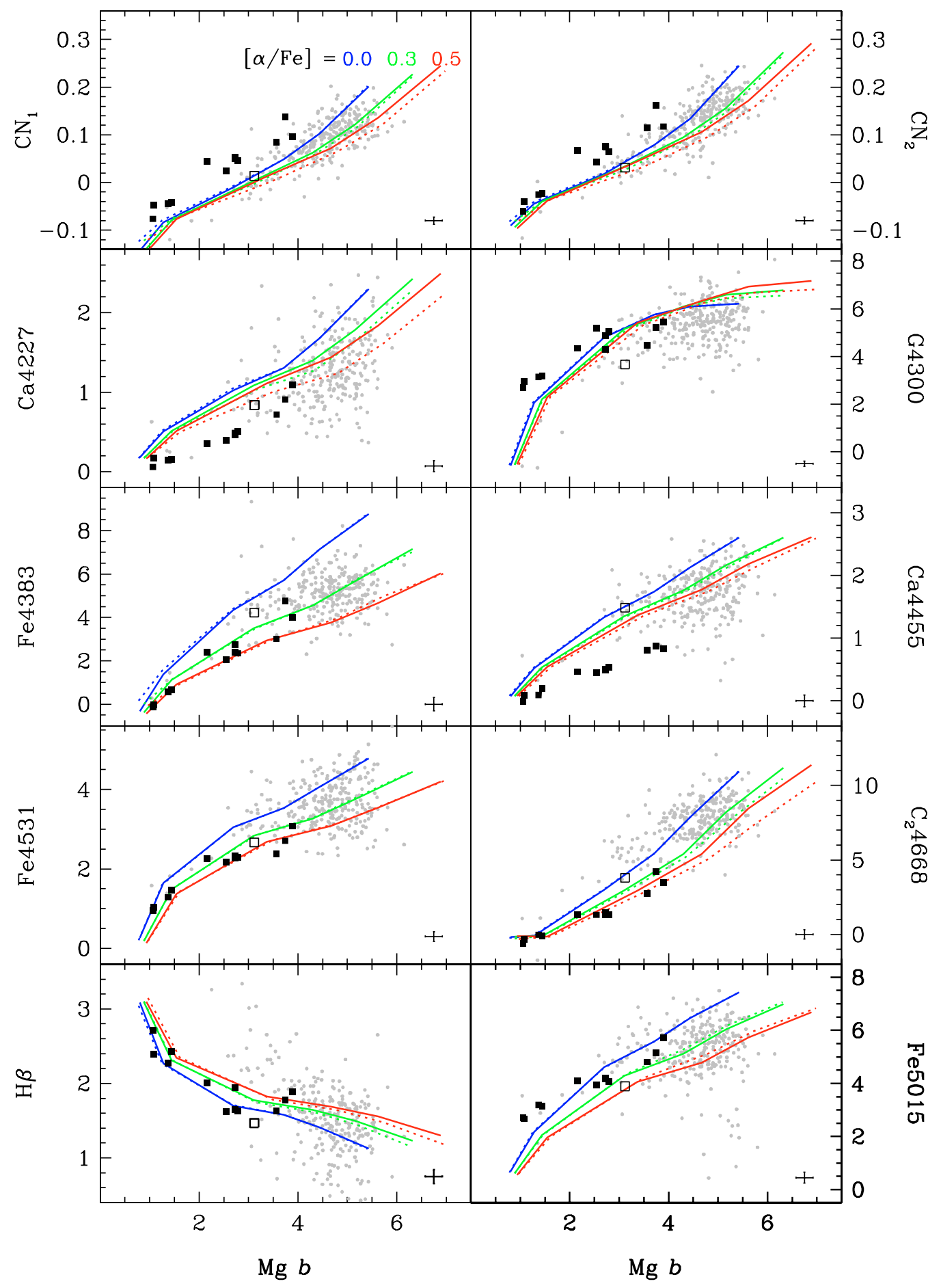

Fig. 3. $\mathrm{Mg} b$ index versus the other 20 Lick indices. Solid lines are the TMB03 models using the new response functions of this paper, dotted lines are the models of TMB03 based on the TB95 response functions. They are plotted for constant age (12 Gyr) and constant $\alpha / \mathrm{Fe}$ ratios in the metallicity range $-2.25 \leq[\mathrm{Z} / \mathrm{H}] \leq 0.67$. The three models with $[\alpha / \mathrm{Fe}]=0.0,0.3,0.5$ are shown in blue, green, and red, respectively (see labels). Models with solar abundance ratios $([\alpha / \mathrm{Fe}]=0.0)$ and models with $[\alpha / \mathrm{Fe}]=0.5$ are those with the lowest and highest $\mathrm{Mg} b$ indices, respectively. Filled squares are globular cluster data, the open square is the integrated Bulge light from Puzia et al. (2002), small grey dots are the Lick data of giant elliptical galaxies from Trager et al. (1998). Error bars indicate typical errors of the globular cluster data. The figure is the equivalent of Fig. 2 in TMB03 and continues on the next page.

response functions presented here. For most indices, the two models are well consistent within the calibration uncertainty introduced by observational errors. If discrepancies are present, they do not originate from the neglect of the metallicity dependence, but are caused by differences between the response functions presented here and those of TB95.

The indices $\mathrm{CN}_{1}, \mathrm{CN}_{2}, \mathrm{H} \beta, \mathrm{Mg} b, \mathrm{Mg}_{2}, \mathrm{Fe} 5270, \mathrm{NaD}$, and $\mathrm{TiO}_{2}$ exhibit only relatively small offsets, while the 


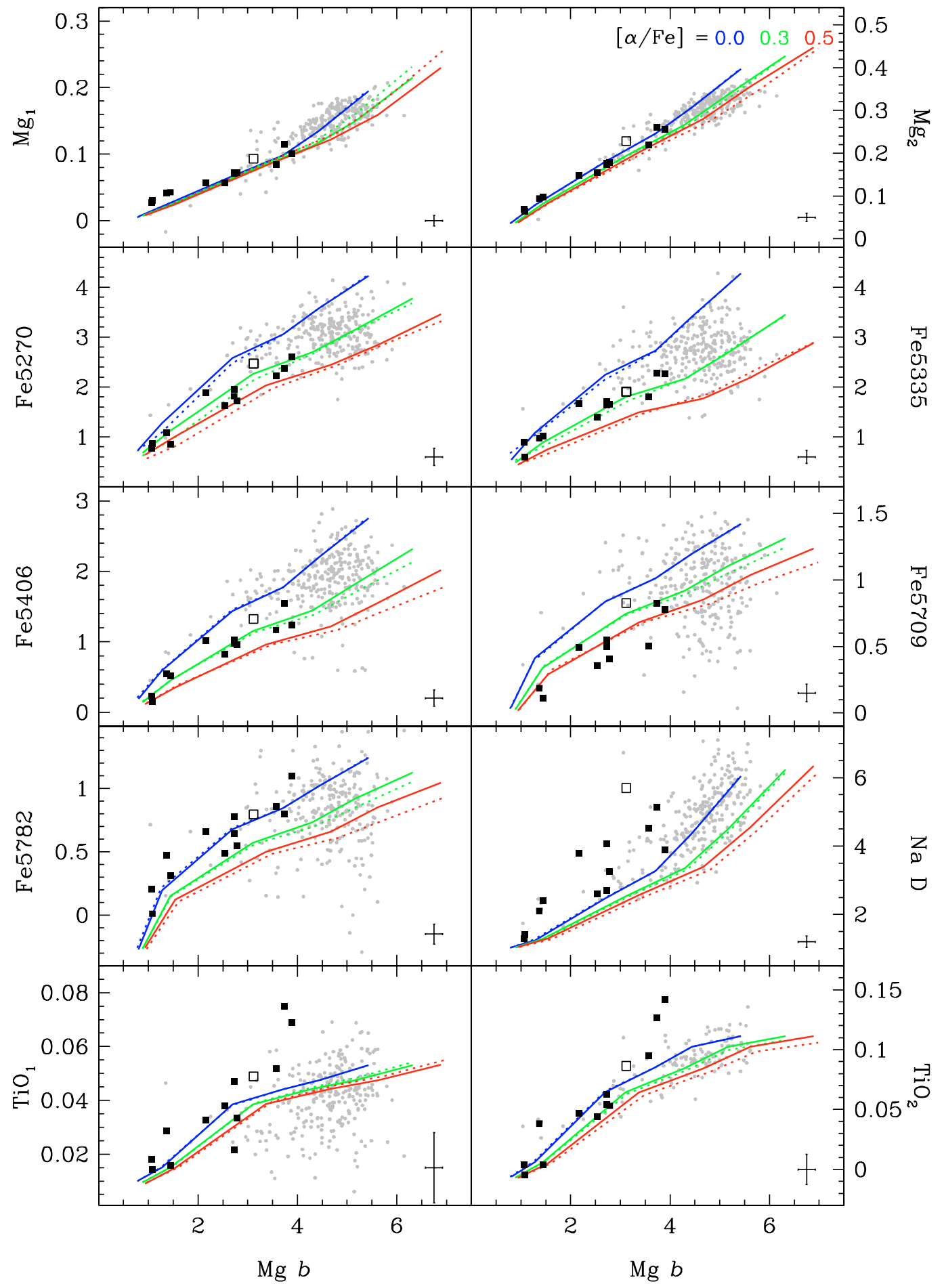

Fig. 3. continued.

indices G4300, Fe4383, Ca4455, Fe4531, Fe5015, Fe5335, and $\mathrm{TiO}_{1}$ basically did not change. Largest differences are found for Ca4227, $\mathrm{C}_{2} 4668, \mathrm{Mg}_{1}, \mathrm{Fe} 5406, \mathrm{Fe} 5709$, and $\mathrm{Fe} 5782$.

Ca4227 and $\mathrm{C}_{2} 4668$ have become more sensitive to $\alpha / \mathrm{Fe}$ ratio, and increase now slightly with increasing $\alpha / \mathrm{Fe}$ ratios. In both cases, the main reason is a more pronounced negative response to the element $\mathrm{Cr}$, the abundance of which decreases relative to the $\alpha$-elements in the enhanced models. As mentioned earlier, Ca4227 and $\mathrm{C}_{2} 4668$ are most sensitive to their name-giving elements, $\mathrm{Ca}$ and $\mathrm{C}$, respectively, which do not vary significantly in the $\alpha / \mathrm{Fe}$ enhanced mixtures of the TMB03 models.

$\mathrm{Mg}_{1}$ is now somewhat less sensitive to $\alpha / \mathrm{Fe}$ because of slightly smaller responses to both $\mathrm{Mg}$ and $\mathrm{Fe}$ in the response function of this work. Fe5406 and Fe5709 decrease less strongly with increasing $\alpha / \mathrm{Fe}$ because the sensitivity to the element $\mathrm{Fe}$ is less pronounced. Fe5782 is interesting, as 


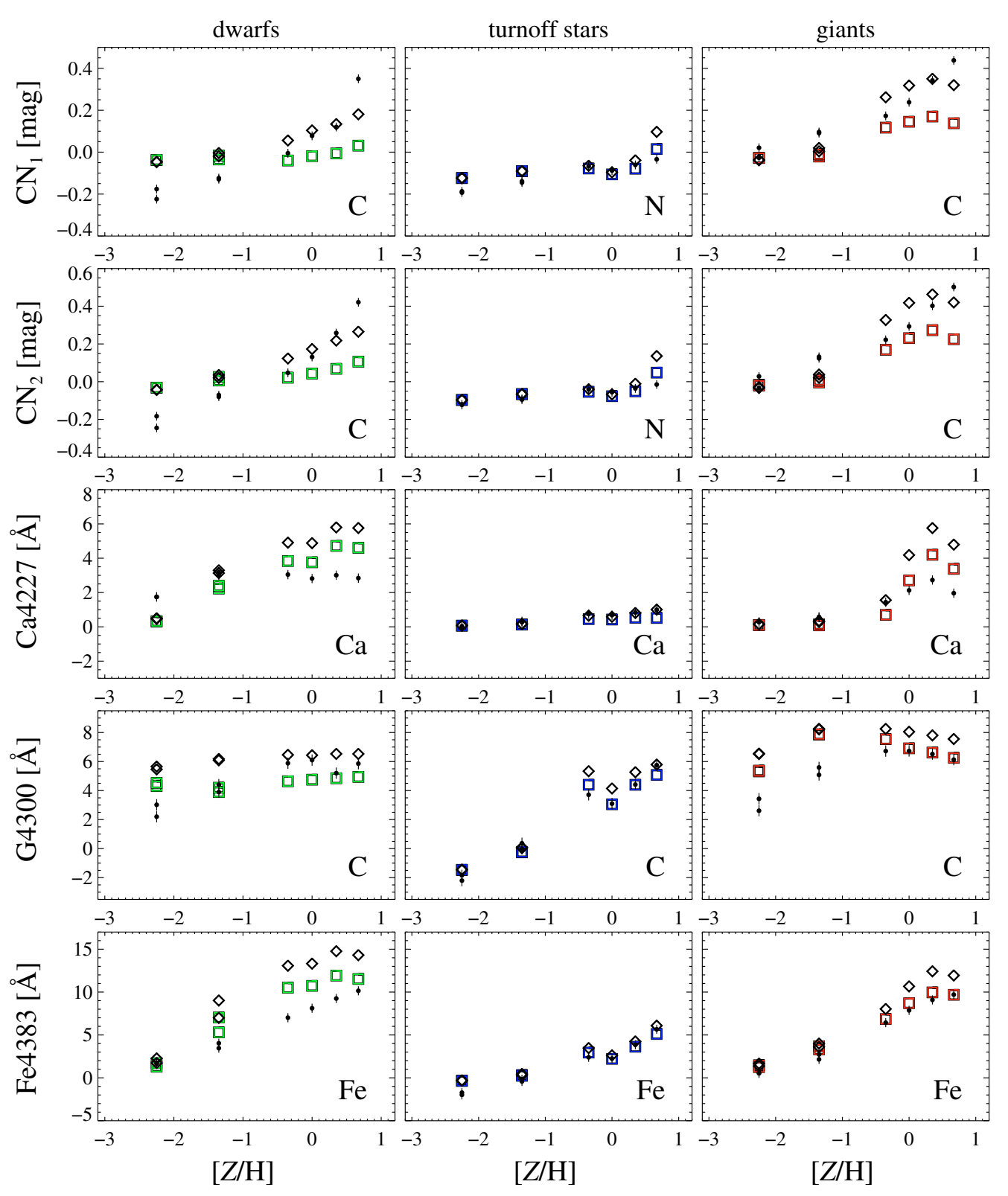

Fig. 4. Theoretical index-strength variations as a function of metallicity for CN1, CN2, Ca4227, G4300 and Fe4383 in the three evolutionary stages dwarf (left), turnoff (middle) and giant phase (right). Squares denote index strengths from this work, diamonds the respective index strength obtained by enhancing the index-dominating element (given in the lower right corner) by 0.3 dex. Bullets are the FFs with IDS standard errors of Worthey et al. (1994).

its sensitivity to $\alpha / \mathrm{Fe}$ ratio comes only from the positive response to abundance changes of the element $\mathrm{Cr}$. In the response functions of this paper, Fe5782 even decreases with increasing $\mathrm{Fe}$ abundances, hence counterbalances the positive response to $\mathrm{Cr}$, which leads to the lower sensitivity to $\alpha / \mathrm{Fe}$ ratios. For all the three $\mathrm{Fe}$ indices, this effect slightly increases with increasing metallicity.

$\mathrm{H} \beta$ is the only case, in which the metallicity dependence of the response functions leaves a small, but measurable trace. The higher the metallicity, the larger is the $\mathrm{H} \beta$ strength of the $\alpha / \mathrm{Fe}$ enhanced models with the new metallicity-dependent response functions relative to the ones based on TB95. The reason is the negative response to $\mathrm{Cr}$, due to a Cr line at $4885 \AA$ in the red pseudo-continuum of the index definition. It makes indeed sense that the influence of metallic lines on a Balmerline index increases with increasing metallicity. Still, the effect is small. In the highest metallicity model $([\mathrm{Z} / \mathrm{H}]=0.67)$, where the effect is maximized, the doubling of the $\alpha / \mathrm{Fe}$ ratio leads to an increase of the $\mathrm{H} \beta$ index by less than 10 per cent.

This is significantly less than the increase of about 100 per cent recently claimed by Tantalo \& Chiosi (2004) on the basis of the TB95 response functions (in contrast to the results in TMB03). According to Tantalo \& Chiosi (2004) this dramatic increase of $\mathrm{H} \beta$ results from a strong sensitivity of $\mathrm{H} \beta$ 


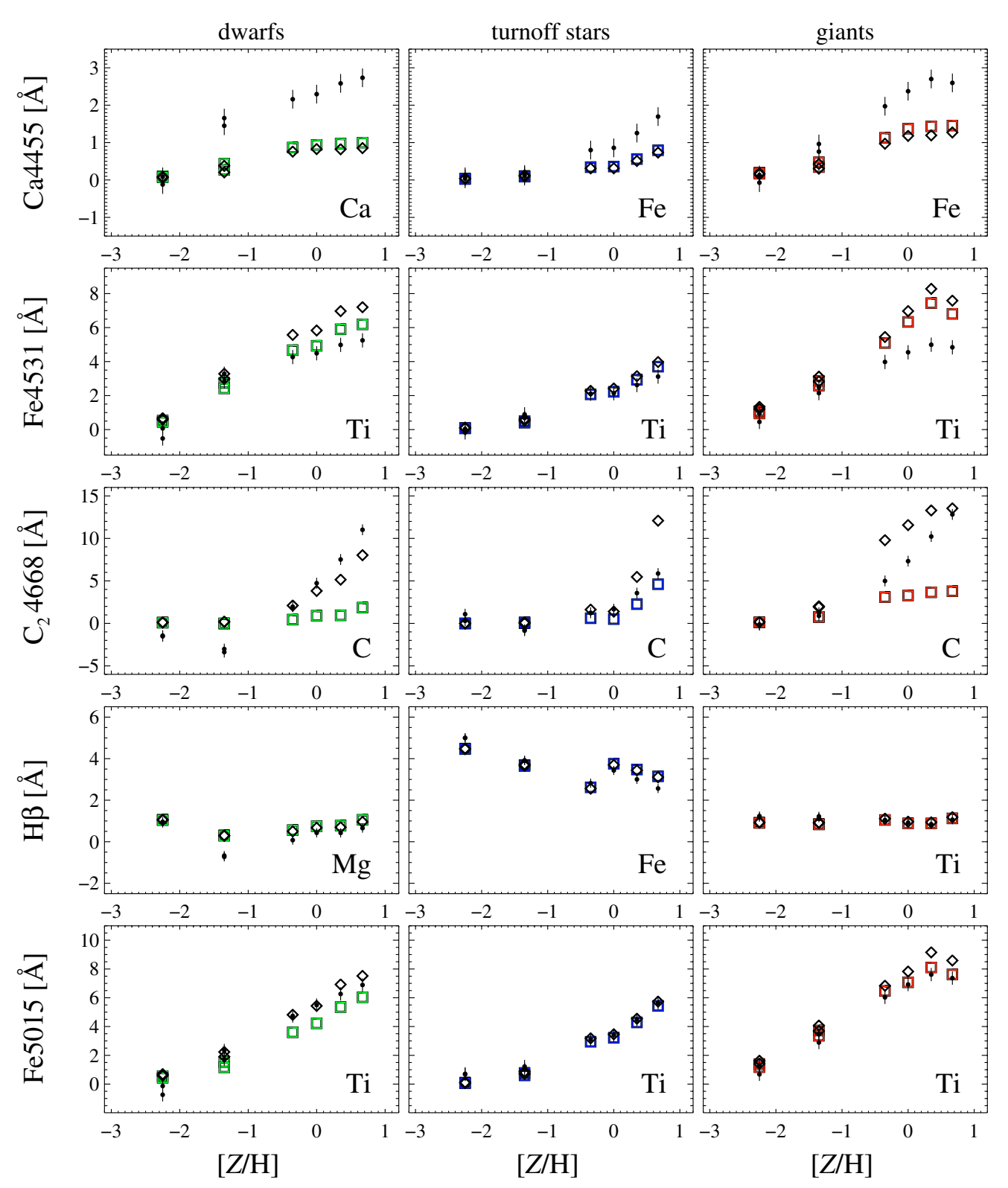

Fig. 5. Same as Fig. 4, here for Ca4455, Fe4531, $\mathrm{C}_{2} 4668, \mathrm{H} \beta$ and Fe5015.

to $\mathrm{Ti}$ abundance in the dwarf evolutionary phase. Inspecting the response function of TB95, however, reveals that $\mathrm{H} \beta$ in the dwarfs actually decreases with increasing $\mathrm{Ti}$, which leads to the conclusion that the result of Tantalo \& Chiosi (2004) is likely a numerical artefact. It should also be noted that the models of Tantalo \& Chiosi (2004) predict such strong $\mathrm{H} \beta$ indices (of the order of $2 \AA$ ) that the vast majority of early-type galaxies would be about 30 Gyr old, which is significantly older than the Universe. It is very important to note that in the response functions of this work, the sensitivity of $\mathrm{H} \beta$ to $\mathrm{Ti}$ abundance does not exceed the few per cent level in all evolutionary phases.

\subsection{Higher-order Balmer-line indices}

As mentioned earlier, $\mathrm{H} \beta$ shows little sensitivity to element ratio variations as well as to total metallicity, because of the lack of strong metallic lines in the wavelength range of the index definition. At bluer wavelengths, this situation naturally changes. The higher-order Balmer-line indices $\mathrm{H} \gamma$ and $\mathrm{H} \delta$ around 4340 and $4100 \AA$ as defined in Worthey \& Ottaviani (1997) are significantly more affected by metallic lines. A wellknown direct consequence is that these indices are more sensitive to metallicity than $\mathrm{H} \beta$. But they are also significantly more sensitive to the $\alpha / \mathrm{Fe}$ ratio as shown here. With increasing metallicity, the influence of metallic lines rises. As a consequence, unlike for $\mathrm{H} \beta$, the fractional index responses increase considerably with metallicity as can be appreciated by comparing Figs. 5 and 8. The impact on the stellar population models is dramatic as shown in Thomas et al. (2004). This effect cannot be neglected when these line indices are used to derive the ages of metal-rich, unresolved stellar populations like earlytype galaxies. In Thomas et al. (2004) we show that consistent 


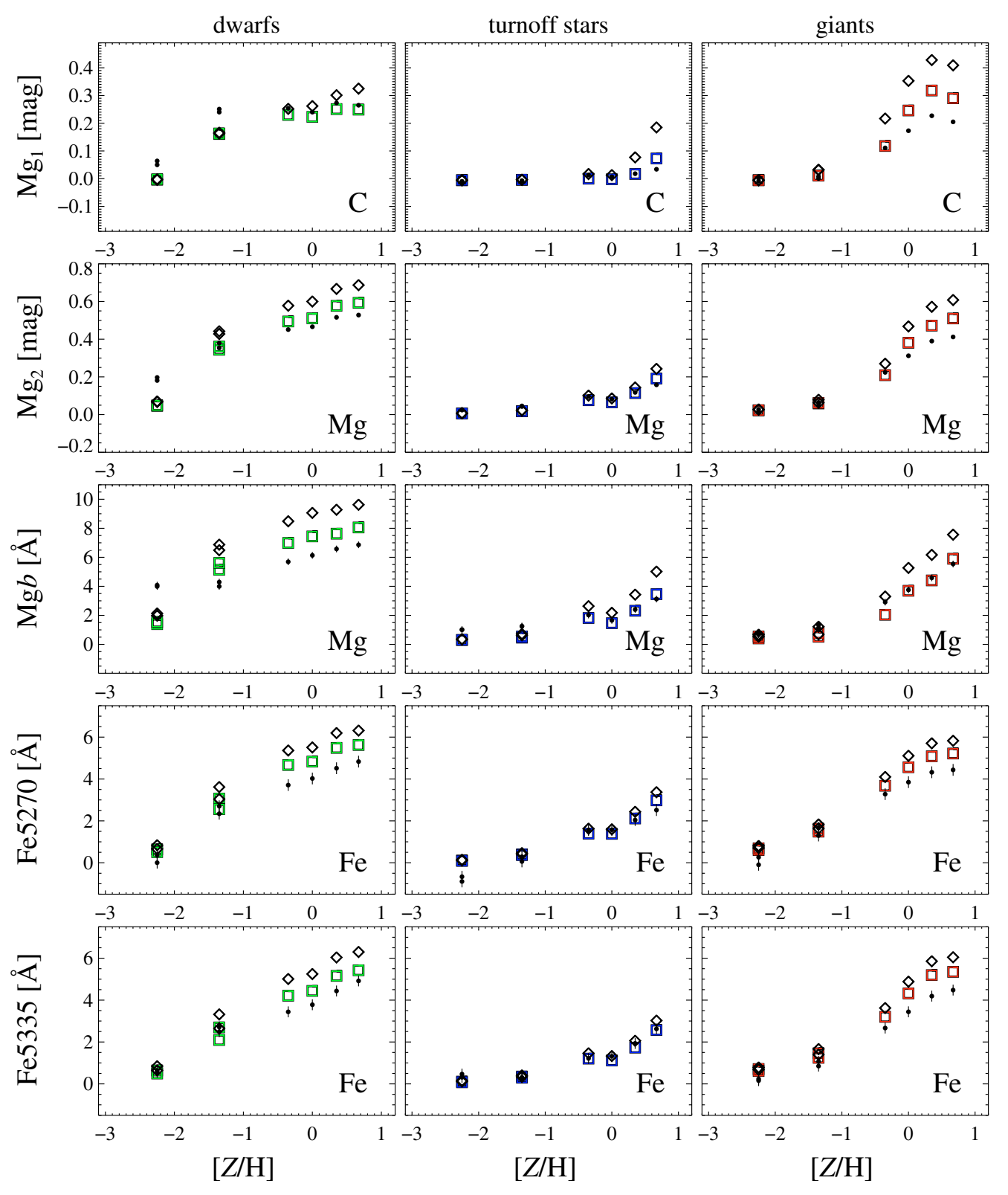

Fig. 6. Same as Fig. 4, here for $\mathrm{Mg}_{1}, \mathrm{Mg}_{2}, \mathrm{Mg} b$, Fe5270 and Fe5335.

age estimates from $\mathrm{H} \beta$ and $\mathrm{H} \gamma_{\mathrm{A}}$ are obtained, only if the effect of $\alpha / \mathrm{Fe}$ enhancement on $\mathrm{H} \gamma_{\mathrm{A}}$ is taken into account in the models. This result rectifies a problem currently present in the literature, namely that $\mathrm{H} \gamma$ and $\mathrm{H} \delta$ have up to now led to significantly younger ages for early-type galaxies than $\mathrm{H} \beta$ (see Thomas et al. 2004 for more details).

\section{Conclusions}

We have computed line indices for the 21 classical and 4 higher-order Balmer-line Lick/IDS indices at six different metallicities ranging from -2.25 to +0.67 in $[Z / H]$. At the lowest two metallicities $(-2.25$ and -1.35$)$ we also computed indices with a general enhancement of $\alpha$ elements. For all of these, we have varied individual elemental abundances of ten elements (plus overall metallicity) and tabulated the index changes. At solar metallicity, we compare our results with the work of Tripicco \& Bell (1995). In the majority of cases, we confirm the findings to TB95. By tabulating index changes for all 25 Lick indices for a wide range of metallicities, we significantly extend the work of TB95.

The major assumptions of TMB03 were checked and verified by these calculations: the use of fractional changes produces accurate results over a wide range of abundances and ages. They can also be used to compute response functions with enhanced or diminished abundances of individual elements (notably $\alpha$ elements). Still, the metallicity-dependent response functions presented here do lead to a higher degree of selfconsistency in the stellar population models. Furthermore, their 


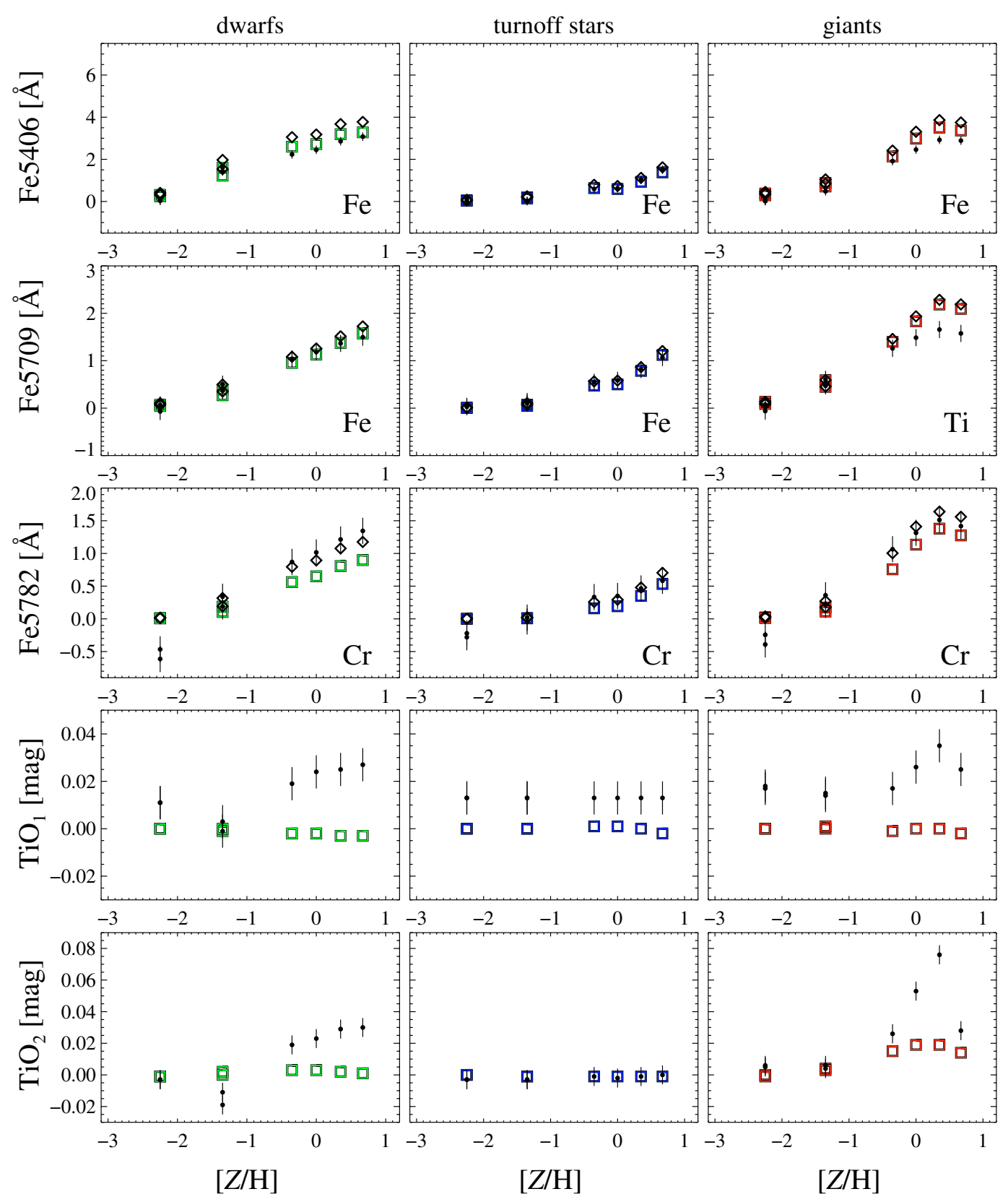

Fig. 7. Same as Fig. 4, here for Fe5406, $\mathrm{Fe} 5709$, $\mathrm{Fe} 5782, \mathrm{TiO}_{1}$ and $\mathrm{TiO}_{2}$.

use turns out to be of particular importance for the Balmerline indices. We find that, different from the metallic indices, the Balmer-line indices become increasingly sensitive to element abundances with increasing metallicity and decreasing wavelength.

Hence, while the $\mathrm{H} \beta$ index only responds moderately (below 10 per cent) to abundance ratio variations, the higher-order Balmer-line indices $\mathrm{H} \gamma$ and $\mathrm{H} \delta$ display very strong dependencies at high metallicities. More specifically, $\mathrm{H} \gamma$ and $\mathrm{H} \delta$ significantly increase with increasing alpha/Fe ratio. This effect must not be neglected when these indices are used as age indicators of unresolved stellar systems. As shown in Thomas et al. (2004), the response functions of this work allow for a proper modelling of these indices, which helped to remove systematic effects in age determinations based on different Balmer-line indices previously present in the literature.

With the general availability of huge, homogeneous sets of galaxy spectra (e.g. Madgwick et al. 2003), direct synthesis of large wavelength ranges will become a more wide-spread analysis technique. To extract useful information from the spectra, the behaviour of different regions to individual abundance changes will have to be established. As a starting point and reference, the Lick indices serve an important purpose in this sense. By defining how they are expected to react to abundance changes under a variety of circumstances, we hope to shed light on the chemical evolution of galaxies throughout the Hubble sequence. 


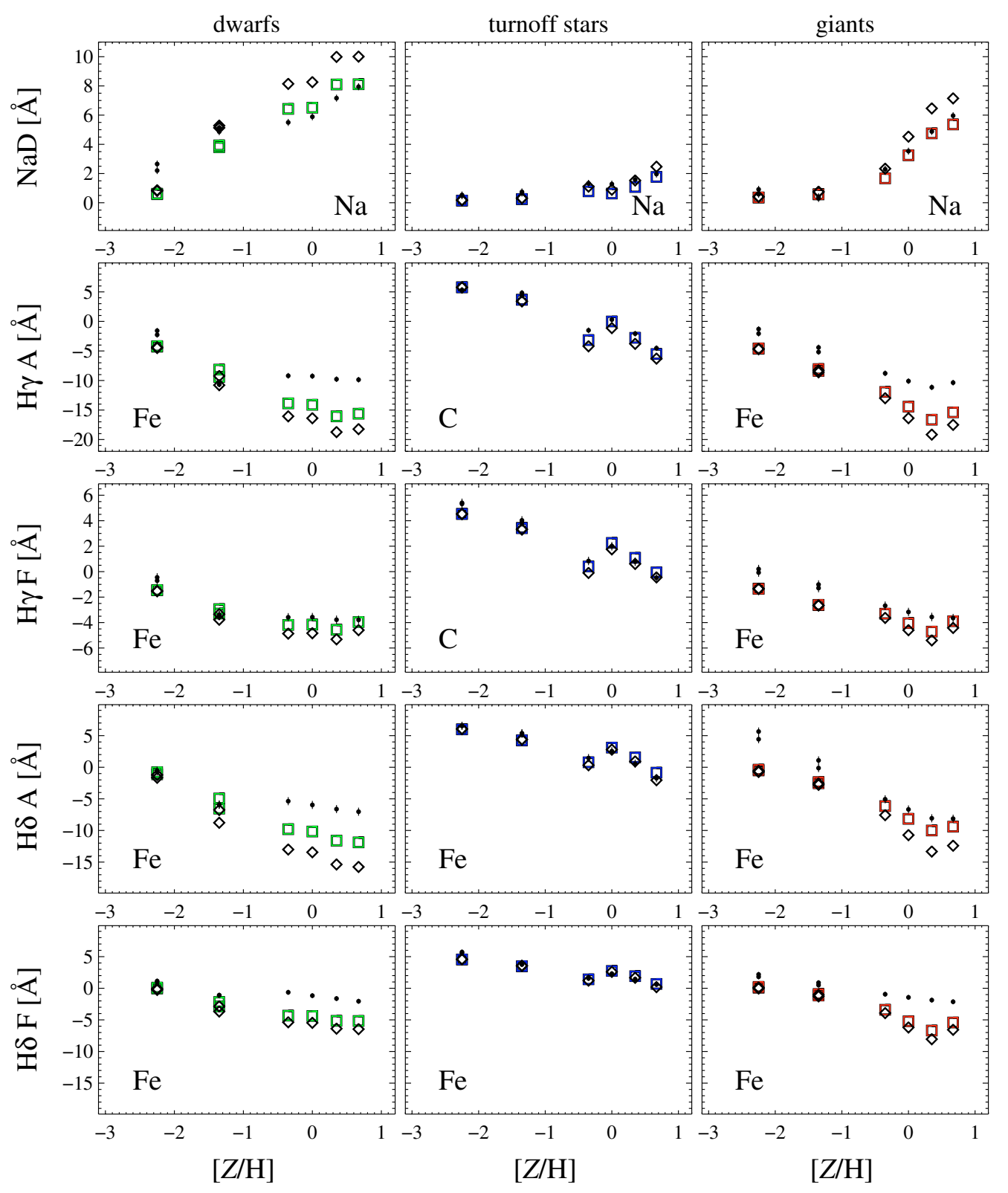

Fig. 8. Same as Fig. 4, here for $\mathrm{NaD}, \mathrm{H} \gamma \mathrm{A}, \mathrm{H} \gamma \mathrm{F}, \mathrm{H} \delta \mathrm{A}$ and $\mathrm{H} \delta \mathrm{F}$.

Acknowledgements. We would like to thank Thomas Gehren (Universitäts-Sternwarte München) for continuous support with his atmospheric code MAFAGS. Laura Greggio, Alvio Renzini and Scott Trager are thanked for repeated fruitful discussions. The referee, Guy Worthey, is thanked for stressing the carbon-star difficulty which prompted us to perform some extra computations. This work was in part supported by the Deutsche Akademie der Naturforscher Leopoldina (Halle, Germany) under grant BMBF-LPD 9901/8-87.

\section{References}

Anstee, S. D., \& O'Mara, B. J. 1995, MNRAS, 276, 859

Barklem, P. S., Stempels, H. C., Allende Prieto, C., et al. 2002, A\&A, 385, 951

Bernkopf, J. 1998, A\&A, 332, 127
Böhm-Vitense, E. 1958, Z. Astrophys., 46, 108

Borges, A. C., Idiart, T. P., \& de Freitas Pacheco, J. A., Thévenin, F. 1995, AJ, 110, 2408

Burstein, D., Faber, S. M., Gaskell, C. M., \& Krumm, N. 1984, ApJ, 287, 586

Canuto, V. M., \& Mazzitelli, I. 1992, ApJ, 389, 724

Carollo, C. M., \& Danziger, I. J. 1994, MNRAS, 270, 523

Cassisi, S., Castellani, M., \& Castellani, V. 1997, A\&A, 317, 10

Davies, R. L., Kuntschner, H., et al. 2001, ApJ, 548, L33

Davies, R. L., Sadler, E. M., \& Peletier, R. F. 1993, MNRAS, 262, 650

Decin, L., Cohen, M., Eriksson, K., et al. 1997, in Proc. of the first ISO workshop on Analytical Spectroscopy, ed. A. M. Heras, K. Leech, N. R. Trams, \& M. Perry, ESA (Noordwijk, The Netherlands), 185

Falcon-Barroso, J., Peletier, R. F., Emsellem, E., et al. 2004, MNRAS, 350,35

Fuhrmann, K., Axer, M., \& Gehren, T. 1993, A\&A, 271, 451 
Gehren, T. 1975a, LTE-Sternatmosphärenmodelle (I), University of Kiel, Germany

Gehren, T. 1975b, LTE-Sternatmosphärenmodelle (II), University Kiel, Germany

Gehren, T., Korn, A. J., \& Shi, J. 2001, A\&A, 380, 645

Gray, D. F. 1977, ApJ, 218, 530

Grevesse, N., \& Sauval, A. J. 1998, Space Sci. Rev., 85, 161

Gorgas, J., Faber, S. M., Burstein, D., et al. 1993, ApJS, 86, 153

Gustafsson, B., Bell, R. A., Eriksson, K., \& Nordlund, A.. 1975, A\&A, 42,407

Houdashelt, M. L., Trager, S. C., Worthey, G., \& Bell, R. A. 2002, BAAS, 34, 1118

Idiart, T. P., Thévenin, F., \& de Freitas Pacheco, J. A. 1997, AJ, 113, 1066

Kurucz, R. L. 1992, Rev. Mex. Astron. Astrof., 23, 45

Kurucz, R. L. 1993a, CD-ROM No. 13, ATLAS9, Smithonian Astrophysical Observatory, Cambridge, USA

Kurucz, R. L. 1993b, CD-ROMs, Opacities for stellar atmospheres, Smithonian Astrophysical Observatory, Cambridge, USA

Kurucz, R. L. 2002, in Atomic and Molecular Data and their Applications, ed. D. R. Schultz, P. S. Krstic, \& F. Ownby, AIP Conf. Proc., 636, 134

Kurucz, R. L., \& Bell, B. 1995, CD-ROM No. 23, Atomic Line List, Smithonian Astrophysical Observatory, Cambridge, USA

Kurucz, R. L., Furenlid, I., Brault, J., \& Testerman, L. 1984, Solar Flux Atlas from 296 to $1300 \mathrm{~nm}$, Kitt Peak National Solar Observatory

Kurucz, R. L., \& Peytremann, E. 1975, SAO Spec. Rep., 362, 1219

LeBorgne, D., Rocca-Volmerange, B., Prugniel, P., et al. 2004, A\&A, 425,881
Lejeune, T., Cuisinier, F., \& Buser, R. 1997, A\&AS, 125, 229

Madgwick, D. S., Coil, A. L., Conselice, C. J., et al. 2003, ApJ, 599, 997

Maraston, C. 1998, MNRAS, 300, 872

Maraston, C. 2005, MNRAS, in press

Maraston, C., Greggio, L., Renzini, A., et al. 2003, A\&A, 400, 823

Peterson, R. C., Dalle Ore, C. M., \& Kurucz, R. L. 1993, ApJ, 404, 333

Pfeiffer, M. J., Frank, C., Baumüller, D., Fuhrmann, K., \& Gehren, T. 1998, A\&AS, 130, 381

Przybilla, N., \& Butler, K. 2004, ApJ, 610, 61

Salasnich, B., Girardi, L., Weiss, A., \& Chiosi, C. 2000, A\&A, 361, 1023

Tantalo, R., \& Chiosi, C. 2004, MNRAS, 353, 917

Thomas, D., Maraston, C., \& Bender, R. 2003a, MNRAS, 339, 897 (TMB03)

Thomas, D., Maraston, C., \& Bender, R. 2003b, MNRAS, 343, 279

Thomas, D., Maraston, C., \& Korn, A. 2004, MNRAS, 351, L19

Thomas, D., Maraston, C., Bender, R., \& Mendes de Oliveira, C. 2005, ApJ, 621, 673

Tripicco, M. J., \& Bell, R. A. 1995, ApJ, 110, 3035

Unsöld, A. 1968, in Physik der Sternatmosphären (Berlin: Springer)

van't Veer-Menneret, C., \& Mégessier, C. 1996, A\&A, 309, 879

Worthey, G. 2004, AJ, 128, 2826

Worthey, G., Faber, S. M., \& González, J. J. 1992, ApJ, 398, 69

Worthey, G., Faber, S. M., González, J. J., \& Burstein, D. 1994, ApJS, 94, 687

Worthey, G., \& Ottaviani, D. L. 1997, ApJS, 111, 377 
A. J. Korn et al.: The sensitivity of Lick indices to abundance variations, Online Material p 1

\section{Online Material}


A. J. Korn et al.: The sensitivity of Lick indices to abundance variations, Online Material $p 2$

Table 6. Spectral index response: Cool dwarf (4667/4.59/+0.67/0.00).

\begin{tabular}{|c|c|c|c|c|c|c|c|c|c|c|c|c|c|}
\hline (1) & (2) & (3) & (4) & (5) & (6) & (7) & (8) & (9) & (10) & (11) & (12) & (13) & (14) \\
\hline Index & $I_{0}$ & Error & $\mathrm{C}$ & $\mathrm{N}$ & $\mathrm{O}$ & $\mathrm{Mg}$ & $\mathrm{Fe}$ & $\mathrm{Ca}$ & $\mathrm{Na}$ & $\mathrm{Si}$ & $\mathrm{Cr}$ & $\mathrm{Ti}$ & {$[Z / H]^{1}$} \\
\hline $\mathrm{CN}_{1}$ & 0.031 & 0.021 & 0.150 & 0.046 & -0.058 & -0.006 & -0.010 & -0.009 & -0.001 & 0.008 & -0.020 & 0.001 & -0.020 \\
\hline $\mathrm{CN}_{2}$ & 0.106 & 0.023 & 0.159 & 0.048 & -0.061 & -0.013 & -0.012 & -0.013 & -0.003 & 0.015 & -0.021 & 0.002 & -0.029 \\
\hline $\mathrm{Ca} 4227$ & 4.606 & 0.270 & -0.638 & -0.143 & 0.281 & -0.075 & -0.077 & 1.158 & -0.043 & -0.077 & -0.201 & -0.030 & -0.741 \\
\hline G4300 & 4.942 & 0.390 & 1.584 & 0.001 & -0.697 & -0.208 & -0.499 & 0.466 & -0.071 & -0.048 & -0.205 & 0.534 & -0.108 \\
\hline $\mathrm{Fe} 4383$ & 11.525 & 0.530 & 0.156 & 0.005 & 0.043 & -1.110 & 2.784 & -0.737 & -0.231 & -0.209 & -0.275 & -0.043 & -0.895 \\
\hline $\mathrm{Ca} 4455$ & 0.997 & 0.250 & -0.050 & 0.000 & 0.012 & -0.039 & -0.042 & -0.144 & -0.019 & -0.006 & 0.055 & -0.001 & -0.010 \\
\hline $\mathrm{Fe} 4531$ & 6.188 & 0.420 & 0.011 & 0.002 & 0.008 & -0.475 & 0.336 & -0.172 & -0.076 & -0.097 & 0.164 & 1.014 & -0.827 \\
\hline $\mathrm{C}_{2} 4668$ & 1.859 & 0.640 & 6.167 & -0.001 & -0.921 & -0.266 & 0.110 & 0.155 & -0.047 & -0.225 & -0.315 & 0.063 & -0.369 \\
\hline $\mathrm{H} \beta$ & 1.058 & 0.220 & -0.020 & 0.001 & 0.010 & -0.100 & -0.012 & -0.050 & -0.018 & -0.011 & -0.096 & 0.020 & -0.089 \\
\hline $\mathrm{Fe} 5015$ & 6.032 & 0.460 & -0.082 & 0.002 & 0.022 & -0.887 & 0.274 & 0.031 & -0.050 & -0.109 & -0.016 & 1.488 & -1.015 \\
\hline $\mathrm{Mg}_{1}$ & 0.249 & 0.007 & 0.076 & 0.000 & -0.012 & 0.031 & -0.025 & -0.006 & -0.006 & -0.004 & -0.005 & -0.001 & -0.024 \\
\hline $\mathrm{Mg}_{2}$ & 0.593 & 0.008 & 0.033 & 0.001 & -0.004 & 0.094 & -0.038 & -0.016 & -0.016 & -0.011 & -0.009 & 0.002 & -0.065 \\
\hline $\operatorname{Mg} b$ & 8.058 & 0.230 & -0.046 & 0.009 & 0.049 & 1.566 & -0.661 & -0.184 & -0.217 & -0.121 & -0.529 & -0.038 & -0.547 \\
\hline Fe5270 & 5.623 & 0.280 & 0.007 & 0.003 & 0.023 & -0.358 & 0.691 & 0.272 & -0.110 & -0.076 & -0.011 & 0.031 & -0.539 \\
\hline Fe5270(Sauron) & 4.834 & & 0.006 & 0.002 & 0.021 & -0.308 & 0.588 & 0.250 & -0.095 & -0.065 & 0.004 & -0.018 & -0.455 \\
\hline $\mathrm{Fe} 5335$ & 5.424 & 0.260 & 0.003 & 0.002 & 0.020 & -0.435 & 0.875 & -0.116 & -0.134 & -0.097 & 0.275 & 0.010 & -0.633 \\
\hline $\mathrm{Fe} 5406$ & 3.283 & 0.200 & -0.017 & 0.001 & 0.013 & -0.236 & 0.493 & -0.075 & -0.077 & -0.060 & 0.154 & 0.015 & -0.374 \\
\hline $\mathrm{Fe} 5709$ & 1.575 & 0.180 & 0.000 & 0.000 & 0.002 & -0.006 & 0.150 & 0.007 & -0.135 & -0.018 & 0.004 & 0.054 & -0.237 \\
\hline $\mathrm{Fe} 5782$ & 0.899 & 0.200 & 0.002 & 0.000 & 0.003 & 0.001 & -0.111 & -0.042 & -0.016 & 0.000 & 0.277 & -0.032 & -0.143 \\
\hline $\mathrm{Na} D$ & 8.115 & 0.240 & 0.019 & 0.006 & 0.057 & -0.329 & -0.227 & -0.196 & 1.893 & -0.112 & -0.044 & -0.088 & -1.252 \\
\hline $\mathrm{TiO}_{1}$ & -0.003 & 0.007 & 0.000 & 0.000 & 0.000 & 0.000 & 0.000 & -0.002 & 0.000 & 0.001 & 0.000 & 0.002 & 0.001 \\
\hline $\mathrm{TiO}_{2}$ & 0.001 & 0.006 & 0.000 & 0.000 & 0.000 & 0.000 & 0.001 & -0.005 & 0.000 & 0.000 & 0.000 & 0.001 & 0.001 \\
\hline $\mathrm{H} \gamma \mathrm{A}$ & -15.625 & 0.480 & -1.258 & -0.006 & 0.603 & 1.643 & -2.608 & -0.289 & 0.338 & 0.241 & 0.205 & -0.603 & 1.517 \\
\hline $\mathrm{H} \gamma \mathrm{F}$ & -3.959 & 0.330 & -0.573 & 0.000 & 0.293 & 0.374 & -0.639 & -0.139 & 0.074 & 0.038 & 0.213 & -0.096 & 0.256 \\
\hline $\mathrm{H} \delta \mathrm{A}$ & -11.880 & 0.640 & -0.365 & 0.136 & 0.305 & 1.209 & -3.885 & 0.357 & 0.343 & 0.595 & 0.093 & -0.187 & 1.198 \\
\hline $\mathrm{H} \delta \mathrm{F}$ & -5.170 & 0.400 & -0.237 & -0.029 & 0.114 & 0.523 & -1.292 & 0.236 & 0.154 & 0.135 & -0.019 & -0.197 & 0.623 \\
\hline
\end{tabular}

${ }^{1}$ Overall metallicity decreased by 0.3 dex.

Table 7. Spectral index response: Turnoff star (5694/4.16/+0.67/0.00).

\begin{tabular}{|c|c|c|c|c|c|c|c|c|c|c|c|c|c|}
\hline (1) & (2) & (3) & (4) & (5) & (6) & (7) & (8) & (9) & (10) & (11) & (12) & (13) & (14) \\
\hline Index & $I_{0}$ & Error & $\mathrm{C}$ & $\mathrm{N}$ & $\mathrm{O}$ & $\mathrm{Mg}$ & $\mathrm{Fe}$ & $\mathrm{Ca}$ & $\mathrm{Na}$ & $\mathrm{Si}$ & $\mathrm{Cr}$ & $\mathrm{Ti}$ & {$[Z / H]^{1}$} \\
\hline $\mathrm{CN}_{1}$ & 0.015 & 0.021 & 0.079 & 0.082 & -0.025 & -0.017 & -0.017 & -0.006 & -0.002 & -0.008 & -0.005 & 0.004 & $\begin{array}{c}-0.044 \\
\end{array}$ \\
\hline $\mathrm{CN}_{2}$ & 0.048 & 0.023 & 0.083 & 0.088 & -0.026 & -0.019 & -0.018 & -0.008 & -0.002 & -0.007 & -0.005 & 0.004 & -0.049 \\
\hline $\mathrm{Ca} 4227$ & 0.517 & 0.270 & -0.492 & -0.345 & 0.151 & 0.107 & 0.153 & 0.490 & 0.008 & 0.047 & -0.103 & -0.009 & -0.010 \\
\hline G4300 & 5.079 & 0.390 & 0.714 & -0.001 & -0.282 & -0.272 & -0.508 & 0.122 & -0.044 & -0.158 & -0.103 & 0.091 & 0.056 \\
\hline $\mathrm{Fe} 4383$ & 5.114 & 0.530 & 0.394 & 0.001 & -0.051 & -0.277 & 0.970 & -0.173 & 0.025 & -0.153 & -0.099 & 0.161 & -0.531 \\
\hline Ca4455 & 0.795 & 0.250 & -0.030 & 0.000 & 0.004 & -0.023 & -0.061 & -0.024 & -0.008 & -0.007 & 0.070 & 0.051 & -0.128 \\
\hline $\mathrm{Fe} 4531$ & 3.701 & 0.420 & -0.026 & 0.000 & 0.003 & -0.078 & 0.186 & -0.004 & 0.023 & -0.040 & 0.093 & 0.274 & -0.479 \\
\hline $\mathrm{C}_{2} 4668$ & 4.607 & 0.640 & 7.481 & -0.003 & -1.086 & -0.399 & -0.311 & -0.001 & 0.271 & -0.471 & -0.103 & 0.129 & -1.349 \\
\hline $\mathrm{H} \beta$ & 3.149 & 0.220 & -0.028 & 0.002 & 0.018 & -0.058 & -0.040 & -0.011 & -0.005 & -0.021 & -0.067 & 0.051 & -0.292 \\
\hline Fe5015 & 5.433 & 0.460 & -0.339 & 0.001 & 0.030 & -0.175 & 0.443 & 0.082 & 0.019 & -0.076 & -0.006 & 0.302 & -0.785 \\
\hline $\mathrm{Mg}_{1}$ & 0.073 & 0.007 & 0.112 & 0.000 & -0.019 & 0.000 & -0.010 & -0.001 & -0.001 & -0.006 & -0.001 & 0.000 & -0.033 \\
\hline $\mathrm{Mg}_{2}$ & 0.191 & 0.008 & 0.041 & 0.000 & -0.009 & 0.052 & -0.011 & -0.001 & 0.000 & -0.007 & -0.003 & 0.001 & -0.041 \\
\hline $\operatorname{Mg} b$ & 3.462 & 0.230 & -0.349 & 0.003 & 0.069 & 1.556 & -0.257 & -0.011 & -0.043 & -0.102 & -0.166 & -0.017 & -0.512 \\
\hline $\mathrm{Fe} 5270$ & 2.981 & 0.280 & -0.005 & 0.001 & 0.008 & -0.065 & 0.391 & 0.134 & -0.004 & -0.046 & -0.034 & 0.057 & -0.474 \\
\hline Fe5270(Sauron) & 2.457 & & -0.004 & 0.001 & 0.007 & -0.061 & 0.359 & 0.118 & -0.004 & -0.042 & 0.003 & 0.019 & -0.364 \\
\hline $\mathrm{Fe} 5335$ & 2.572 & 0.260 & -0.023 & 0.001 & 0.012 & -0.062 & 0.451 & -0.006 & -0.004 & -0.041 & 0.097 & 0.024 & -0.446 \\
\hline $\mathrm{Fe} 5406$ & 1.379 & 0.200 & -0.058 & 0.000 & 0.009 & -0.018 & 0.243 & -0.002 & -0.001 & -0.032 & 0.044 & 0.014 & -0.219 \\
\hline $\mathrm{Fe} 5709$ & 1.121 & 0.180 & -0.005 & 0.000 & 0.002 & 0.032 & 0.084 & 0.017 & -0.032 & -0.001 & 0.017 & 0.037 & -0.208 \\
\hline $\mathrm{Fe} 5782$ & 0.533 & 0.200 & 0.010 & 0.000 & 0.000 & 0.036 & -0.100 & -0.012 & 0.000 & 0.011 & 0.171 & -0.020 & -0.121 \\
\hline $\mathrm{Na} D$ & 1.768 & 0.240 & -0.004 & 0.001 & 0.010 & -0.057 & -0.032 & -0.043 & 0.704 & -0.064 & 0.013 & -0.004 & -0.346 \\
\hline $\mathrm{TiO}_{1}$ & -0.002 & 0.007 & 0.000 & 0.000 & 0.000 & 0.000 & 0.000 & -0.001 & 0.000 & 0.000 & 0.000 & 0.001 & 0.001 \\
\hline $\mathrm{TiO}_{2}$ & -0.001 & 0.006 & 0.000 & 0.000 & 0.000 & 0.000 & -0.001 & -0.001 & 0.000 & 0.000 & 0.000 & 0.001 & 0.000 \\
\hline $\mathrm{H} \gamma \mathrm{A}$ & -5.515 & 0.480 & -0.780 & 0.002 & 0.300 & 0.526 & -0.567 & -0.089 & 0.004 & 0.219 & 0.011 & -0.196 & 0.319 \\
\hline $\mathrm{H} \gamma \mathrm{F}$ & -0.055 & 0.330 & -0.396 & 0.002 & 0.150 & 0.188 & -0.162 & -0.035 & 0.008 & 0.074 & -0.029 & -0.007 & -0.058 \\
\hline $\mathrm{H} \delta \mathrm{A}$ & -0.854 & 0.640 & -0.306 & 0.086 & 0.124 & 0.268 & -1.190 & 0.051 & 0.017 & 0.169 & -0.012 & -0.182 & 0.303 \\
\hline $\mathrm{H} \delta \mathrm{F}$ & 0.683 & 0.400 & -0.124 & -0.030 & 0.052 & 0.103 & -0.500 & 0.027 & 0.006 & 0.064 & -0.041 & -0.143 & 0.128 \\
\hline
\end{tabular}

${ }^{1}$ Overall metallicity decreased by 0.3 dex. 
A. J. Korn et al.: The sensitivity of Lick indices to abundance variations, Online Material p 3

Table 8. Spectral index response: Cool giant (4590/3.42/+0.67/0.00).

\begin{tabular}{|c|c|c|c|c|c|c|c|c|c|c|c|c|c|}
\hline (1) & (2) & (3) & (4) & (5) & (6) & (7) & (8) & (9) & (10) & (11) & (12) & (13) & (14) \\
\hline Index & $I_{0}$ & Error & $\mathrm{C}$ & $\mathrm{N}$ & $\mathrm{O}$ & $\mathrm{Mg}$ & $\mathrm{Fe}$ & $\mathrm{Ca}$ & $\mathrm{Na}$ & $\mathrm{Si}$ & $\mathrm{Cr}$ & $\mathrm{Ti}$ & {$[\mathrm{Z} / \mathrm{H}]^{1}$} \\
\hline $\mathrm{CN}_{1}$ & 0.138 & 0.021 & 0.182 & 0.063 & -0.080 & -0.016 & -0.021 & -0.010 & -0.002 & 0.010 & -0.016 & 0.002 & -0.034 \\
\hline $\mathrm{CN}_{2}$ & 0.225 & 0.023 & 0.195 & 0.067 & -0.087 & -0.024 & -0.026 & -0.014 & -0.003 & 0.021 & -0.016 & 0.003 & -0.047 \\
\hline Ca4227 & 3.380 & 0.270 & -0.810 & -0.187 & 0.384 & 0.014 & 0.015 & 1.416 & 0.015 & -0.068 & -0.175 & -0.024 & -0.879 \\
\hline G4300 & 6.254 & 0.390 & 1.300 & 0.000 & -0.704 & -0.129 & -0.459 & 0.238 & -0.037 & -0.025 & -0.213 & 0.270 & 0.133 \\
\hline $\mathrm{Fe} 4383$ & 9.680 & 0.530 & 0.276 & 0.003 & -0.018 & -0.844 & 2.260 & -0.443 & -0.094 & -0.172 & -0.279 & 0.041 & -0.721 \\
\hline Ca4455 & 1.455 & 0.250 & -0.044 & 0.000 & 0.012 & -0.018 & -0.183 & -0.061 & -0.009 & -0.003 & 0.149 & 0.067 & -0.071 \\
\hline $\mathrm{Fe} 4531$ & 6.808 & 0.420 & -0.027 & 0.000 & 0.002 & -0.307 & 0.304 & -0.049 & -0.005 & -0.060 & 0.125 & 0.779 & -0.803 \\
\hline$C_{2} 4668$ & 3.785 & 0.640 & 9.748 & -0.002 & -1.783 & -0.552 & -0.139 & 0.058 & -0.131 & -0.369 & -0.381 & 0.078 & -0.719 \\
\hline $\mathrm{H} \beta$ & 1.124 & 0.220 & -0.028 & 0.000 & 0.010 & -0.105 & -0.017 & -0.032 & -0.014 & 0.007 & -0.118 & 0.057 & -0.091 \\
\hline Fe5015 & 7.624 & 0.460 & -0.132 & -0.001 & 0.011 & -0.953 & 0.549 & 0.097 & 0.034 & -0.053 & 0.080 & 0.965 & -0.972 \\
\hline $\mathrm{Mg}_{1}$ & 0.290 & 0.007 & 0.119 & 0.000 & -0.022 & 0.043 & -0.028 & -0.006 & -0.005 & -0.007 & -0.003 & 0.000 & -0.043 \\
\hline $\mathrm{Mg}_{2}$ & 0.510 & 0.008 & 0.046 & 0.000 & -0.009 & 0.098 & -0.030 & -0.010 & -0.008 & -0.010 & -0.006 & 0.004 & -0.067 \\
\hline $\operatorname{Mg} b$ & 5.899 & 0.230 & -0.196 & 0.006 & 0.049 & 1.663 & -0.717 & -0.106 & -0.131 & -0.096 & -0.487 & 0.017 & -0.531 \\
\hline Fe5270 & 5.217 & 0.280 & 0.001 & 0.001 & 0.011 & -0.241 & 0.608 & 0.163 & -0.039 & -0.053 & -0.111 & 0.051 & -0.431 \\
\hline Fe5270(Sauron) & 4.235 & & 0.002 & 0.001 & 0.012 & -0.215 & 0.558 & 0.140 & -0.036 & -0.047 & -0.042 & -0.004 & -0.363 \\
\hline Fe5335 & 5.348 & 0.260 & -0.003 & 0.001 & 0.010 & -0.319 & 0.699 & -0.053 & -0.053 & -0.070 & 0.238 & 0.061 & -0.700 \\
\hline $\mathrm{Fe} 5406$ & 3.368 & 0.200 & -0.035 & 0.001 & 0.010 & -0.160 & 0.383 & -0.032 & -0.028 & -0.046 & 0.106 & 0.032 & -0.395 \\
\hline $\mathrm{Fe} 5709$ & 2.093 & 0.180 & -0.001 & 0.000 & 0.001 & -0.006 & 0.093 & 0.032 & -0.055 & -0.002 & 0.020 & 0.096 & -0.316 \\
\hline $\mathrm{Fe} 5782$ & 1.276 & 0.200 & 0.003 & 0.000 & 0.000 & 0.019 & -0.145 & -0.018 & -0.004 & 0.013 & 0.284 & -0.044 & -0.205 \\
\hline $\mathrm{NaD}$ & 5.362 & 0.240 & 0.010 & 0.004 & 0.035 & -0.249 & -0.138 & -0.102 & 1.785 & -0.086 & 0.017 & -0.062 & -1.069 \\
\hline $\mathrm{TiO}_{1}$ & -0.002 & 0.007 & 0.000 & 0.000 & 0.000 & 0.000 & 0.000 & -0.001 & 0.000 & 0.000 & 0.000 & 0.003 & 0.000 \\
\hline $\mathrm{TiO}_{2}$ & 0.014 & 0.006 & 0.000 & 0.000 & 0.000 & 0.000 & 0.000 & -0.003 & 0.000 & 0.000 & 0.000 & 0.002 & 0.000 \\
\hline $\mathrm{H} \gamma \mathrm{A}$ & -15.396 & 0.480 & -0.825 & -0.003 & 0.625 & 1.113 & -2.113 & -0.151 & 0.126 & 0.140 & 0.030 & -0.339 & 1.327 \\
\hline $\mathrm{H} \gamma \mathrm{F}$ & -3.894 & 0.330 & -0.491 & 0.000 & 0.317 & 0.285 & -0.525 & -0.070 & 0.036 & 0.031 & -0.011 & -0.007 & 0.307 \\
\hline $\mathrm{H} \delta \mathrm{A}$ & -9.397 & 0.640 & -0.102 & 0.350 & 0.258 & 0.785 & -3.009 & 0.124 & 0.133 & 0.665 & 0.018 & -0.347 & 1.094 \\
\hline $\mathrm{H} \delta \mathrm{F}$ & -5.415 & 0.400 & -0.212 & 0.014 & 0.173 & 0.463 & -1.149 & 0.130 & 0.077 & 0.118 & -0.073 & -0.298 & 0.872 \\
\hline
\end{tabular}

Table 9. Spectral index response: Cool dwarf (4543/4.58/+0.35/0.00).

\begin{tabular}{|c|c|c|c|c|c|c|c|c|c|c|c|c|c|}
\hline (1) & (2) & (3) & (4) & (5) & (6) & (7) & (8) & (9) & (10) & (11) & (12) & (13) & (14) \\
\hline Index & $I_{0}$ & Error & $\mathrm{C}$ & $\mathrm{N}$ & $\mathrm{O}$ & $\mathrm{Mg}$ & $\mathrm{Fe}$ & $\mathrm{Ca}$ & $\mathrm{Na}$ & $\mathrm{Si}$ & $\mathrm{Cr}$ & $\mathrm{Ti}$ & {$[\mathrm{Z} / \mathrm{H}]$} \\
\hline $\mathrm{CN}_{1}$ & -0.006 & 0.021 & 0.140 & 0.040 & -0.040 & 0.000 & -0.010 & -0.010 & 0.000 & 0.010 & -0.020 & 0.000 & 0.010 \\
\hline $\mathrm{CN}_{2}$ & 0.068 & 0.023 & 0.150 & 0.040 & -0.050 & -0.010 & -0.010 & -0.010 & 0.000 & 0.020 & -0.020 & 0.000 & 0.020 \\
\hline Ca4227 & 4.718 & 0.270 & -0.640 & -0.130 & 0.230 & -0.080 & -0.080 & 1.080 & -0.030 & -0.050 & -0.190 & -0.010 & 0.660 \\
\hline G4300 & 4.848 & 0.390 & 1.680 & 0.000 & -0.710 & -0.210 & -0.500 & 0.430 & -0.080 & -0.040 & -0.220 & 0.560 & 0.170 \\
\hline $\mathrm{Fe} 4383$ & 11.923 & 0.530 & 0.100 & 0.000 & 0.040 & -1.150 & 2.840 & -0.800 & -0.270 & -0.180 & -0.240 & -0.020 & 0.850 \\
\hline Ca4455 & 0.972 & 0.250 & -0.050 & 0.000 & 0.010 & -0.040 & -0.030 & -0.150 & -0.020 & -0.010 & 0.050 & -0.010 & -0.020 \\
\hline $\mathrm{Fe} 4531$ & 5.902 & 0.420 & 0.020 & 0.000 & 0.000 & -0.480 & 0.310 & -0.190 & -0.060 & -0.060 & 0.190 & 1.070 & 0.800 \\
\hline$C_{2} 4668$ & 0.946 & 0.640 & 4.200 & 0.000 & -0.500 & -0.220 & 0.220 & 0.170 & -0.020 & -0.140 & -0.310 & 0.120 & 0.210 \\
\hline $\mathrm{H} \beta$ & 0.778 & 0.220 & -0.020 & 0.000 & 0.000 & -0.080 & 0.030 & -0.040 & -0.010 & 0.000 & -0.090 & 0.020 & 0.070 \\
\hline $\mathrm{Fe} 5015$ & 5.352 & 0.460 & -0.030 & 0.000 & 0.000 & -0.870 & 0.270 & 0.000 & -0.030 & -0.070 & 0.010 & 1.570 & 1.040 \\
\hline $\mathrm{Mg}_{1}$ & 0.251 & 0.007 & 0.050 & 0.000 & -0.010 & 0.030 & -0.020 & -0.010 & -0.010 & 0.000 & 0.000 & 0.000 & 0.020 \\
\hline $\mathrm{Mg}_{2}$ & 0.577 & 0.008 & 0.020 & 0.000 & 0.000 & 0.090 & -0.040 & -0.020 & -0.020 & -0.010 & -0.010 & 0.000 & 0.050 \\
\hline $\operatorname{Mg} b$ & 7.628 & 0.230 & -0.040 & 0.000 & 0.030 & 1.650 & -0.630 & -0.200 & -0.200 & -0.080 & -0.520 & -0.040 & 0.480 \\
\hline $\mathrm{Fe} 5270$ & 5.485 & 0.280 & 0.000 & 0.000 & 0.010 & -0.360 & 0.710 & 0.230 & -0.110 & -0.060 & 0.010 & 0.050 & 0.500 \\
\hline $\mathrm{Fe} 5270$ (S & 4.716 & & 0.000 & 0.000 & 0.010 & -0.310 & 0.590 & 0.220 & -0.100 & -0.050 & 0.020 & 0.000 & 0.420 \\
\hline $\mathrm{Fe} 5335$ & 5.158 & 0.260 & 0.000 & 0.000 & 0.010 & -0.390 & 0.880 & -0.140 & -0.130 & -0.070 & 0.300 & 0.030 & 0.590 \\
\hline $\mathrm{Fe} 5406$ & 3.194 & 0.200 & -0.010 & 0.000 & 0.010 & -0.240 & 0.480 & -0.090 & -0.080 & -0.040 & 0.170 & 0.030 & 0.350 \\
\hline $\mathrm{Fe} 5709$ & 1.375 & 0.180 & 0.000 & 0.000 & 0.000 & -0.010 & 0.140 & 0.000 & -0.120 & -0.010 & 0.020 & 0.060 & 0.210 \\
\hline Fe5782 & 0.807 & 0.200 & 0.000 & 0.000 & 0.000 & 0.000 & -0.100 & -0.040 & -0.010 & 0.000 & 0.270 & -0.030 & 0.130 \\
\hline $\mathrm{NaD}$ & 8.099 & 0.240 & 0.010 & 0.000 & 0.030 & -0.330 & -0.220 & -0.210 & 1.890 & -0.070 & 0.000 & -0.050 & 1.220 \\
\hline $\mathrm{TiO}_{1}$ & -0.003 & 0.007 & 0.000 & 0.000 & 0.000 & 0.000 & 0.000 & 0.000 & 0.000 & 0.000 & 0.000 & 0.000 & 0.000 \\
\hline $\mathrm{TiO}_{2}$ & 0.002 & 0.006 & 0.000 & 0.000 & 0.000 & 0.000 & 0.000 & 0.000 & 0.000 & 0.000 & 0.000 & 0.000 & 0.000 \\
\hline $\mathrm{H} \gamma \mathrm{A}$ & -16.066 & 0.480 & -1.280 & 0.000 & 0.620 & 1.680 & -2.670 & -0.180 & 0.390 & 0.210 & 0.180 & -0.680 & -1.640 \\
\hline $\mathrm{H} \gamma \mathrm{F}$ & -4.565 & 0.330 & -0.580 & 0.000 & 0.290 & 0.430 & -0.750 & -0.100 & 0.110 & 0.050 & 0.240 & -0.110 & -0.310 \\
\hline $\mathrm{H} \delta \mathrm{A}$ & -11.612 & 0.640 & -0.680 & 0.020 & 0.360 & 1.240 & -3.760 & 0.440 & 0.370 & 0.540 & 0.060 & -0.230 & -1.120 \\
\hline $\mathrm{H} \delta \mathrm{F}$ & -5.153 & 0.400 & -0.280 & -0.040 & 0.100 & 0.530 & -1.230 & 0.270 & 0.160 & 0.140 & -0.030 & -0.220 & -0.580 \\
\hline
\end{tabular}


A. J. Korn et al.: The sensitivity of Lick indices to abundance variations, Online Material p 4

Table 10. Spectral index response: Turnoff star (5969/4.18/+0.35/0.00).

\begin{tabular}{|c|c|c|c|c|c|c|c|c|c|c|c|c|c|}
\hline (1) & (2) & (3) & (4) & (5) & (6) & (7) & (8) & (9) & (10) & (11) & (12) & (13) & (14) \\
\hline Index & $I_{0}$ & Error & $\mathrm{C}$ & $\mathrm{N}$ & $\mathrm{O}$ & $\mathrm{Mg}$ & $\mathrm{Fe}$ & $\mathrm{Ca}$ & $\mathrm{Na}$ & $\mathrm{Si}$ & $\mathrm{Cr}$ & $\mathrm{Ti}$ & {$[\mathrm{Z} / \mathrm{H}]$} \\
\hline $\mathrm{CN}_{1}$ & -0.079 & 0.021 & 0.030 & 0.040 & 0.000 & -0.010 & -0.010 & 0.000 & 0.000 & 0.000 & 0.000 & 0.000 & 0.030 \\
\hline $\mathrm{CN}_{2}$ & -0.051 & 0.023 & 0.030 & 0.040 & 0.000 & -0.010 & -0.010 & 0.000 & 0.000 & 0.000 & 0.000 & 0.000 & 0.030 \\
\hline $\mathrm{Ca} 4227$ & 0.529 & 0.270 & -0.260 & -0.200 & 0.030 & 0.050 & 0.120 & 0.280 & 0.000 & 0.030 & -0.080 & 0.000 & 0.030 \\
\hline G4300 & 4.397 & 0.390 & 0.870 & 0.000 & -0.120 & -0.280 & -0.440 & 0.090 & -0.040 & -0.210 & -0.070 & 0.080 & 0.040 \\
\hline $\mathrm{Fe} 4383$ & 3.627 & 0.530 & 0.380 & 0.000 & -0.030 & -0.160 & 0.620 & -0.120 & 0.030 & -0.110 & -0.060 & 0.160 & 0.480 \\
\hline $\mathrm{Ca} 4455$ & 0.560 & 0.250 & -0.020 & 0.000 & 0.000 & -0.010 & -0.050 & -0.010 & -0.010 & 0.000 & 0.050 & 0.040 & 0.130 \\
\hline $\mathrm{Fe} 4531$ & 2.933 & 0.420 & -0.010 & 0.000 & 0.000 & -0.040 & 0.110 & 0.000 & 0.010 & -0.020 & 0.100 & 0.210 & 0.450 \\
\hline $\mathrm{C}_{2} 4668$ & 2.268 & 0.640 & 3.200 & 0.000 & -0.210 & -0.370 & -0.260 & -0.270 & -0.330 & -0.250 & -0.340 & -0.150 & 1.110 \\
\hline $\mathrm{H} \beta$ & 3.478 & 0.220 & -0.020 & 0.000 & 0.010 & -0.020 & -0.040 & -0.010 & 0.000 & -0.010 & -0.050 & 0.050 & 0.310 \\
\hline Fe5015 & 4.285 & 0.460 & -0.090 & 0.000 & 0.000 & -0.060 & 0.350 & 0.070 & 0.020 & -0.050 & -0.040 & 0.260 & 0.760 \\
\hline $\mathrm{Mg}_{1}$ & 0.017 & 0.007 & 0.060 & 0.000 & 0.000 & 0.000 & -0.010 & 0.000 & 0.000 & 0.000 & 0.000 & 0.000 & 0.030 \\
\hline $\mathrm{Mg}_{2}$ & 0.114 & 0.008 & 0.030 & 0.000 & 0.000 & 0.030 & -0.010 & 0.000 & 0.000 & 0.000 & 0.000 & 0.000 & 0.030 \\
\hline $\operatorname{Mg} b$ & 2.318 & 0.230 & -0.170 & 0.000 & 0.020 & 1.110 & -0.120 & -0.010 & -0.030 & -0.060 & -0.110 & -0.020 & 0.430 \\
\hline $\mathrm{Fe} 5270$ & 2.115 & 0.280 & 0.000 & 0.000 & 0.000 & -0.020 & 0.320 & 0.110 & 0.000 & -0.020 & 0.010 & 0.070 & 0.470 \\
\hline Fe5270(Sauron) & 1.786 & & 0.000 & 0.000 & 0.000 & -0.020 & 0.280 & 0.090 & 0.000 & -0.020 & 0.030 & 0.030 & 0.350 \\
\hline Fe5335 & 1.729 & 0.260 & -0.020 & 0.000 & 0.010 & -0.020 & 0.330 & 0.000 & 0.000 & -0.020 & 0.060 & 0.020 & 0.390 \\
\hline Fe5406 & 0.932 & 0.200 & -0.040 & 0.000 & 0.000 & 0.000 & 0.190 & 0.000 & 0.000 & -0.010 & 0.040 & 0.020 & 0.200 \\
\hline Fe5709 & 0.785 & 0.180 & 0.000 & 0.000 & 0.000 & 0.030 & 0.080 & 0.010 & -0.020 & 0.010 & 0.010 & 0.010 & 0.200 \\
\hline Fe 5782 & 0.350 & 0.200 & 0.010 & 0.000 & 0.000 & 0.040 & -0.070 & -0.010 & 0.000 & 0.020 & 0.130 & -0.010 & 0.120 \\
\hline $\mathrm{NaD}$ & 1.078 & 0.240 & 0.000 & 0.000 & & -0.030 & -0.020 & -0.030 & 0.450 & -0.040 & 0.010 & 0.000 & 0.270 \\
\hline $\mathrm{TiO}_{1}$ & 0.000 & 0.007 & 0.000 & 0.000 & 0.000 & 0.000 & 0.000 & 0.000 & 0.000 & 0.000 & 0.000 & 0.000 & 0.000 \\
\hline $\mathrm{TiO}_{2}$ & -0.001 & 0.006 & 0.000 & 0.000 & 0.000 & 0.000 & 0.000 & 0.000 & 0.000 & 0.000 & 0.000 & 0.000 & 0.000 \\
\hline $\mathrm{H} \gamma \mathrm{A}$ & -2.781 & 0.480 & -1.010 & 0.000 & 0.130 & 0.450 & -0.210 & -0.050 & 0.010 & 0.260 & 0.000 & -0.190 & -0.210 \\
\hline $\mathrm{H} \gamma \mathrm{F}$ & 1.087 & 0.330 & -0.480 & 0.000 & 0.060 & 0.190 & -0.050 & -0.020 & 0.010 & 0.110 & -0.020 & -0.020 & 0.090 \\
\hline $\mathrm{H} \delta \mathrm{A}$ & 1.555 & 0.640 & -0.390 & -0.090 & 0.030 & 0.200 & -0.630 & -0.020 & 0.010 & 0.140 & -0.030 & -0.130 & -0.100 \\
\hline $\mathrm{H} \delta \mathrm{F}$ & 1.914 & 0.400 & -0.090 & -0.020 & 0.010 & 0.080 & -0.250 & 0.030 & 0.000 & 0.060 & -0.040 & -0.090 & 0.000 \\
\hline
\end{tabular}

Table 11. Spectral index response: Red giant (4236/2.00/+0.35/0.00).

\begin{tabular}{|c|c|c|c|c|c|c|c|c|c|c|c|c|c|}
\hline (1) & (2) & (3) & (4) & (5) & (6) & (7) & (8) & (9) & (10) & (11) & (12) & (13) & (14) \\
\hline Index & $I_{0}$ & Error & $\mathrm{C}$ & $\mathrm{N}$ & $\mathrm{O}$ & $\mathrm{Mg}$ & $\mathrm{Fe}$ & $\mathrm{Ca}$ & $\mathrm{Na}$ & $\mathrm{Si}$ & $\mathrm{Cr}$ & $\mathrm{Ti}$ & {$[\mathrm{Z} / \mathrm{H}]$} \\
\hline $\mathrm{CN}_{1}$ & 0.170 & 0.021 & 0.180 & 0.060 & -0.080 & -0.020 & -0.020 & -0.010 & 0.000 & 0.010 & -0.020 & 0.000 & 0.030 \\
\hline $\mathrm{CN}_{2}$ & 0.273 & 0.023 & 0.190 & 0.060 & -0.090 & -0.030 & -0.030 & -0.010 & 0.000 & 0.020 & -0.020 & 0.000 & 0.040 \\
\hline $\mathrm{Ca} 4227$ & 4.200 & 0.270 & -0.730 & -0.150 & 0.330 & 0.080 & 0.050 & 1.560 & 0.040 & -0.060 & -0.180 & -0.020 & 1.210 \\
\hline G4300 & 6.623 & 0.390 & 1.180 & 0.000 & -0.670 & -0.080 & -0.400 & 0.190 & -0.030 & 0.000 & -0.220 & 0.370 & -0.030 \\
\hline $\mathrm{Fe} 4383$ & 9.961 & 0.530 & 0.270 & 0.000 & -0.040 & -0.710 & 2.460 & -0.360 & -0.080 & -0.140 & -0.260 & 0.050 & 1.140 \\
\hline $\mathrm{Ca} 4455$ & 1.434 & 0.250 & -0.040 & 0.000 & 0.010 & 0.000 & -0.240 & -0.040 & -0.010 & 0.000 & 0.150 & 0.090 & -0.010 \\
\hline $\mathrm{Fe} 4531$ & 7.441 & 0.420 & -0.030 & 0.000 & 0.000 & -0.280 & 0.360 & -0.030 & 0.000 & -0.050 & 0.100 & 0.840 & 1.120 \\
\hline$C_{2} 4668$ & 3.655 & 0.640 & 9.640 & 0.000 & -1.870 & -0.660 & -0.160 & 0.050 & -0.130 & -0.400 & -0.410 & 0.050 & 0.780 \\
\hline $\mathrm{H} \beta$ & 0.885 & 0.220 & -0.020 & 0.000 & 0.000 & -0.080 & 0.000 & -0.020 & -0.010 & 0.020 & -0.110 & 0.050 & 0.050 \\
\hline $\mathrm{Fe} 5015$ & 8.105 & 0.460 & -0.130 & 0.000 & 0.010 & -0.890 & 0.620 & 0.090 & 0.040 & -0.040 & 0.100 & 1.050 & 1.360 \\
\hline $\mathrm{Mg}_{1}$ & 0.318 & 0.007 & 0.110 & 0.000 & -0.020 & 0.040 & -0.020 & -0.010 & -0.010 & -0.010 & 0.000 & 0.000 & 0.040 \\
\hline $\mathrm{Mg}_{2}$ & 0.472 & 0.008 & 0.040 & 0.000 & -0.010 & 0.100 & -0.030 & -0.010 & -0.010 & -0.010 & -0.010 & 0.000 & 0.070 \\
\hline $\operatorname{Mg} b$ & 4.408 & 0.230 & -0.250 & 0.000 & 0.030 & 1.760 & -0.530 & -0.090 & -0.110 & -0.070 & -0.500 & 0.020 & 0.660 \\
\hline $\mathrm{Fe} 5270$ & 5.085 & 0.280 & 0.000 & 0.000 & 0.000 & -0.180 & 0.620 & 0.110 & -0.030 & -0.040 & -0.120 & 0.050 & 0.480 \\
\hline Fe5270(Sauron) & 4.007 & & 0.000 & 0.000 & 0.000 & -0.170 & 0.580 & 0.100 & -0.030 & -0.040 & -0.050 & 0.000 & 0.400 \\
\hline $\mathrm{Fe} 5335$ & 5.196 & 0.260 & 0.000 & 0.000 & 0.000 & -0.250 & 0.660 & -0.040 & -0.040 & -0.050 & 0.230 & 0.060 & 0.800 \\
\hline $\mathrm{Fe} 5406$ & 3.503 & 0.200 & -0.040 & 0.000 & 0.010 & -0.130 & 0.360 & -0.030 & -0.020 & -0.040 & 0.100 & 0.020 & 0.410 \\
\hline $\mathrm{Fe} 5709$ & 2.185 & 0.180 & 0.000 & 0.000 & 0.000 & 0.000 & 0.080 & 0.030 & -0.030 & 0.000 & 0.020 & 0.100 & 0.330 \\
\hline $\mathrm{Fe} 5782$ & 1.379 & 0.200 & 0.000 & 0.000 & 0.000 & 0.020 & -0.140 & -0.010 & 0.000 & 0.010 & 0.260 & -0.040 & 0.200 \\
\hline $\mathrm{NaD}$ & 4.750 & 0.240 & 0.000 & 0.000 & 0.010 & -0.120 & -0.040 & -0.060 & 1.710 & -0.060 & 0.020 & -0.050 & 1.410 \\
\hline $\mathrm{TiO}_{1}$ & 0.000 & 0.007 & 0.000 & 0.000 & 0.000 & 0.000 & 0.000 & 0.000 & 0.000 & 0.000 & 0.000 & 0.000 & 0.000 \\
\hline $\mathrm{TiO}_{2}$ & 0.019 & 0.006 & 0.000 & 0.000 & 0.000 & 0.000 & 0.000 & 0.000 & 0.000 & 0.000 & 0.000 & 0.000 & 0.000 \\
\hline $\mathrm{H} \gamma \mathrm{A}$ & -16.649 & 0.480 & -0.400 & 0.000 & 0.520 & 0.840 & -2.510 & -0.150 & 0.100 & 0.070 & -0.090 & -0.450 & -2.470 \\
\hline $\mathrm{H} \gamma \mathrm{F}$ & -4.709 & 0.330 & -0.350 & 0.000 & 0.280 & 0.240 & -0.690 & -0.060 & 0.030 & 0.020 & -0.090 & -0.020 & -0.710 \\
\hline $\mathrm{H} \delta \mathrm{A}$ & -10.003 & 0.640 & -0.230 & 0.350 & 0.260 & 0.630 & -3.330 & 0.030 & 0.100 & 0.610 & 0.020 & -0.360 & -1.920 \\
\hline $\mathrm{H} \delta \mathrm{F}$ & -6.687 & 0.400 & -0.240 & 0.030 & 0.190 & 0.430 & -1.370 & 0.120 & 0.070 & 0.120 & -0.080 & -0.310 & -1.390 \\
\hline
\end{tabular}


A. J. Korn et al.: The sensitivity of Lick indices to abundance variations, Online Material p 5

Table 12. Spectral index response: Cool dwarf (4575/4.60/0.00/0.00).

\begin{tabular}{|c|c|c|c|c|c|c|c|c|c|c|c|c|c|c|c|}
\hline (1) & (2) & (3) & (4) & (5) & (6) & (7) & (8) & (9) & (10) & (11) & (12) & (13) & (14) & (15) & (16) \\
\hline Index & $I_{0}$ & Error & $\mathrm{C}$ & $\mathrm{N}$ & $\mathrm{O}$ & $\mathrm{Mg}$ & $\mathrm{Fe}$ & $\mathrm{Ca}$ & $\mathrm{Na}$ & $\mathrm{Si}$ & $\mathrm{Cr}$ & $\mathrm{Ti}$ & {$[\mathrm{Z} / \mathrm{H}]$} & $\mathrm{C} 0.15$ & $\mathrm{C}+\mathrm{O} 0.3$ \\
\hline $\mathrm{CN}_{1}$ & -0.019 & 0.021 & 0.123 & 0.037 & -0.033 & -0.004 & -0.007 & -0.007 & 0.000 & 0.010 & -0.017 & 0.002 & 0.014 & 0.038 & 0.009 \\
\hline $\mathrm{CN}_{2}$ & 0.043 & 0.023 & 0.130 & 0.039 & -0.034 & -0.009 & -0.008 & -0.010 & -0.002 & 0.017 & -0.018 & 0.004 & 0.022 & 0.040 & 0.010 \\
\hline $\mathrm{Ca} 4227$ & 3.763 & 0.270 & -0.669 & -0.148 & 0.202 & -0.087 & -0.069 & 1.118 & -0.028 & -0.058 & -0.175 & -0.007 & 0.653 & -0.212 & -0.039 \\
\hline G4300 & 4.749 & 0.390 & 1.687 & 0.000 & -0.768 & -0.196 & -0.470 & 0.323 & -0.063 & -0.035 & -0.205 & 0.453 & 0.073 & 0.591 & 0.040 \\
\hline $\mathrm{Fe} 4383$ & 10.723 & 0.530 & 0.199 & 0.001 & 0.003 & -1.060 & 2.595 & -0.642 & -0.183 & -0.168 & -0.179 & 0.024 & 0.890 & 0.047 & 0.042 \\
\hline $\mathrm{Ca} 4455$ & 0.936 & 0.250 & -0.052 & 0.000 & 0.012 & -0.046 & -0.021 & -0.109 & -0.020 & -0.007 & 0.050 & -0.007 & 0.038 & -0.017 & -0.011 \\
\hline $\mathrm{Fe} 4531$ & 4.930 & 0.420 & 0.032 & 0.000 & -0.006 & -0.413 & 0.272 & -0.125 & -0.036 & -0.055 & 0.168 & 0.902 & 0.723 & 0.010 & 0.007 \\
\hline$C_{2} 4668$ & 0.906 & 0.640 & 2.914 & 0.000 & -0.311 & -0.169 & 0.228 & 0.118 & -0.036 & -0.105 & -0.229 & 0.129 & 0.141 & 0.730 & 0.555 \\
\hline $\mathrm{H} \beta$ & 0.748 & 0.220 & -0.012 & 0.000 & 0.003 & -0.074 & 0.026 & -0.035 & -0.011 & -0.013 & -0.072 & 0.024 & 0.063 & -0.005 & -0.006 \\
\hline $\mathrm{Fe} 5015$ & 4.220 & 0.460 & -0.025 & 0.000 & 0.005 & -0.801 & 0.336 & 0.026 & 0.001 & -0.048 & 0.007 & 1.216 & 0.891 & -0.008 & -0.004 \\
\hline $\mathrm{Mg}_{1}$ & 0.223 & 0.007 & 0.039 & 0.000 & -0.004 & 0.032 & -0.021 & -0.005 & -0.004 & -0.002 & -0.004 & 0.000 & 0.019 & 0.010 & 0.007 \\
\hline $\mathrm{Mg}_{2}$ & 0.511 & 0.008 & 0.020 & 0.000 & -0.001 & 0.089 & -0.032 & -0.013 & -0.011 & -0.007 & -0.004 & 0.004 & 0.055 & 0.005 & 0.004 \\
\hline $\operatorname{Mg} b$ & 7.440 & 0.230 & -0.084 & 0.001 & 0.008 & 1.623 & -0.688 & -0.149 & -0.150 & -0.077 & -0.552 & -0.089 & 0.355 & -0.051 & -0.043 \\
\hline $\mathrm{Fe} 5270$ & 4.831 & 0.280 & 0.001 & 0.001 & 0.005 & -0.336 & 0.677 & 0.203 & -0.081 & -0.052 & 0.027 & 0.040 & 0.490 & 0.001 & 0.007 \\
\hline Fe5270(Sauron) & 4.162 & & 0.001 & 0.000 & 0.005 & -0.292 & 0.572 & 0.195 & -0.071 & -0.045 & 0.036 & 0.000 & 0.417 & 0.000 & 0.006 \\
\hline Fe5335 & 4.440 & 0.260 & 0.000 & 0.000 & 0.004 & -0.380 & 0.806 & -0.059 & -0.092 & -0.062 & 0.243 & 0.022 & 0.549 & 0.000 & 0.005 \\
\hline $\mathrm{Fe} 5406$ & 2.723 & 0.200 & -0.008 & 0.000 & 0.003 & -0.213 & 0.456 & -0.063 & -0.054 & -0.037 & 0.153 & 0.031 & 0.350 & -0.002 & 0.000 \\
\hline $\mathrm{Fe} 5709$ & 1.130 & 0.180 & 0.000 & 0.000 & 0.000 & -0.009 & 0.128 & -0.005 & -0.094 & -0.005 & 0.019 & 0.058 & 0.202 & 0.000 & 0.000 \\
\hline $\mathrm{Fe} 5782$ & 0.650 & 0.200 & 0.000 & 0.000 & 0.001 & 0.005 & -0.081 & -0.033 & -0.008 & 0.002 & 0.244 & -0.027 & 0.125 & 0.000 & 0.001 \\
\hline $\mathrm{NaD}$ & 6.509 & 0.240 & 0.004 & 0.001 & 0.013 & -0.313 & -0.207 & -0.160 & 1.751 & -0.058 & -0.005 & -0.039 & 1.125 & 0.002 & 0.017 \\
\hline $\mathrm{TiO}_{1}$ & -0.002 & 0.007 & 0.000 & 0.000 & 0.000 & 0.000 & 0.000 & -0.001 & 0.000 & 0.000 & 0.000 & 0.002 & -0.001 & 0.000 & 0.000 \\
\hline $\mathrm{TiO}_{2}$ & 0.003 & 0.006 & 0.000 & 0.000 & 0.000 & 0.000 & 0.001 & -0.004 & 0.000 & 0.000 & 0.000 & 0.001 & -0.001 & 0.000 & 0.000 \\
\hline $\mathrm{H} \gamma \mathrm{A}$ & -14.121 & 0.480 & -1.311 & -0.001 & 0.691 & 1.446 & -2.269 & -0.134 & 0.247 & 0.166 & 0.156 & -0.549 & -1.381 & -0.475 & 0.027 \\
\hline $\mathrm{H} \gamma \mathrm{F}$ & -4.159 & 0.330 & -0.588 & 0.000 & 0.319 & 0.390 & -0.679 & -0.081 & 0.072 & 0.038 & 0.207 & -0.084 & -0.269 & -0.218 & 0.011 \\
\hline $\mathrm{H} \delta \mathrm{A}$ & -10.165 & 0.640 & -0.942 & -0.063 & 0.368 & 1.109 & -3.277 & 0.306 & 0.249 & 0.515 & 0.056 & -0.220 & -1.089 & -0.372 & -0.133 \\
\hline $\mathrm{H} \delta \mathrm{F}$ & -4.386 & 0.400 & -0.301 & -0.044 & 0.090 & 0.471 & -1.077 & 0.189 & 0.109 & 0.120 & -0.015 & -0.203 & -0.546 & -0.104 & -0.037 \\
\hline
\end{tabular}

Table 13. Spectral index response: Turnoff star (6200/4.10/0.00/0.00).

\begin{tabular}{|c|c|c|c|c|c|c|c|c|c|c|c|c|c|c|c|}
\hline$\overline{(1)}$ & (2) & (3) & (4) & $\overline{(\overline{(5)}}$ & (6) & (7) & (8) & (9) & (10) & (11) & $\overline{~(12) ~}$ & (13) & (14) & (15) & $\overline{~(16)}$ \\
\hline Index & $I_{0}$ & Error & $\mathrm{C}$ & $\mathrm{N}$ & $\mathrm{O}$ & $\mathrm{Mg}$ & $\mathrm{Fe}$ & $\mathrm{Ca}$ & $\mathrm{Na}$ & $\mathrm{Si}$ & $\mathrm{Cr}$ & $\mathrm{Ti}$ & {$[\mathrm{Z} / \mathrm{H}]$} & $\mathrm{C} 0.15$ & $\mathrm{C}+\mathrm{O} 0.3$ \\
\hline $\mathrm{CN}_{1}$ & -0.106 & 0.021 & 0.001 & 0.010 & 0.000 & -0.001 & -0.002 & -0.002 & 0.000 & -0.001 & -0.001 & 0.001 & -0.002 & 0.000 & 0.000 \\
\hline $\mathrm{CN}_{2}$ & -0.077 & 0.023 & 0.000 & 0.010 & 0.000 & -0.001 & -0.003 & -0.002 & 0.000 & -0.001 & -0.001 & 0.002 & -0.001 & -0.001 & 0.000 \\
\hline $\mathrm{Ca} 4227$ & 0.426 & 0.270 & -0.076 & -0.052 & 0.002 & 0.008 & 0.057 & 0.160 & 0.001 & 0.006 & -0.055 & 0.004 & 0.071 & -0.032 & -0.071 \\
\hline G4300 & 3.053 & 0.390 & 1.092 & 0.000 & -0.034 & -0.199 & -0.258 & 0.065 & -0.020 & -0.158 & -0.046 & 0.101 & 0.406 & 0.553 & 1.059 \\
\hline $\mathrm{Fe} 4383$ & 2.212 & 0.530 & 0.280 & 0.000 & -0.016 & -0.082 & 0.408 & -0.072 & 0.017 & -0.050 & -0.030 & 0.129 & 0.459 & 0.125 & 0.261 \\
\hline $\mathrm{Ca} 4455$ & 0.359 & 0.250 & -0.009 & 0.000 & 0.000 & -0.011 & -0.045 & -0.005 & -0.005 & 0.001 & 0.035 & 0.019 & 0.109 & -0.004 & -0.009 \\
\hline $\mathrm{Fe} 4531$ & 2.222 & 0.420 & 0.003 & 0.000 & 0.000 & -0.017 & 0.090 & 0.002 & 0.006 & 0.000 & 0.102 & 0.198 & 0.440 & 0.001 & 0.002 \\
\hline$C_{2} 4668$ & 0.504 & 0.640 & 0.883 & 0.000 & -0.015 & 0.259 & 0.174 & 0.029 & -0.002 & -0.095 & -0.061 & 0.107 & 0.595 & 0.303 & 0.830 \\
\hline $\mathrm{H} \beta$ & 3.757 & 0.220 & -0.011 & 0.000 & 0.002 & 0.008 & -0.060 & -0.003 & 0.000 & 0.004 & -0.024 & 0.051 & 0.252 & -0.005 & -0.009 \\
\hline $\mathrm{Fe} 5015$ & 3.222 & 0.460 & -0.015 & 0.000 & -0.007 & -0.005 & 0.241 & 0.057 & 0.019 & -0.018 & -0.037 & 0.241 & 0.669 & -0.005 & -0.021 \\
\hline $\mathrm{Mg}_{1}$ & -0.002 & 0.007 & 0.015 & 0.000 & 0.000 & 0.000 & -0.004 & 0.000 & 0.000 & 0.000 & -0.002 & 0.000 & 0.006 & 0.005 & 0.014 \\
\hline $\mathrm{Mg}_{2}$ & 0.065 & 0.008 & 0.008 & 0.000 & 0.000 & 0.021 & -0.001 & 0.000 & 0.000 & -0.001 & -0.002 & 0.001 & 0.019 & 0.003 & 0.008 \\
\hline $\operatorname{Mg} b$ & 1.461 & 0.230 & -0.047 & 0.000 & 0.004 & 0.717 & -0.053 & -0.002 & -0.019 & -0.027 & -0.065 & -0.012 & 0.329 & -0.016 & -0.041 \\
\hline $\mathrm{Fe} 5270$ & 1.382 & 0.280 & 0.001 & 0.000 & 0.000 & 0.000 & 0.217 & 0.081 & 0.000 & 0.000 & 0.024 & 0.057 & 0.384 & 0.000 & 0.002 \\
\hline Fe5270(Sauron) & 1.228 & & 0.001 & 0.000 & 0.001 & -0.004 & 0.170 & 0.074 & 0.000 & -0.003 & 0.027 & 0.033 & 0.285 & 0.000 & 0.001 \\
\hline $\mathrm{Fe} 5335$ & 1.119 & 0.260 & -0.012 & 0.000 & -0.061 & -0.002 & 0.212 & -0.001 & 0.000 & -0.001 & 0.034 & -0.053 & 0.270 & -0.005 & -0.072 \\
\hline Fe5406 & 0.591 & 0.200 & -0.023 & 0.000 & 0.000 & 0.007 & 0.143 & 0.000 & 0.000 & -0.001 & 0.027 & 0.010 & 0.159 & -0.010 & -0.022 \\
\hline Fe5709 & 0.500 & 0.180 & -0.002 & 0.000 & 0.000 & 0.029 & 0.082 & 0.004 & -0.019 & 0.010 & 0.006 & 0.005 & 0.157 & -0.001 & -0.002 \\
\hline Fe5782 & 0.192 & 0.200 & 0.008 & 0.000 & 0.000 & 0.029 & -0.045 & -0.007 & 0.000 & 0.014 & 0.101 & -0.007 & 0.097 & 0.003 & 0.007 \\
\hline $\mathrm{NaD}$ & 0.630 & 0.240 & -0.002 & 0.000 & 0.001 & -0.011 & -0.014 & -0.025 & 0.262 & -0.025 & 0.004 & -0.005 & 0.163 & -0.001 & -0.001 \\
\hline $\mathrm{TiO}_{1}$ & 0.001 & 0.007 & 0.000 & 0.000 & 0.000 & 0.000 & 0.000 & 0.000 & 0.000 & 0.000 & 0.000 & 0.001 & 0.000 & 0.000 & 0.000 \\
\hline $\mathrm{TiO}_{2}$ & -0.001 & 0.006 & 0.000 & 0.000 & 0.000 & 0.000 & 0.000 & 0.000 & 0.000 & 0.000 & 0.000 & 0.000 & 0.000 & 0.000 & 0.000 \\
\hline $\mathrm{H} \gamma \mathrm{A}$ & -0.012 & 0.480 & -1.115 & 0.000 & 0.034 & 0.303 & -0.118 & -0.036 & 0.005 & 0.185 & -0.007 & -0.167 & -0.427 & -0.554 & -1.079 \\
\hline $\mathrm{H} \gamma \mathrm{F}$ & 2.258 & 0.330 & -0.504 & 0.000 & 0.014 & 0.133 & -0.017 & -0.013 & 0.006 & 0.084 & -0.007 & -0.016 & -0.015 & -0.246 & -0.489 \\
\hline $\mathrm{H} \delta \mathrm{A}$ & 3.106 & 0.640 & -0.196 & -0.019 & 0.008 & 0.118 & -0.319 & 0.011 & 0.007 & 0.095 & -0.009 & -0.073 & 0.021 & -0.086 & -0.186 \\
\hline $\mathrm{H} \delta \mathrm{F}$ & 2.748 & 0.400 & -0.039 & -0.004 & 0.004 & 0.056 & -0.149 & 0.028 & 0.003 & 0.042 & -0.024 & -0.056 & 0.020 & -0.017 & -0.035 \\
\hline
\end{tabular}


A. J. Korn et al.: The sensitivity of Lick indices to abundance variations, Online Material $p 6$

Table 14. Spectral index response: Cool giant (4255/1.90/0.00/0.00).

\begin{tabular}{|c|c|c|c|c|c|c|c|c|c|c|c|c|c|c|c|}
\hline (1) & (2) & (3) & (4) & (5) & (6) & (7) & (8) & (9) & (10) & (11) & (12) & (13) & (14) & (15) & (16) \\
\hline Index & $I_{0}$ & Error & $\mathrm{C}$ & $\mathrm{N}$ & $\mathrm{O}$ & $\mathrm{Mg}$ & $\mathrm{Fe}$ & $\mathrm{Ca}$ & $\mathrm{Na}$ & $\mathrm{Si}$ & $\mathrm{Cr}$ & $\mathrm{Ti}$ & {$[\mathrm{Z} / \mathrm{H}]$} & $\mathrm{C} 0.15$ & $\mathrm{C}+\mathrm{O} 0.3$ \\
\hline $\mathrm{CN}_{1}$ & 0.145 & 0.021 & 0.173 & 0.067 & -0.072 & -0.014 & -0.019 & -0.002 & 0.000 & 0.014 & -0.012 & 0.004 & 0.030 & 0.062 & 0.014 \\
\hline $\mathrm{CN}_{2}$ & 0.231 & 0.023 & 0.187 & 0.072 & -0.078 & -0.022 & -0.025 & -0.005 & -0.001 & 0.025 & -0.013 & 0.006 & 0.043 & 0.068 & 0.016 \\
\hline $\mathrm{Ca} 4227$ & 2.704 & .270 & -0.805 & -0.185 & 0.401 & 0.109 & 0.087 & 1.479 & 0.053 & -0.038 & -0.132 & -0.012 & 1.124 & -0.317 & -0.063 \\
\hline G4300 & 6.912 & 0.390 & 1.139 & 0.079 & -0.566 & 0.007 & -0.300 & 0.212 & 0.045 & 0.091 & -0.118 & 0.292 & -0.162 & 0.394 & -0.060 \\
\hline $\mathrm{Fe} 4383$ & 8.705 & 0.530 & 0.387 & -0.001 & -0.077 & -0.597 & 1.961 & -0.245 & -0.037 & -0.141 & -0.206 & 0.072 & 1.015 & 0.144 & 0.133 \\
\hline $\mathrm{Ca} 4455$ & 1.372 & 0.250 & -0.041 & 0.007 & 0.018 & 0.001 & -0.192 & -0.015 & 0.000 & 0.007 & 0.153 & 0.071 & 0.047 & -0.018 & -0.015 \\
\hline $\mathrm{Fe} 45$ & 6.333 & 0.420 & 0.009 & 0.010 & 0.005 & -0.204 & 0.290 & 0.010 & 0.025 & -0.031 & 0.102 & 0.638 & 0.929 & 0.000 & -0.003 \\
\hline$C_{2} 4668$ & 3.279 & 0.640 & 8.289 & 0.098 & -1.230 & -0.380 & 0.058 & 0.126 & -0.037 & -0.226 & -0.219 & 0.186 & 0.733 & 2.683 & 2.454 \\
\hline $\mathrm{H} \beta$ & 0.887 & 0.220 & 0.006 & 0.024 & 0.028 & -0.030 & 0.017 & 0.008 & 0.016 & 0.031 & -0.072 & 0.080 & 0.048 & -0.007 & -0.010 \\
\hline Fe5015 & 7.071 & 0.460 & -0.114 & 0.059 & 0.090 & -0.736 & 0.692 & 0.140 & 0.100 & 0.038 & 0.142 & 0.751 & 1.075 & -0.055 & -0.041 \\
\hline $\mathrm{Mg}_{1}$ & 0.246 & 0.007 & 0.107 & 0.000 & -0.019 & 0.041 & -0.020 & -0.005 & -0.004 & -0.007 & 0.000 & 0.001 & 0.050 & 0.035 & 0.029 \\
\hline $\mathrm{Mg}_{2}$ & 0.381 & 0.008 & 0.041 & -0.001 & -0.010 & 0.087 & -0.025 & -0.007 & -0.006 & -0.009 & -0.005 & 0.002 & 0.066 & 0.015 & 0.011 \\
\hline $\operatorname{Mg} b$ & 3.694 & 0.230 & -0.261 & -0.013 & 0.006 & 1.577 & -0.423 & -0.077 & -0.108 & -0.085 & -0.407 & 0.008 & 0.620 & -0.068 & -0.069 \\
\hline $\mathrm{Fe} 5270$ & 4.560 & 0.280 & 0.016 & 0.014 & 0.015 & -0.147 & 0.548 & 0.111 & -0.005 & -0.022 & -0.101 & 0.057 & 0.428 & 0.000 & 0.005 \\
\hline Fe5270(S & 3.537 & & 0.009 & 0.008 & 0.009 & -0.135 & 0.505 & 0.095 & -0.008 & -0.023 & -0.031 & 0.009 & 0.374 & 0.000 & 0.003 \\
\hline $\mathrm{Fe} 5335$ & 4.320 & 0.260 & -0.002 & -0.001 & -0.001 & -0.196 & 0.563 & -0.021 & -0.026 & -0.046 & 0.171 & 0.059 & 0.716 & -0.001 & 0.000 \\
\hline $\mathrm{Fe} 5406$ & 2.984 & 0.200 & -0.029 & 0.003 & 0.007 & -0.106 & 0.329 & -0.012 & -0.010 & -0.028 & 0.089 & 0.046 & 0.421 & -0.011 & -0.008 \\
\hline $\mathrm{Fe} 5709$ & 1.832 & 0.180 & 0.009 & 0.009 & 0.009 & 0.005 & 0.074 & 0.025 & -0.017 & 0.015 & 0.038 & 0.105 & 0.306 & 0.000 & 0.000 \\
\hline $\mathrm{Fe} 5782$ & 1.135 & 0.200 & 0.008 & 0.006 & 0.006 & 0.035 & -0.124 & -0.005 & 0.005 & 0.019 & 0.276 & -0.042 & 0.208 & 0.001 & 0.002 \\
\hline $\mathrm{Na} D$ & 3.247 & 0.240 & -0.005 & -0.008 & -0.005 & -0.105 & -0.022 & -0.054 & 1.282 & -0.058 & 0.014 & -0.063 & 1.068 & 0.000 & 0.010 \\
\hline $\mathrm{TiO}_{1}$ & 0.000 & 0.007 & 0.000 & 0.000 & 0.000 & 0.000 & 0.000 & -0.001 & 0.000 & 0.000 & 0.000 & 0.003 & 0.000 & 0.000 & 0.000 \\
\hline $\mathrm{TiO}_{2}$ & 0.019 & 0.006 & 0.000 & 0.000 & 0.000 & 0.000 & 0.001 & -0.001 & 0.000 & 0.000 & 0.000 & 0.002 & 0.000 & 0.000 & 0.000 \\
\hline $\mathrm{H} \gamma \mathrm{A}$ & -14.427 & 0.480 & -0.413 & -0.058 & 0.451 & 0.560 & -1.953 & -0.145 & -0.011 & -0.023 & -0.070 & -0.330 & -1.820 & -0.158 & 0.248 \\
\hline $\mathrm{H} \gamma \mathrm{F}$ & & 0.330 & & -0.005 & 0.269 & 0.171 & & & 0.015 & 0.001 & -0.071 & 0.012 & -0.534 & -0.116 & 0.101 \\
\hline $\mathrm{H} \delta \mathrm{A}$ & & 0.640 & & 0.395 & 0.344 & 0.372 & -2.568 & -0.110 & 0.053 & 0.571 & 0.063 & -0.344 & -1.533 & -0.089 & -0.021 \\
\hline $\mathrm{H} \delta \mathrm{F}$ & -5.224 & 0.400 & -0.180 & 0.042 & 0.219 & 0.341 & -0.975 & 0.024 & 0.069 & 0.146 & -0.017 & -0.279 & -1.252 & -0.112 & -0.032 \\
\hline
\end{tabular}

Table 15. Spectral index response: Cool dwarf (5297/4.56/0.00/0.00).

\begin{tabular}{|c|c|c|c|c|c|c|c|c|c|c|c|c|c|}
\hline (1) & (2) & (3) & (4) & (5) & (6) & (7) & (8) & (9) & (10) & (11) & (12) & (13) & (14) \\
\hline Index & $I_{0}$ & Error & C & $\mathrm{N}$ & $\mathrm{O}$ & $\mathrm{Mg}$ & $\mathrm{Fe}$ & $\mathrm{Ca}$ & $\mathrm{Na}$ & $\mathrm{Si}$ & $\mathrm{Cr}$ & $\mathrm{Ti}$ & {$[\mathrm{Z} / \mathrm{H}]$} \\
\hline $\mathrm{CN}_{1}$ & -0.015 & 0.021 & 0.069 & 0.054 & -0.024 & -0.009 & -0.009 & -0.002 & -0.001 & 0.002 & -0.005 & 0.003 & 0.034 \\
\hline $\mathrm{CN}_{2}$ & 0.012 & 0.023 & 0.072 & 0.058 & -0.025 & -0.011 & -0.010 & -0.003 & -0.001 & 0.006 & -0.006 & 0.004 & 0.040 \\
\hline $\mathrm{Ca} 4227$ & 0.864 & 0.270 & -0.498 & -0.269 & 0.189 & 0.045 & 0.061 & 0.583 & 0.004 & -0.013 & -0.102 & -0.006 & 0.125 \\
\hline G4300 & 5.206 & 0.390 & 0.779 & 0.000 & -0.525 & -0.221 & -0.460 & 0.128 & -0.035 & -0.090 & -0.099 & 0.122 & -0.074 \\
\hline Fe4383 & 5.973 & 0.530 & 0.438 & 0.000 & -0.101 & -0.450 & 1.260 & -0.222 & 0.002 & -0.171 & -0.063 & 0.134 & 0.710 \\
\hline $\mathrm{Ca} 4455$ & 0.669 & 0.250 & -0.035 & 0.000 & 0.008 & -0.027 & -0.017 & -0.037 & -0.009 & -0.008 & 0.047 & 0.035 & 0.131 \\
\hline $\mathrm{Fe} 4531$ & 3.001 & 0.420 & 0.015 & 0.000 & -0.004 & -0.133 & 0.171 & -0.018 & 0.008 & -0.045 & 0.113 & 0.316 & 0.470 \\
\hline $\mathrm{C}_{2} 4668$ & 1.984 & 0.640 & 3.881 & 0.000 & -0.525 & -0.032 & 0.059 & 0.025 & 0.246 & -0.179 & 0.239 & 0.119 & 0.841 \\
\hline $\mathrm{H} \beta$ & 1.797 & 0.220 & -0.009 & 0.000 & 0.004 & -0.061 & -0.009 & -0.014 & -0.005 & -0.019 & -0.046 & 0.047 & 0.178 \\
\hline Fe5015 & 3.866 & 0.460 & -0.101 & 0.000 & 0.015 & -0.396 & 0.370 & 0.049 & 0.019 & -0.052 & -0.012 & 0.352 & 0.638 \\
\hline $\mathrm{Mg}_{1}$ & 0.048 & 0.007 & 0.062 & 0.000 & -0.009 & 0.020 & -0.007 & -0.001 & -0.001 & -0.003 & 0.000 & 0.001 & 0.032 \\
\hline $\mathrm{Mg}_{2}$ & 0.215 & 0.008 & 0.031 & 0.000 & -0.005 & 0.067 & -0.016 & -0.002 & -0.001 & -0.007 & -0.002 & 0.001 & 0.047 \\
\hline $\operatorname{Mg} b$ & 4.655 & 0.230 & -0.097 & 0.001 & 0.015 & 1.502 & -0.373 & -0.029 & -0.051 & -0.123 & -0.209 & -0.018 & 0.692 \\
\hline Fe5270 & 2.807 & 0.280 & -0.001 & 0.000 & 0.003 & -0.130 & 0.439 & 0.139 & -0.010 & -0.052 & 0.020 & 0.051 & 0.460 \\
\hline Fe5270(Sauron) & 2.424 & & -0.001 & 0.000 & 0.003 & -0.118 & 0.386 & 0.129 & -0.009 & -0.048 & 0.033 & 0.017 & 0.377 \\
\hline $\mathrm{Fe} 5335$ & 2.504 & 0.260 & -0.004 & 0.000 & 0.003 & -0.132 & 0.487 & -0.007 & -0.011 & -0.055 & 0.092 & 0.018 & 0.446 \\
\hline $\mathrm{Fe} 5406$ & 1.374 & 0.200 & -0.023 & 0.000 & 0.004 & -0.058 & 0.282 & -0.006 & -0.005 & -0.031 & 0.064 & 0.009 & 0.249 \\
\hline $\mathrm{Fe} 5709$ & 0.836 & 0.180 & -0.001 & 0.000 & 0.000 & 0.017 & 0.092 & 0.004 & -0.038 & -0.005 & 0.015 & 0.022 & 0.178 \\
\hline $\mathrm{Fe} 5782$ & 0.367 & 0.200 & 0.002 & 0.000 & 0.000 & 0.031 & -0.069 & -0.013 & 0.000 & 0.007 & 0.150 & -0.015 & 0.108 \\
\hline $\mathrm{Na} D$ & 2.210 & 0.240 & -0.001 & 0.000 & 0.004 & -0.113 & -0.098 & -0.047 & 0.863 & -0.065 & 0.002 & -0.008 & 0.491 \\
\hline $\mathrm{TiO}_{1}$ & -0.001 & 0.007 & 0.000 & 0.000 & 0.000 & 0.000 & 0.000 & -0.001 & 0.000 & 0.000 & 0.000 & 0.001 & -0.001 \\
\hline $\mathrm{TiO}_{2}$ & 0.000 & 0.006 & 0.000 & 0.000 & 0.000 & 0.000 & 0.000 & -0.001 & 0.000 & 0.000 & 0.000 & 0.000 & 0.000 \\
\hline $\mathrm{H} \gamma \mathrm{A}$ & -7.829 & 0.480 & -0.712 & 0.000 & 0.525 & 0.653 & -0.800 & -0.095 & 0.019 & 0.187 & 0.032 & -0.213 & -0.620 \\
\hline $\mathrm{H} \gamma \mathrm{F}$ & -1.733 & 0.330 & -0.328 & 0.000 & 0.252 & 0.216 & -0.234 & -0.042 & 0.012 & 0.058 & 0.023 & -0.008 & -0.064 \\
\hline $\mathrm{H} \delta \mathrm{A}$ & -4.019 & 0.640 & -0.577 & -0.068 & 0.233 & 0.456 & -1.483 & 0.018 & 0.038 & 0.264 & 0.004 & -0.142 & -0.681 \\
\hline $\mathrm{H} \delta \mathrm{F}$ & -0.908 & 0.400 & -0.160 & -0.037 & 0.058 & 0.162 & -0.558 & 0.034 & 0.014 & 0.093 & -0.023 & -0.114 & -0.286 \\
\hline
\end{tabular}


A. J. Korn et al.: The sensitivity of Lick indices to abundance variations, Online Material $p 7$

Table 16. Spectral index response: Turnoff star (8048/3.91/0.00/0.00).

\begin{tabular}{|c|c|c|c|c|c|c|c|c|c|c|c|c|c|}
\hline (1) & (2) & (3) & (4) & (5) & (6) & (7) & (8) & (9) & (10) & (11) & (12) & (13) & (14) \\
\hline Index & $I_{0}$ & Error & $\mathrm{C}$ & $\mathrm{N}$ & $\mathrm{O}$ & $\mathrm{Mg}$ & $\mathrm{Fe}$ & $\mathrm{Ca}$ & $\mathrm{Na}$ & $\mathrm{Si}$ & $\mathrm{Cr}$ & $\mathrm{Ti}$ & {$[\mathrm{Z} / \mathrm{H}]$} \\
\hline $\mathrm{CN}_{1}$ & -0.299 & 0.021 & 0.000 & 0.000 & 0.000 & 0.000 & 0.002 & 0.000 & 0.000 & -0.001 & -0.001 & 0.002 & -0.001 \\
\hline $\mathrm{CN}_{2}$ & -0.257 & 0.023 & 0.000 & 0.000 & 0.000 & 0.000 & 0.003 & 0.000 & 0.000 & -0.001 & -0.001 & 0.002 & 0.000 \\
\hline $\mathrm{Ca} 4227$ & 0.151 & 0.270 & 0.018 & 0.002 & 0.000 & 0.000 & 0.005 & 0.017 & 0.000 & 0.000 & -0.025 & 0.009 & 0.037 \\
\hline G4300 & -2.942 & 0.390 & -0.008 & 0.000 & 0.001 & -0.007 & 0.020 & 0.055 & -0.002 & -0.009 & -0.038 & 0.133 & 0.092 \\
\hline $\mathrm{Fe} 4383$ & -2.126 & 0.530 & -0.026 & -0.001 & -0.039 & 0.028 & -0.011 & -0.031 & 0.006 & -0.004 & -0.021 & 0.116 & 0.001 \\
\hline $\mathrm{Ca} 4455$ & 0.089 & 0.250 & 0.000 & 0.000 & 0.000 & -0.015 & -0.026 & 0.006 & -0.001 & 0.000 & 0.010 & 0.009 & 0.051 \\
\hline $\mathrm{Fe} 4531$ & 0.923 & 0.420 & 0.001 & 0.000 & 0.000 & -0.011 & 0.105 & -0.009 & 0.001 & 0.002 & 0.063 & 0.168 & 0.327 \\
\hline $\mathrm{C}_{2} 4668$ & -0.307 & 0.640 & -0.019 & 0.000 & 0.000 & 0.016 & 0.085 & 0.035 & 0.007 & -0.033 & -0.094 & 0.023 & -0.003 \\
\hline $\mathrm{H} \beta$ & 8.504 & 0.220 & -0.005 & 0.000 & 0.001 & 0.003 & -0.059 & -0.001 & 0.000 & 0.028 & -0.004 & 0.018 & 0.109 \\
\hline $\mathrm{Fe} 5015$ & 1.193 & 0.460 & 0.014 & 0.000 & -0.030 & -0.006 & 0.236 & 0.054 & 0.014 & -0.045 & -0.014 & 0.151 & 0.471 \\
\hline $\mathrm{Mg}_{1}$ & -0.022 & 0.007 & 0.000 & 0.000 & 0.000 & 0.000 & 0.001 & 0.000 & 0.000 & 0.000 & -0.002 & 0.000 & 0.000 \\
\hline $\mathrm{Mg}_{2}$ & 0.006 & 0.008 & 0.000 & 0.000 & 0.000 & 0.002 & 0.002 & 0.000 & 0.000 & 0.000 & -0.002 & 0.001 & 0.003 \\
\hline $\operatorname{Mg} b$ & 0.315 & 0.230 & 0.000 & 0.000 & 0.000 & 0.072 & -0.050 & 0.000 & -0.004 & 0.000 & -0.031 & 0.009 & -0.021 \\
\hline $\mathrm{Fe} 5270$ & 0.630 & 0.280 & 0.008 & 0.000 & 0.000 & -0.002 & 0.095 & 0.068 & 0.000 & 0.002 & 0.001 & 0.041 & 0.196 \\
\hline Fe5270(Sauron) & 0.656 & & 0.006 & 0.000 & 0.000 & -0.002 & 0.077 & 0.063 & 0.000 & 0.002 & 0.004 & 0.027 & 0.170 \\
\hline Fe5335 & 0.359 & 0.260 & -0.025 & 0.000 & 0.014 & -0.001 & 0.073 & -0.015 & 0.000 & 0.001 & 0.006 & 0.015 & 0.076 \\
\hline $\mathrm{Fe} 5406$ & 0.137 & 0.200 & -0.023 & 0.000 & 0.000 & -0.001 & 0.076 & 0.000 & 0.000 & -0.001 & 0.017 & -0.015 & 0.048 \\
\hline $\mathrm{Fe} 5709$ & 0.113 & 0.180 & -0.005 & 0.000 & 0.000 & 0.018 & 0.049 & 0.001 & -0.017 & 0.004 & -0.001 & 0.001 & 0.059 \\
\hline $\mathrm{Fe} 5782$ & 0.041 & 0.200 & 0.013 & 0.000 & 0.000 & 0.010 & -0.020 & -0.002 & 0.000 & 0.001 & 0.033 & -0.001 & 0.031 \\
\hline $\mathrm{Na} \mathrm{D}$ & 0.223 & 0.240 & -0.002 & & 0.000 & 0.000 & -0.016 & -0.015 & 0.035 & -0.008 & 0.003 & 0.000 & 0.009 \\
\hline $\mathrm{TiO}_{1}$ & 0.001 & 0.007 & 0.000 & 0.000 & 0.000 & 0.000 & 0.000 & 0.000 & 0.000 & 0.001 & 0.000 & 0.000 & 0.000 \\
\hline $\mathrm{TiO}_{2}$ & -0.001 & 0.006 & 0.000 & 0.000 & 0.000 & 0.000 & 0.000 & 0.000 & 0.000 & 0.000 & 0.000 & 0.000 & 0.000 \\
\hline $\mathrm{H} \gamma \mathrm{A}$ & 13.220 & 0.480 & 0.020 & 0.001 & 0.005 & 0.010 & -0.082 & -0.026 & -0.001 & 0.039 & -0.010 & -0.092 & 0.066 \\
\hline $\mathrm{H} \gamma \mathrm{F}$ & 8.812 & 0.330 & 0.013 & 0.000 & -0.002 & 0.006 & -0.033 & -0.009 & 0.000 & 0.024 & -0.006 & -0.009 & 0.083 \\
\hline $\mathrm{H} \delta \mathrm{A}$ & 13.588 & 0.640 & -0.001 & 0.001 & 0.005 & -0.001 & -0.128 & -0.007 & 0.000 & 0.034 & -0.008 & -0.024 & 0.027 \\
\hline $\mathrm{H} \delta \mathrm{F}$ & 8.526 & 0.400 & 0.006 & 0.000 & 0.001 & 0.003 & -0.092 & 0.001 & 0.000 & 0.015 & -0.006 & -0.013 & 0.000 \\
\hline
\end{tabular}

Table 17. Spectral index response: Cool giant (4336/1.83/0.00/0.00).

\begin{tabular}{|c|c|c|c|c|c|c|c|c|c|c|c|c|c|}
\hline (1) & (2) & (3) & (4) & (5) & (6) & (7) & (8) & (9) & (10) & (11) & (12) & (13) & (14) \\
\hline Index & $I_{0}$ & Error & $\mathrm{C}$ & $\mathrm{N}$ & $\mathrm{O}$ & $\mathrm{Mg}$ & $\mathrm{Fe}$ & $\mathrm{Ca}$ & $\mathrm{Na}$ & $\mathrm{Si}$ & $\mathrm{Cr}$ & $\mathrm{Ti}$ & {$[\mathrm{Z} / \mathrm{H}]$} \\
\hline $\mathrm{CN}_{1}$ & 0.162 & 0.021 & 0.165 & 0.069 & -0.075 & -0.017 & -0.021 & -0.006 & -0.002 & 0.009 & -0.012 & 0.002 & 0.032 \\
\hline $\mathrm{CN}_{2}$ & 0.238 & 0.023 & 0.178 & 0.075 & -0.082 & -0.024 & -0.027 & -0.008 & -0.003 & 0.020 & -0.013 & 0.004 & 0.046 \\
\hline $\mathrm{Ca} 4227$ & 2.050 & 0.270 & -0.842 & -0.222 & 0.406 & 0.091 & 0.064 & 1.333 & 0.023 & -0.060 & -0.139 & -0.031 & 1.038 \\
\hline G4300 & 7.165 & 0.390 & 0.908 & 0.000 & -0.610 & -0.077 & -0.384 & 0.116 & -0.035 & 0.006 & -0.176 & 0.172 & -0.195 \\
\hline $\mathrm{Fe} 4383$ & 8.111 & 0.530 & 0.421 & 0.000 & -0.085 & -0.513 & 1.737 & -0.197 & -0.013 & -0.140 & -0.194 & 0.092 & 0.989 \\
\hline $\mathrm{Ca} 4455$ & 1.326 & 0.250 & -0.049 & 0.000 & 0.011 & -0.008 & -0.201 & -0.017 & -0.008 & -0.001 & 0.142 & 0.067 & 0.062 \\
\hline $\mathrm{Fe} 4531$ & 6.161 & 0.420 & -0.009 & 0.000 & -0.004 & -0.193 & 0.271 & 0.005 & 0.016 & -0.044 & 0.088 & 0.543 & 0.878 \\
\hline$C_{2} 4668$ & 3.937 & 0.640 & 8.827 & -0.001 & -1.440 & -0.480 & -0.095 & 0.014 & -0.138 & -0.366 & -0.288 & 0.091 & 1.043 \\
\hline $\mathrm{H} \beta$ & 1.021 & 0.220 & -0.018 & 0.000 & 0.003 & -0.064 & -0.014 & -0.014 & -0.007 & 0.008 & -0.095 & 0.068 & 0.059 \\
\hline $\mathrm{Fe} 5015$ & 7.417 & 0.460 & -0.266 & 0.000 & 0.047 & -0.702 & 0.614 & 0.070 & 0.032 & -0.029 & 0.073 & 0.571 & 1.036 \\
\hline $\mathrm{Mg}_{1}$ & 0.195 & 0.007 & 0.127 & 0.000 & -0.020 & 0.047 & -0.006 & -0.003 & -0.002 & -0.007 & 0.010 & 0.010 & 0.065 \\
\hline $\mathrm{Mg}_{2}$ & 0.321 & 0.008 & 0.044 & 0.000 & -0.011 & 0.081 & -0.021 & -0.004 & -0.003 & -0.008 & -0.004 & 0.003 & 0.067 \\
\hline $\operatorname{Mg} b$ & 3.051 & 0.230 & -0.349 & 0.001 & 0.038 & 1.565 & -0.378 & -0.044 & -0.080 & -0.070 & -0.348 & 0.017 & 0.647 \\
\hline $\mathrm{Fe} 5270$ & 4.427 & 0.280 & -0.001 & 0.000 & 0.001 & -0.148 & 0.500 & 0.098 & -0.015 & -0.041 & -0.112 & 0.038 & 0.436 \\
\hline Fe5270(Sauron) & 3.403 & & -0.001 & 0.000 & 0.001 & -0.130 & 0.465 & 0.086 & -0.013 & -0.036 & -0.039 & -0.001 & 0.379 \\
\hline $\mathrm{Fe} 5335$ & 4.130 & 0.260 & -0.003 & 0.000 & 0.001 & -0.169 & 0.527 & -0.012 & -0.018 & -0.045 & 0.153 & 0.058 & 0.716 \\
\hline $\mathrm{Fe} 5406$ & 2.818 & 0.200 & -0.040 & 0.000 & 0.005 & -0.095 & 0.306 & -0.011 & -0.009 & -0.035 & 0.074 & 0.045 & 0.422 \\
\hline $\mathrm{Fe} 5709$ & 1.779 & 0.180 & -0.001 & 0.000 & 0.000 & -0.002 & 0.064 & 0.014 & -0.025 & 0.006 & 0.030 & 0.092 & 0.308 \\
\hline $\mathrm{Fe} 5782$ & 1.080 & 0.200 & 0.002 & 0.000 & 0.000 & 0.030 & -0.132 & -0.011 & -0.001 & 0.013 & 0.269 & -0.049 & 0.216 \\
\hline $\mathrm{NaD}$ & 2.751 & 0.240 & 0.000 & 0.001 & 0.003 & -0.087 & -0.007 & -0.045 & 1.098 & -0.054 & 0.017 & -0.059 & 0.938 \\
\hline $\mathrm{TiO}_{1}$ & 0.000 & 0.007 & 0.000 & 0.000 & 0.000 & 0.000 & 0.000 & -0.001 & 0.000 & 0.000 & 0.000 & 0.003 & 0.000 \\
\hline $\mathrm{TiO}_{2}$ & 0.018 & 0.006 & 0.000 & 0.000 & 0.000 & 0.000 & 0.000 & -0.001 & 0.000 & 0.000 & 0.000 & 0.001 & 0.000 \\
\hline $\mathrm{H} \gamma \mathrm{A}$ & -13.729 & 0.480 & -0.240 & 0.000 & 0.482 & 0.508 & -1.645 & -0.082 & 0.023 & 0.036 & 0.020 & -0.243 & -1.669 \\
\hline $\mathrm{H} \gamma \mathrm{F}$ & -3.646 & 0.330 & -0.230 & 0.000 & 0.263 & 0.130 & -0.436 & -0.041 & 0.012 & 0.003 & -0.058 & 0.024 & -0.458 \\
\hline $\mathrm{H} \delta \mathrm{A}$ & -7.909 & 0.640 & 0.117 & 0.470 & 0.286 & 0.302 & -2.423 & -0.070 & 0.032 & 0.554 & 0.060 & -0.033 & -1.338 \\
\hline $\mathrm{H} \delta \mathrm{F}$ & -4.884 & 0.400 & -0.152 & 0.036 & 0.173 & 0.235 & -0.974 & 0.000 & 0.025 & 0.087 & -0.044 & -0.303 & -1.201 \\
\hline
\end{tabular}


A. J. Korn et al.: The sensitivity of Lick indices to abundance variations, Online Material $p 8$

Table 18. Spectral index response: Cool dwarf (4466/4.60/-0.35/0.00).

\begin{tabular}{|c|c|c|c|c|c|c|c|c|c|c|c|c|c|}
\hline (1) & (2) & (3) & (4) & (5) & (6) & (7) & (8) & (9) & (10) & (11) & (12) & (13) & (14) \\
\hline Index & $I_{0}$ & Error & $\mathrm{C}$ & $\mathrm{N}$ & $\mathrm{O}$ & $\mathrm{Mg}$ & $\mathrm{Fe}$ & $\mathrm{Ca}$ & $\mathrm{Na}$ & $\mathrm{Si}$ & $\mathrm{Cr}$ & $\mathrm{Ti}$ & {$[\mathrm{Z} / \mathrm{H}]$} \\
\hline$\overline{\mathrm{CN}_{1}}$ & -0.040 & 0.021 & 0.096 & 0.027 & -0.020 & -0.001 & -0.004 & -0.006 & 0.000 & 0.010 & -0.019 & 0.003 & 0.006 \\
\hline $\mathrm{CN}_{2}$ & 0.021 & 0.023 & 0.102 & 0.028 & -0.021 & -0.006 & -0.006 & -0.009 & -0.001 & 0.017 & -0.019 & 0.004 & 0.013 \\
\hline $\mathrm{Ca} 4227$ & 3.836 & 0.270 & -0.589 & -0.111 & 0.149 & -0.098 & -0.083 & 1.073 & -0.035 & -0.057 & -0.182 & -0.007 & 0.626 \\
\hline G4300 & 4.639 & 0.390 & 1.821 & 0.000 & -0.802 & -0.198 & -0.475 & 0.301 & -0.060 & -0.031 & -0.224 & 0.477 & 0.070 \\
\hline $\mathrm{Fe} 4383$ & 10.513 & 0.530 & 0.180 & 0.000 & 0.007 & -1.050 & 2.560 & -0.659 & -0.209 & -0.155 & -0.158 & 0.029 & 0.862 \\
\hline Ca4455 & 0.868 & 0.250 & -0.053 & 0.000 & 0.012 & -0.049 & -0.005 & -0.108 & -0.022 & -0.007 & 0.046 & -0.008 & 0.060 \\
\hline $\mathrm{Fe} 4531$ & 4.672 & 0.420 & 0.040 & 0.000 & -0.010 & -0.416 & 0.250 & -0.131 & -0.053 & -0.049 & 0.169 & 0.901 & 0.655 \\
\hline $\mathrm{C}_{2} 4668$ & 0.447 & 0.640 & 1.653 & 0.000 & -0.148 & -0.182 & 0.276 & 0.120 & -0.004 & -0.065 & -0.196 & 0.158 & 0.050 \\
\hline $\mathrm{H} \beta$ & 0.563 & 0.220 & -0.009 & 0.000 & 0.002 & -0.063 & 0.032 & -0.032 & -0.009 & -0.013 & -0.065 & 0.018 & 0.038 \\
\hline Fe5015 & 3.599 & 0.460 & -0.010 & 0.000 & -0.001 & -0.785 & 0.310 & 0.004 & -0.003 & -0.040 & -0.010 & 1.221 & 0.808 \\
\hline $\mathrm{Mg}_{1}$ & 0.230 & 0.007 & 0.022 & 0.000 & -0.002 & 0.032 & -0.019 & -0.006 & -0.005 & -0.002 & -0.003 & 0.000 & 0.016 \\
\hline $\mathrm{Mg}_{2}$ & 0.494 & 0.008 & 0.012 & 0.000 & -0.001 & 0.084 & -0.030 & -0.014 & -0.012 & -0.006 & -0.005 & 0.003 & 0.046 \\
\hline $\operatorname{Mg} b$ & 6.990 & 0.230 & -0.031 & 0.000 & 0.006 & 1.494 & -0.632 & -0.146 & -0.150 & -0.057 & -0.530 & -0.110 & 0.263 \\
\hline Fe5270 & 4.667 & 0.280 & 0.001 & 0.000 & 0.002 & -0.334 & 0.695 & 0.178 & -0.091 & -0.047 & 0.051 & 0.037 & 0.478 \\
\hline Fe5270(Sauron) & 4.019 & & 0.000 & 0.000 & 0.002 & -0.288 & 0.576 & 0.175 & -0.079 & -0.041 & 0.050 & 0.000 & 0.405 \\
\hline Fe5335 & 4.211 & 0.260 & 0.000 & 0.000 & 0.002 & -0.371 & 0.798 & -0.104 & -0.101 & -0.056 & 0.233 & 0.020 & 0.531 \\
\hline $\mathrm{Fe} 5406$ & 2.600 & 0.200 & -0.004 & 0.000 & 0.001 & -0.211 & 0.454 & -0.069 & -0.060 & -0.031 & 0.156 & 0.029 & 0.334 \\
\hline $\mathrm{Fe} 5709$ & 0.954 & 0.180 & 0.000 & 0.000 & 0.000 & -0.011 & 0.129 & -0.011 & -0.089 & -0.004 & 0.020 & 0.051 & 0.182 \\
\hline $\mathrm{Fe} 5782$ & 0.562 & 0.200 & 0.000 & 0.000 & 0.000 & -0.003 & -0.062 & -0.028 & -0.009 & 0.000 & 0.233 & -0.027 & 0.117 \\
\hline $\mathrm{NaD}$ & & 0.2 & & & & -0 . & & & & -0.051 & -0.008 & & 1.089 \\
\hline $\mathrm{TiO}_{1}$ & -0.002 & 0.007 & 0.000 & 0.000 & 0.000 & 0.000 & 0.000 & -0.001 & 0.000 & 0.000 & 0.000 & 0.002 & -0.001 \\
\hline $\mathrm{TiO}_{2}$ & 0.003 & 0.006 & 0.000 & 0.000 & 0.000 & 0.000 & 0.001 & -0.003 & 0.000 & 0.000 & 0.000 & 0.001 & 0.000 \\
\hline $\mathrm{H} \gamma \mathrm{A}$ & -13.875 & 0.480 & -1.386 & -0.001 & 0.711 & 1.396 & -2.188 & -0.083 & 0.276 & 0.151 & 0.156 & -0.582 & -1.290 \\
\hline $\mathrm{H} \gamma \mathrm{F}$ & -4.187 & 0.330 & -0.618 & 0.000 & 0.325 & 0.378 & -0.680 & -0.067 & 0.079 & 0.035 & 0.228 & -0.096 & -0.249 \\
\hline $\mathrm{H} \delta \mathrm{A}$ & -9.800 & 0.640 & -1.123 & -0.089 & 0.337 & 1.088 & -3.209 & 0.331 & 0.265 & 0.472 & 0.054 & -0.208 & -0.983 \\
\hline $\mathrm{H} \delta \mathrm{F}$ & -4.325 & 0.400 & -0.294 & -0.034 & 0.073 & 0.460 & -1.053 & 0.200 & 0.116 & 0.121 & -0.009 & -0.201 & -0.489 \\
\hline
\end{tabular}

Table 19. Spectral index response: Turnoff star (5822/4.22/-0.35/0.00).

\begin{tabular}{|c|c|c|c|c|c|c|c|c|c|c|c|c|c|}
\hline (1) & (2) & (3) & (4) & (5) & (6) & (7) & (8) & (9) & (10) & (11) & (12) & (13) & (14) \\
\hline Index & $I_{0}$ & Error & $\mathrm{C}$ & $\mathrm{N}$ & $\mathrm{O}$ & $\mathrm{Mg}$ & $\mathrm{Fe}$ & $\mathrm{Ca}$ & $\mathrm{Na}$ & $\mathrm{Si}$ & $\mathrm{Cr}$ & $\mathrm{Ti}$ & {$[\mathrm{Z} / \mathrm{H}]$} \\
\hline $\mathrm{CN}_{1}$ & -0.078 & 0.021 & 0.004 & 0.013 & 0.000 & -0.001 & -0.003 & -0.002 & 0.000 & 0.000 & -0.002 & 0.001 & 0.002 \\
\hline $\mathrm{CN}_{2}$ & -0.054 & 0.023 & 0.003 & 0.014 & 0.000 & -0.001 & -0.003 & -0.002 & 0.000 & 0.000 & -0.002 & 0.002 & 0.003 \\
\hline $\mathrm{Ca} 4227$ & 0.449 & 0.270 & -0.129 & -0.074 & 0.011 & 0.014 & 0.050 & 0.201 & 0.001 & 0.007 & -0.054 & 0.004 & 0.045 \\
\hline G4300 & 4.399 & 0.390 & 0.937 & 0.000 & -0.110 & -0.250 & -0.356 & 0.059 & -0.021 & -0.179 & -0.052 & 0.089 & 0.277 \\
\hline $\mathrm{Fe} 4383$ & 2.943 & 0.530 & 0.362 & 0.000 & -0.024 & -0.131 & 0.529 & -0.088 & 0.009 & -0.076 & -0.021 & 0.129 & 0.560 \\
\hline $\mathrm{Ca} 4455$ & 0.343 & 0.250 & -0.014 & 0.000 & 0.001 & -0.010 & -0.031 & -0.012 & -0.004 & 0.001 & 0.028 & 0.016 & 0.106 \\
\hline $\mathrm{Fe} 4531$ & 2.071 & 0.420 & 0.010 & 0.000 & -0.001 & -0.028 & 0.101 & 0.000 & 0.004 & -0.007 & 0.108 & 0.207 & 0.435 \\
\hline $\mathrm{C}_{2} 4668$ & 0.609 & 0.640 & 1.012 & 0.000 & -0.050 & 0.223 & 0.150 & 0.023 & 0.004 & -0.096 & -0.071 & 0.097 & 0.578 \\
\hline $\mathrm{H} \beta$ & 2.619 & 0.220 & -0.007 & 0.000 & 0.001 & -0.005 & -0.060 & -0.004 & -0.001 & -0.004 & -0.018 & 0.050 & 0.188 \\
\hline $\mathrm{Fe} 5015$ & 2.940 & 0.460 & -0.019 & 0.000 & -0.001 & -0.034 & 0.222 & 0.040 & 0.020 & -0.009 & -0.033 & 0.240 & 0.629 \\
\hline $\mathrm{Mg}_{1}$ & 0.000 & 0.007 & 0.017 & 0.000 & -0.001 & 0.002 & -0.005 & 0.000 & 0.000 & 0.000 & -0.001 & 0.000 & 0.007 \\
\hline $\mathrm{Mg}_{2}$ & 0.076 & 0.008 & 0.010 & 0.000 & 0.000 & 0.025 & -0.003 & 0.000 & 0.000 & -0.002 & -0.001 & 0.001 & 0.021 \\
\hline $\operatorname{Mg} b$ & 1.818 & 0.230 & -0.048 & 0.000 & 0.004 & 0.814 & -0.094 & -0.004 & -0.017 & -0.044 & -0.074 & -0.013 & 0.370 \\
\hline $\mathrm{Fe} 5270$ & 1.390 & 0.280 & 0.000 & 0.000 & 0.000 & -0.011 & 0.240 & 0.085 & -0.001 & -0.008 & 0.023 & 0.055 & 0.364 \\
\hline Fe5270(Sauron) & 1.241 & & 0.000 & 0.000 & 0.000 & -0.015 & 0.199 & 0.079 & -0.001 & -0.011 & 0.027 & 0.030 & 0.282 \\
\hline $\mathrm{Fe} 5335$ & 1.206 & 0.260 & -0.004 & 0.000 & 0.001 & -0.015 & 0.256 & 0.004 & -0.001 & -0.010 & 0.036 & 0.016 & 0.291 \\
\hline $\mathrm{Fe} 5406$ & 0.633 & 0.200 & -0.016 & 0.000 & 0.001 & 0.002 & 0.160 & 0.000 & 0.000 & -0.002 & 0.029 & 0.002 & 0.165 \\
\hline $\mathrm{Fe} 5709$ & 0.475 & 0.180 & -0.001 & 0.000 & 0.000 & 0.027 & 0.089 & 0.003 & -0.021 & 0.007 & 0.006 & 0.005 & 0.152 \\
\hline $\mathrm{Fe} 5782$ & 0.160 & 0.200 & 0.003 & 0.000 & 0.000 & 0.026 & -0.036 & -0.005 & 0.000 & 0.010 & 0.099 & -0.007 & 0.084 \\
\hline $\mathrm{Na} D$ & 0.781 & 0.240 & -0.001 & 0.000 & 0.001 & -0.023 & -0.028 & -0.027 & 0.327 & -0.029 & 0.002 & -0.007 & 0.185 \\
\hline $\mathrm{TiO}_{1}$ & 0.001 & 0.007 & 0.000 & 0.000 & 0.000 & 0.000 & 0.000 & 0.000 & 0.000 & 0.000 & 0.000 & 0.001 & 0.000 \\
\hline $\mathrm{TiO}_{2}$ & -0.001 & 0.006 & 0.000 & 0.000 & 0.000 & 0.000 & 0.000 & 0.000 & 0.000 & 0.000 & 0.000 & 0.000 & 0.000 \\
\hline $\mathrm{H} \gamma \mathrm{A}$ & -3.160 & 0.480 & -1.045 & 0.000 & 0.112 & 0.392 & -0.133 & -0.037 & 0.012 & 0.225 & 0.003 & -0.167 & -0.522 \\
\hline $\mathrm{H} \gamma \mathrm{F}$ & 0.406 & 0.330 & -0.507 & 0.000 & 0.052 & 0.176 & -0.005 & -0.013 & 0.009 & 0.107 & 0.005 & -0.009 & -0.051 \\
\hline $\mathrm{H} \delta \mathrm{A}$ & 0.785 & 0.640 & -0.239 & -0.032 & 0.022 & 0.154 & -0.462 & 0.019 & 0.010 & 0.119 & -0.001 & -0.072 & -0.159 \\
\hline $\mathrm{H} \delta \mathrm{F}$ & 1.413 & 0.400 & -0.069 & -0.007 & 0.006 & 0.069 & -0.195 & 0.032 & 0.004 & 0.056 & -0.016 & -0.055 & -0.041 \\
\hline
\end{tabular}


A. J. Korn et al.: The sensitivity of Lick indices to abundance variations, Online Material $p 9$

Table 20. Spectral index response: Cool giant (4414/1.77/-0.35/0.00).

\begin{tabular}{|c|c|c|c|c|c|c|c|c|c|c|c|c|c|}
\hline (1) & (2) & (3) & (4) & (5) & (6) & (7) & (8) & (9) & (10) & (11) & (12) & (13) & (14) \\
\hline Index & $I_{0}$ & Error & C & $\mathrm{N}$ & $\mathrm{O}$ & $\mathrm{Mg}$ & $\mathrm{Fe}$ & $\mathrm{Ca}$ & $\mathrm{Na}$ & $\mathrm{Si}$ & $\mathrm{Cr}$ & $\mathrm{Ti}$ & {$[\mathrm{Z} / \mathrm{H}]$} \\
\hline $\mathrm{CN}_{1}$ & 0.117 & 0.021 & 0.145 & 0.078 & -0.063 & -0.019 & -0.022 & -0.011 & -0.002 & 0.004 & -0.008 & 0.004 & 0.046 \\
\hline $\mathrm{CN}_{2}$ & 0.169 & 0.023 & 0.158 & 0.085 & -0.068 & -0.025 & -0.027 & -0.014 & -0.002 & 0.014 & -0.008 & 0.005 & 0.058 \\
\hline Ca4227 & 0.698 & 0.270 & -0.902 & -0.322 & 0.423 & 0.129 & 0.099 & 0.859 & 0.013 & -0.032 & -0.120 & -0.025 & 0.556 \\
\hline G4300 & 7.545 & 0.390 & 0.707 & 0.000 & -0.570 & -0.086 & -0.368 & 0.079 & -0.029 & -0.005 & -0.124 & 0.104 & -0.144 \\
\hline Fe4383 & 6.857 & 0.530 & 0.523 & 0.000 & -0.117 & -0.405 & 1.173 & -0.129 & 0.006 & -0.141 & -0.115 & 0.147 & 0.855 \\
\hline Ca4455 & 1.129 & 0.250 & -0.055 & 0.000 & 0.013 & -0.008 & -0.159 & -0.009 & -0.009 & -0.001 & 0.107 & 0.054 & 0.126 \\
\hline $\mathrm{Fe} 4531$ & 5.094 & 0.420 & 0.011 & 0.000 & -0.007 & -0.131 & 0.153 & 0.010 & 0.011 & -0.039 & 0.107 & 0.355 & 0.663 \\
\hline$C_{2} 4668$ & 3.092 & 0.640 & 6.699 & 0.000 & -0.905 & -0.294 & 0.028 & 0.010 & -0.082 & -0.273 & -0.135 & 0.149 & 1.061 \\
\hline $\mathrm{H} \beta$ & 1.047 & 0.220 & -0.010 & 0.000 & 0.001 & -0.053 & -0.021 & -0.009 & -0.004 & -0.005 & -0.073 & 0.064 & 0.094 \\
\hline Fe5015 & 6.476 & 0.460 & -0.236 & 0.000 & 0.042 & -0.470 & 0.511 & 0.044 & 0.024 & -0.029 & 0.030 & 0.360 & 0.891 \\
\hline $\mathrm{Mg}_{1}$ & 0.118 & 0.007 & 0.099 & 0.000 & -0.015 & 0.026 & -0.013 & -0.002 & -0.001 & -0.005 & 0.000 & 0.000 & 0.043 \\
\hline $\mathrm{Mg}_{2}$ & 0.209 & 0.008 & 0.043 & 0.000 & -0.009 & 0.061 & -0.014 & -0.002 & -0.001 & -0.006 & -0.002 & 0.002 & 0.053 \\
\hline $\operatorname{Mg} b$ & 2.038 & 0.230 & -0.326 & 0.000 & 0.027 & 1.262 & -0.248 & -0.022 & -0.059 & -0.061 & -0.228 & -0.019 & 0.477 \\
\hline Fe5270 & 3.677 & 0.280 & -0.001 & 0.000 & 0.000 & -0.110 & 0.422 & 0.094 & -0.009 & -0.040 & -0.058 & 0.049 & 0.494 \\
\hline Fe5270(Sauron) & 2.773 & & 0.000 & 0.000 & 0.001 & -0.093 & 0.377 & 0.086 & -0.008 & -0.033 & -0.006 & 0.012 & 0.403 \\
\hline Fe5335 & 3.200 & 0.260 & -0.002 & 0.000 & 0.001 & -0.110 & 0.423 & -0.001 & -0.009 & -0.038 & 0.096 & 0.038 & 0.585 \\
\hline Fe5406 & 2.139 & 0.200 & -0.032 & 0.000 & 0.004 & -0.060 & 0.277 & -0.006 & -0.005 & -0.028 & 0.058 & 0.046 & 0.399 \\
\hline Fe5709 & 1.400 & 0.180 & 0.000 & 0.000 & 0.000 & 0.002 & 0.063 & 0.005 & -0.024 & 0.005 & 0.033 & 0.059 & 0.248 \\
\hline $\mathrm{Fe} 5782$ & 0.757 & 0.200 & 0.001 & 0.000 & 0.000 & 0.033 & -0.108 & -0.009 & 0.000 & 0.012 & 0.247 & -0.040 & 0.204 \\
\hline $\mathrm{NaD}$ & & & & & & -0.0 & & & 0.665 & & & -0 & 0.546 \\
\hline $\mathrm{TiO}_{1}$ & -0.001 & 0.007 & 0.000 & 0.000 & 0.000 & 0.000 & 0.000 & 0.000 & 0.000 & 0.000 & 0.000 & 0.002 & 0.000 \\
\hline $\mathrm{TiO}_{2}$ & 0.015 & 0.006 & 0.000 & 0.000 & 0.000 & 0.000 & 0.000 & -0.001 & 0.000 & 0.000 & 0.000 & 0.001 & 0.002 \\
\hline $\mathrm{H} \gamma \mathrm{A}$ & -11.941 & 0.480 & -0.425 & 0.000 & 0.468 & 0.343 & -1.060 & -0.047 & 0.001 & 0.034 & 0.095 & -0.213 & -1.195 \\
\hline $\mathrm{H} \gamma \mathrm{F}$ & -3.307 & 0.330 & -0.157 & 0.000 & 0.258 & 0.099 & -0.326 & -0.027 & 0.007 & 0.005 & -0.001 & 0.025 & -0.281 \\
\hline $\mathrm{H} \delta \mathrm{A}$ & -6.145 & 0.640 & -0.208 & 0.247 & 0.410 & 0.340 & -1.426 & 0.205 & 0.029 & 0.487 & 0.050 & -0.296 & -1.092 \\
\hline $\mathrm{H} \delta \mathrm{F}$ & -3.404 & 0.400 & -0.225 & -0.028 & 0.153 & 0.202 & -0.518 & 0.176 & 0.017 & 0.131 & -0.035 & -0.269 & -0.866 \\
\hline
\end{tabular}

Table 21. Spectral index response: Cool dwarf (4385/4.83/-1.35/0.00).

\begin{tabular}{|c|c|c|c|c|c|c|c|c|c|c|c|c|c|}
\hline (1) & (2) & (3) & (4) & (5) & (6) & (7) & (8) & (9) & (10) & (11) & (12) & (13) & (14) \\
\hline Index & $I_{0}$ & Error & $\mathrm{C}$ & $\mathrm{N}$ & $\mathrm{O}$ & $\mathrm{Mg}$ & $\mathrm{Fe}$ & $\mathrm{Ca}$ & $\mathrm{Na}$ & $\mathrm{Si}$ & $\mathrm{Cr}$ & $\mathrm{Ti}$ & {$[\mathrm{Z} / \mathrm{H}]$} \\
\hline $\mathrm{CN}_{1}$ & -0.035 & 0.021 & 0.015 & 0.006 & 0.000 & -0.002 & -0.002 & -0.004 & -0.001 & 0.014 & -0.013 & 0.001 & -0.009 \\
\hline $\mathrm{CN}_{2}$ & 0.006 & 0.023 & 0.014 & 0.007 & 0.001 & -0.004 & -0.003 & -0.005 & -0.001 & 0.023 & -0.013 & 0.002 & 0.000 \\
\hline $\mathrm{Ca} 4227$ & 2.230 & 0.270 & -0.281 & -0.036 & 0.067 & 0.031 & -0.039 & 0.905 & 0.017 & -0.069 & -0.112 & -0.003 & 0.704 \\
\hline G4300 & 3.900 & 0.390 & 2.188 & 0.000 & -0.971 & -0.069 & -0.374 & 0.189 & 0.002 & -0.022 & -0.182 & 0.316 & 0.100 \\
\hline $\mathrm{Fe} 4383$ & 7.041 & 0.530 & 0.218 & 0.000 & -0.005 & -0.453 & 1.979 & -0.313 & -0.049 & -0.099 & -0.044 & 0.054 & 1.349 \\
\hline $\mathrm{Ca} 4455$ & 0.436 & 0.250 & -0.041 & 0.000 & 0.010 & -0.020 & 0.030 & -0.058 & -0.005 & -0.004 & 0.019 & 0.008 & 0.131 \\
\hline $\mathrm{Fe} 4531$ & 2.748 & 0.420 & 0.051 & 0.000 & -0.011 & -0.179 & 0.252 & -0.028 & -0.004 & -0.027 & 0.154 & 0.532 & 0.702 \\
\hline$C_{2} 4668$ & -0.031 & 0.640 & 0.219 & 0.000 & -0.010 & -0.124 & 0.216 & 0.057 & 0.025 & -0.005 & -0.080 & 0.124 & 0.044 \\
\hline $\mathrm{H} \beta$ & 0.312 & 0.220 & -0.001 & 0.000 & 0.001 & -0.007 & -0.014 & -0.008 & 0.002 & -0.007 & -0.027 & 0.021 & 0.033 \\
\hline $\mathrm{Fe} 5015$ & 1.528 & 0.460 & -0.005 & 0.000 & 0.000 & -0.610 & 0.311 & 0.037 & 0.044 & -0.006 & -0.035 & 0.706 & 0.572 \\
\hline $\mathrm{Mg}_{1}$ & 0.161 & 0.007 & 0.002 & 0.000 & 0.000 & 0.040 & -0.008 & -0.002 & -0.002 & -0.003 & 0.000 & 0.001 & 0.035 \\
\hline $\mathrm{Mg}_{2}$ & 0.344 & 0.008 & 0.001 & 0.000 & 0.000 & 0.084 & -0.017 & -0.003 & -0.003 & -0.004 & -0.002 & 0.002 & 0.064 \\
\hline $\operatorname{Mg} b$ & 5.141 & 0.230 & 0.010 & 0.000 & -0.001 & 1.346 & -0.313 & -0.038 & -0.038 & -0.052 & -0.327 & -0.031 & 0.724 \\
\hline $\mathrm{Fe} 5270$ & 3.063 & 0.280 & 0.000 & 0.000 & 0.000 & -0.145 & 0.554 & 0.154 & -0.017 & -0.032 & 0.082 & 0.036 & 0.633 \\
\hline Fe5270(Sauron) & 2.657 & & 0.000 & 0.000 & 0.000 & -0.126 & 0.481 & 0.148 & -0.016 & -0.028 & 0.060 & 0.009 & 0.531 \\
\hline $\mathrm{Fe} 5335$ & 2.697 & 0.260 & 0.000 & 0.000 & 0.000 & -0.164 & 0.622 & -0.017 & -0.023 & -0.035 & 0.141 & 0.013 & 0.550 \\
\hline $\mathrm{Fe} 5406$ & 1.601 & 0.200 & -0.001 & 0.000 & 0.000 & -0.094 & 0.371 & -0.016 & -0.013 & -0.020 & 0.098 & 0.013 & 0.355 \\
\hline Fe5709 & 0.394 & 0.180 & 0.000 & 0.000 & 0.000 & 0.016 & 0.103 & -0.003 & -0.050 & -0.003 & 0.007 & 0.013 & 0.143 \\
\hline Fe5782 & 0.187 & 0.200 & 0.000 & 0.000 & 0.000 & 0.000 & -0.015 & -0.002 & 0.000 & -0.001 & 0.130 & -0.011 & 0.108 \\
\hline $\mathrm{Na} D$ & 3.802 & 0.240 & 0.000 & 0.000 & 0.000 & -0.065 & -0.100 & -0.032 & 1.330 & -0.032 & 0.001 & -0.015 & 1.115 \\
\hline $\mathrm{TiO}_{1}$ & -0.001 & 0.007 & 0.000 & 0.000 & 0.000 & 0.000 & 0.000 & -0.001 & 0.000 & 0.000 & 0.000 & 0.001 & 0.000 \\
\hline $\mathrm{TiO}_{2}$ & 0.002 & 0.006 & 0.000 & 0.000 & 0.000 & 0.000 & 0.001 & -0.002 & 0.000 & 0.000 & 0.000 & 0.000 & 0.001 \\
\hline $\mathrm{H} \gamma \mathrm{A}$ & -9.406 & 0.480 & & 0.000 & 0.870 & 0.535 & -1.385 & -0.164 & 0.036 & 0.089 & 0.044 & -0.397 & -1.582 \\
\hline $\mathrm{H} \gamma \mathrm{F}$ & -3.293 & 0.330 & -0.865 & 0.000 & 0.413 & 0.195 & -0.482 & -0.063 & 0.017 & 0.029 & 0.149 & -0.071 & -0.337 \\
\hline $\mathrm{H} \delta \mathrm{A}$ & -6.547 & 0.640 & -0.852 & -0.027 & 0.238 & 0.446 & -2.228 & 0.092 & 0.060 & 0.383 & 0.008 & -0.088 & -1.207 \\
\hline $\mathrm{H} \delta \mathrm{F}$ & -2.870 & 0.400 & -0.184 & -0.005 & 0.050 & 0.207 & -0.802 & 0.087 & 0.029 & 0.084 & -0.011 & -0.087 & -0.583 \\
\hline
\end{tabular}


A. J. Korn et al.: The sensitivity of Lick indices to abundance variations, Online Material p 10

Table 22. Spectral index response: Turnoff star (6383/4.16/-1.35/0.00).

\begin{tabular}{|c|c|c|c|c|c|c|c|c|c|c|c|c|c|}
\hline (1) & (2) & (3) & (4) & (5) & (6) & (7) & (8) & (9) & (10) & (11) & (12) & (13) & (14) \\
\hline Index & $I_{0}$ & Error & $\mathrm{C}$ & $\mathrm{N}$ & $\mathrm{O}$ & $\mathrm{Mg}$ & $\mathrm{Fe}$ & $\mathrm{Ca}$ & $\mathrm{Na}$ & $\mathrm{Si}$ & $\mathrm{Cr}$ & $\mathrm{Ti}$ & {$[\mathrm{Z} / \mathrm{H}]$} \\
\hline $\mathrm{CN}_{1}$ & -0.091 & 0.021 & -0.001 & 0.000 & 0.000 & 0.000 & 0.001 & 0.000 & 0.000 & 0.000 & -0.001 & 0.001 & -0.002 \\
\hline $\mathrm{CN}_{2}$ & -0.066 & 0.023 & -0.002 & 0.000 & 0.000 & 0.000 & 0.002 & 0.000 & 0.000 & 0.000 & 0.000 & 0.001 & -0.001 \\
\hline $\mathrm{Ca} 4227$ & 0.128 & 0.270 & -0.001 & 0.000 & 0.000 & 0.000 & 0.007 & 0.038 & 0.000 & 0.000 & -0.008 & 0.004 & 0.037 \\
\hline G4300 & -0.259 & 0.390 & 0.296 & 0.000 & 0.000 & -0.008 & 0.023 & 0.052 & -0.001 & -0.003 & -0.015 & 0.111 & 0.388 \\
\hline $\mathrm{Fe} 4383$ & 0.323 & 0.530 & 0.027 & 0.000 & -0.001 & -0.004 & 0.129 & -0.029 & 0.001 & 0.000 & -0.010 & 0.078 & 0.211 \\
\hline Ca4455 & 0.105 & 0.250 & -0.001 & 0.000 & 0.000 & -0.009 & -0.019 & -0.003 & 0.000 & 0.000 & 0.001 & 0.010 & 0.021 \\
\hline $\mathrm{Fe} 4531$ & 0.498 & 0.420 & 0.001 & 0.000 & 0.000 & -0.011 & 0.085 & -0.015 & 0.000 & 0.000 & 0.039 & 0.122 & 0.231 \\
\hline $\mathrm{C}_{2} 4668$ & 0.021 & 0.640 & 0.001 & 0.000 & 0.000 & 0.096 & 0.038 & 0.044 & 0.039 & -0.009 & -0.031 & 0.008 & -0.005 \\
\hline $\mathrm{H} \beta$ & 3.692 & 0.220 & -0.001 & 0.000 & 0.000 & 0.003 & -0.032 & -0.003 & 0.000 & 0.002 & 0.003 & 0.007 & 0.065 \\
\hline $\mathrm{Fe} 5015$ & 0.774 & 0.460 & 0.001 & 0.000 & -0.001 & -0.001 & 0.149 & 0.013 & -0.015 & 0.002 & -0.004 & 0.087 & 0.357 \\
\hline $\mathrm{Mg}_{1}$ & -0.004 & 0.007 & 0.000 & 0.000 & 0.000 & 0.000 & 0.000 & 0.000 & 0.000 & 0.000 & -0.001 & 0.000 & 0.001 \\
\hline $\mathrm{Mg}_{2}$ & 0.018 & 0.008 & 0.000 & 0.000 & 0.000 & 0.004 & 0.001 & 0.000 & 0.000 & 0.000 & -0.001 & 0.001 & 0.005 \\
\hline $\operatorname{Mg} b$ & 0.463 & 0.230 & 0.000 & 0.000 & 0.000 & 0.165 & -0.063 & 0.000 & -0.001 & 0.000 & -0.021 & 0.011 & 0.074 \\
\hline $\mathrm{Fe} 5270$ & 0.403 & 0.280 & 0.000 & 0.000 & 0.000 & 0.000 & 0.058 & 0.061 & 0.000 & 0.000 & 0.001 & 0.012 & 0.122 \\
\hline Fe5270(Sauron) & 0.414 & & 0.000 & 0.000 & 0.000 & 0.000 & 0.050 & 0.059 & 0.000 & 0.000 & 0.005 & 0.007 & 0.116 \\
\hline $\mathrm{Fe} 5335$ & 0.352 & 0.260 & -0.001 & 0.000 & 0.000 & 0.000 & 0.052 & 0.001 & 0.000 & 0.000 & 0.019 & 0.013 & 0.087 \\
\hline Fe5406 & 0.194 & 0.200 & -0.003 & 0.000 & 0.000 & 0.000 & 0.052 & 0.000 & 0.000 & 0.000 & 0.014 & -0.012 & 0.050 \\
\hline Fe 5709 & 0.073 & 0.180 & 0.000 & 0.000 & 0.000 & 0.012 & 0.034 & 0.000 & -0.010 & 0.002 & 0.000 & 0.000 & 0.045 \\
\hline Fe5782 & 0.011 & 0.200 & 0.001 & 0.000 & 0.000 & 0.002 & -0.007 & 0.000 & 0.000 & 0.000 & 0.014 & 0.000 & 0.011 \\
\hline $\mathrm{Na} D$ & 0.247 & 0.240 & 0.000 & 0.000 & 0.000 & 0.000 & -0.015 & -0.008 & 0.055 & -0.003 & 0.000 & -0.001 & 0.033 \\
\hline $\mathrm{TiO}_{1}$ & 0.000 & 0.007 & 0.000 & 0.000 & 0.000 & 0.000 & 0.000 & 0.000 & 0.000 & 0.000 & 0.000 & 0.000 & 0.000 \\
\hline $\mathrm{TiO}_{2}$ & -0.001 & 0.006 & 0.000 & 0.000 & 0.000 & 0.000 & 0.000 & 0.000 & 0.000 & 0.000 & 0.000 & 0.000 & 0.000 \\
\hline $\mathrm{H} \gamma \mathrm{A}$ & 3.669 & 0.480 & -0.236 & 0.000 & 0.000 & 0.032 & -0.114 & -0.036 & 0.000 & 0.006 & 0.018 & -0.088 & -0.305 \\
\hline $\mathrm{H} \gamma \mathrm{F}$ & 3.440 & 0.330 & -0.099 & 0.000 & 0.000 & 0.015 & -0.034 & -0.013 & 0.000 & 0.004 & 0.013 & -0.010 & -0.052 \\
\hline $\mathrm{H} \delta \mathrm{A}$ & 4.226 & 0.640 & -0.016 & 0.000 & 0.000 & 0.007 & -0.147 & 0.000 & 0.000 & 0.012 & 0.006 & -0.018 & -0.048 \\
\hline $\mathrm{H} \delta \mathrm{F}$ & 3.464 & 0.400 & -0.004 & 0.000 & 0.000 & 0.005 & -0.084 & 0.002 & 0.000 & 0.010 & 0.002 & -0.010 & -0.038 \\
\hline
\end{tabular}

Table 23. Spectral index response: Cool giant (4662/1.83/-1.35/0.00).

\begin{tabular}{|c|c|c|c|c|c|c|c|c|c|c|c|c|c|}
\hline (1) & (2) & (3) & (4) & (5) & (6) & (7) & (8) & (9) & (10) & (11) & (12) & (13) & (14) \\
\hline Index & $I_{0}$ & Error & C & $\mathrm{N}$ & $\mathrm{O}$ & $\mathrm{Mg}$ & $\mathrm{Fe}$ & $\mathrm{Ca}$ & $\mathrm{Na}$ & $\mathrm{Si}$ & $\mathrm{Cr}$ & $\mathrm{Ti}$ & {$[\mathrm{Z} / \mathrm{H}]$} \\
\hline $\mathrm{CN}_{1}$ & -0.021 & 0.021 & 0.025 & 0.030 & -0.005 & 0.000 & -0.007 & -0.002 & 0.000 & 0.002 & -0.002 & 0.001 & 0.021 \\
\hline $\mathrm{CN}_{2}$ & -0.004 & 0.023 & 0.025 & 0.032 & -0.005 & 0.000 & -0.008 & -0.002 & 0.000 & 0.006 & -0.002 & 0.002 & 0.025 \\
\hline Ca4227 & 0.149 & 0.270 & -0.364 & -0.200 & 0.103 & 0.000 & 0.064 & 0.196 & 0.004 & 0.019 & -0.041 & 0.004 & -0.015 \\
\hline G4300 & 7.853 & 0.390 & 0.401 & 0.000 & -0.333 & -0.008 & -0.243 & 0.043 & -0.010 & -0.073 & -0.044 & 0.071 & 0.118 \\
\hline Fe4383 & 3.683 & 0.530 & 0.628 & 0.000 & -0.123 & -0.004 & 0.316 & -0.061 & -0.005 & -0.110 & -0.005 & 0.165 & 0.650 \\
\hline $\mathrm{Ca} 4455$ & 0.475 & 0.250 & -0.036 & 0.000 & 0.007 & -0.009 & -0.046 & -0.003 & -0.002 & 0.002 & 0.024 & 0.005 & 0.135 \\
\hline $\mathrm{Fe} 4531$ & 2.863 & 0.420 & 0.037 & 0.000 & -0.008 & -0.011 & 0.092 & 0.002 & 0.000 & -0.015 & 0.141 & 0.252 & 0.561 \\
\hline $\mathrm{C}_{2} 4668$ & 0.747 & 0.640 & 1.165 & 0.000 & -0.136 & 0.096 & 0.211 & 0.021 & 0.006 & -0.067 & -0.124 & 0.148 & 0.502 \\
\hline $\mathrm{H} \beta$ & 0.853 & 0.220 & 0.004 & 0.000 & -0.002 & 0.003 & -0.083 & -0.004 & -0.001 & -0.007 & 0.001 & 0.070 & 0.100 \\
\hline Fe5015 & 3.725 & 0.460 & -0.042 & 0.000 & 0.006 & -0.001 & 0.214 & 0.020 & 0.020 & -0.001 & -0.042 & 0.346 & 0.777 \\
\hline $\mathrm{Mg}_{1}$ & 0.012 & 0.007 & 0.020 & 0.000 & -0.002 & 0.000 & -0.001 & 0.000 & 0.000 & 0.000 & -0.001 & 0.000 & 0.011 \\
\hline $\mathrm{Mg}_{2}$ & 0.059 & 0.008 & 0.013 & 0.000 & -0.002 & 0.004 & -0.002 & 0.000 & 0.000 & -0.001 & -0.002 & 0.001 & 0.016 \\
\hline $\operatorname{Mg} b$ & 0.525 & 0.230 & -0.055 & 0.000 & 0.005 & 0.165 & -0.111 & -0.003 & -0.009 & -0.019 & -0.059 & -0.037 & 0.092 \\
\hline $\mathrm{Fe} 5270$ & 1.624 & 0.280 & 0.000 & 0.000 & 0.000 & 0.000 & 0.208 & 0.081 & 0.000 & -0.007 & 0.008 & 0.082 & 0.373 \\
\hline Fe5270(Sauron) & 1.281 & & 0.000 & 0.000 & 0.000 & 0.000 & 0.154 & 0.077 & -0.001 & -0.007 & 0.013 & 0.039 & 0.257 \\
\hline $\mathrm{Fe} 5335$ & 1.464 & 0.260 & 0.000 & 0.000 & 0.000 & 0.000 & 0.200 & 0.008 & -0.001 & -0.009 & 0.046 & 0.020 & 0.304 \\
\hline $\mathrm{Fe} 5406$ & 0.879 & 0.200 & -0.007 & 0.000 & 0.001 & 0.000 & 0.169 & 0.000 & 0.000 & -0.001 & 0.027 & 0.002 & 0.216 \\
\hline $\mathrm{Fe} 5709$ & 0.588 & 0.180 & 0.000 & 0.000 & 0.000 & 0.012 & 0.110 & 0.001 & -0.022 & 0.009 & 0.005 & 0.005 & 0.198 \\
\hline $\mathrm{Fe} 5782$ & 0.173 & 0.200 & 0.000 & 0.000 & 0.000 & 0.002 & -0.019 & -0.001 & 0.000 & 0.005 & 0.098 & -0.009 & 0.095 \\
\hline $\mathrm{Na} D$ & 30 & 0.240 & 0.000 & & 0.0 & & -0.030 & -0.029 & 0.162 & -0.018 & 0.001 & -0.010 & 0.099 \\
\hline $\mathrm{TiO}_{1}$ & 0.000 & 0.007 & 0.000 & 0.000 & 0.000 & & 0.000 & 0.000 & 0.000 & 0.000 & 0.000 & 0.001 & 0.000 \\
\hline $\mathrm{TiO}_{2}$ & 0.004 & 0.006 & 0.000 & 0.000 & 0.000 & 0.000 & 0.001 & 0.000 & 0.000 & 0.000 & 0.000 & 0.001 & 0.002 \\
\hline $\mathrm{H} \gamma \mathrm{A}$ & -8.376 & 0.480 & -0.192 & 0.000 & 0.305 & 0.032 & -0.228 & -0.041 & 0.005 & 0.076 & 0.071 & -0.203 & -0.676 \\
\hline $\mathrm{H} \gamma \mathrm{F}$ & -2.629 & 0.330 & -0.112 & 0.000 & 0.169 & 0.015 & -0.026 & -0.014 & 0.005 & 0.044 & 0.055 & 0.013 & -0.052 \\
\hline $\mathrm{H} \delta \mathrm{A}$ & -2.538 & 0.640 & -0.667 & -0.132 & 0.179 & 0.007 & -0.240 & 0.016 & 0.013 & 0.132 & 0.025 & -0.100 & -0.572 \\
\hline $\mathrm{H} \delta \mathrm{F}$ & -1.151 & 0.400 & -0.160 & -0.032 & 0.043 & 0.005 & -0.124 & 0.031 & 0.004 & 0.064 & -0.005 & -0.078 & -0.342 \\
\hline
\end{tabular}


A. J. Korn et al.: The sensitivity of Lick indices to abundance variations, Online Material $p 11$

Table 24. Spectral index response: Cool dwarf (4385/4.83/-1.35/+0.30).

\begin{tabular}{|c|c|c|c|c|c|c|c|c|c|c|c|c|c|}
\hline (1) & (2) & (3) & (4) & (5) & (6) & (7) & (8) & (9) & (10) & (11) & (12) & (13) & (14) \\
\hline Index & $I_{0}$ & Error & $\mathrm{C}$ & $\mathrm{N}$ & $\mathrm{O}$ & $\mathrm{Mg}$ & $\mathrm{Fe}$ & $\mathrm{Ca}$ & $\mathrm{Na}$ & $\mathrm{Si}$ & $\mathrm{Cr}$ & $\mathrm{Ti}$ & {$[\mathrm{Z} / \mathrm{H}]$} \\
\hline $\mathrm{CN}_{1}$ & -0.016 & 0.021 & 0.012 & 0.007 & 0.001 & -0.003 & -0.001 & -0.004 & -0.001 & 0.014 & -0.010 & 0.001 & -0.004 \\
\hline $\mathrm{CN}_{2}$ & 0.025 & 0.023 & 0.010 & 0.007 & 0.002 & -0.005 & -0.002 & -0.005 & -0.001 & 0.022 & -0.010 & 0.002 & 0.003 \\
\hline $\mathrm{Ca} 4227$ & 2.395 & 0.270 & -0.271 & -0.037 & 0.073 & 0.035 & -0.034 & 0.901 & 0.020 & -0.073 & -0.089 & -0.003 & 0.721 \\
\hline G4300 & 4.197 & 0.390 & 1.981 & 0.000 & -0.943 & -0.087 & -0.328 & 0.209 & 0.001 & -0.028 & -0.162 & 0.332 & 0.122 \\
\hline $\mathrm{Fe} 4383$ & 5.305 & 0.530 & 0.260 & 0.000 & -0.030 & -0.440 & 1.686 & -0.335 & -0.045 & -0.100 & -0.025 & 0.057 & 1.039 \\
\hline $\mathrm{Ca} 4455$ & 0.268 & 0.250 & -0.036 & 0.000 & 0.009 & -0.025 & 0.032 & -0.064 & -0.006 & -0.005 & 0.011 & 0.008 & 0.091 \\
\hline $\mathrm{Fe} 4531$ & 2.420 & 0.420 & 0.048 & 0.000 & -0.012 & -0.181 & 0.231 & -0.029 & -0.002 & -0.029 & 0.123 & 0.563 & 0.667 \\
\hline $\mathrm{C}_{2} 4668$ & 0.010 & 0.640 & 0.186 & 0.000 & -0.008 & -0.139 & 0.169 & 0.060 & 0.028 & -0.004 & -0.069 & 0.130 & 0.056 \\
\hline $\mathrm{H} \beta$ & 0.290 & 0.220 & 0.001 & 0.000 & 0.001 & -0.004 & -0.010 & -0.008 & 0.003 & -0.008 & -0.014 & 0.023 & 0.024 \\
\hline $\mathrm{Fe} 5015$ & 1.165 & 0.460 & -0.003 & 0.000 & 0.000 & -0.579 & 0.257 & 0.047 & 0.050 & -0.002 & -0.033 & 0.739 & 0.546 \\
\hline $\mathrm{Mg}_{1}$ & 0.163 & 0.007 & 0.003 & 0.000 & 0.000 & 0.038 & -0.002 & -0.002 & -0.002 & -0.002 & 0.002 & 0.002 & 0.038 \\
\hline $\mathrm{Mg}_{2}$ & 0.361 & 0.008 & 0.000 & 0.000 & 0.000 & 0.081 & -0.012 & -0.004 & -0.003 & -0.005 & -0.002 & 0.002 & 0.065 \\
\hline $\operatorname{Mg} b$ & 5.611 & 0.230 & 0.008 & 0.000 & 0.000 & 1.262 & -0.235 & -0.046 & -0.044 & -0.067 & -0.242 & -0.032 & 0.788 \\
\hline $\mathrm{Fe} 5270$ & 2.560 & 0.280 & 0.000 & 0.000 & 0.000 & -0.139 & 0.478 & 0.176 & -0.016 & -0.033 & 0.059 & 0.037 & 0.552 \\
\hline Fe5270(Sauron) & 2.227 & & 0.000 & 0.000 & 0.000 & -0.122 & 0.418 & 0.169 & -0.014 & -0.029 & 0.040 & 0.009 & 0.465 \\
\hline Fe5335 & 2.096 & 0.260 & 0.000 & 0.000 & 0.000 & -0.150 & 0.553 & -0.014 & -0.021 & -0.034 & 0.107 & 0.014 & 0.430 \\
\hline $\mathrm{Fe} 5406$ & 1.227 & 0.200 & -0.001 & 0.000 & 0.000 & -0.082 & 0.313 & -0.013 & -0.011 & -0.019 & 0.071 & 0.015 & 0.281 \\
\hline $\mathrm{Fe} 5709$ & 0.272 & 0.180 & 0.000 & 0.000 & 0.000 & 0.020 & 0.080 & -0.003 & -0.051 & -0.003 & 0.004 & 0.014 & 0.108 \\
\hline $\mathrm{Fe} 5782$ & 0.105 & 0.200 & 0.000 & 0.000 & 0.000 & 0.002 & -0.009 & -0.002 & 0.000 & -0.001 & 0.088 & -0.011 & 0.074 \\
\hline $\mathrm{Na} \mathrm{D}$ & 3.929 & 0.240 & 0.000 & & 0.000 & -0.081 & -0.074 & -0.031 & 1.352 & -0.040 & 0.001 & -0.015 & 1.126 \\
\hline $\mathrm{TiO}_{1}$ & 0.000 & 0.007 & 0.000 & 0.000 & 0.000 & 0.000 & 0.000 & -0.001 & 0.000 & 0.000 & 0.000 & 0.001 & 0.000 \\
\hline $\mathrm{TiO}_{2}$ & 0.000 & 0.006 & 0.000 & 0.000 & 0.000 & 0.000 & 0.001 & -0.002 & 0.000 & 0.000 & 0.000 & 0.000 & 0.000 \\
\hline $\mathrm{H} \gamma \mathrm{A}$ & -8.157 & 0.480 & -1.687 & 0.000 & 0.870 & 0.521 & -1.091 & -0.187 & 0.032 & 0.089 & 0.036 & -0.410 & -1.254 \\
\hline $\mathrm{H} \gamma \mathrm{F}$ & -2.944 & 0.330 & -0.825 & 0.000 & 0.421 & 0.197 & -0.398 & -0.072 & 0.016 & 0.031 & 0.110 & -0.077 & -0.272 \\
\hline $\mathrm{H} \delta \mathrm{A}$ & -4.938 & 0.640 & -0.769 & -0.023 & 0.237 & 0.397 & -1.818 & 0.062 & 0.054 & 0.365 & 0.001 & -0.093 & -0.924 \\
\hline $\mathrm{H} \delta \mathrm{F}$ & -2.165 & 0.400 & -0.173 & -0.005 & 0.053 & 0.188 & -0.684 & 0.074 & 0.026 & 0.089 & -0.008 & -0.091 & -0.472 \\
\hline
\end{tabular}

Table 25. Spectral index response: Turnoff star (6383/4.16/-1.35/+0.30).

\begin{tabular}{|c|c|c|c|c|c|c|c|c|c|c|c|c|c|}
\hline (1) & (2) & (3) & (4) & (5) & (6) & (7) & (8) & (9) & (10) & (11) & (12) & (13) & (14) \\
\hline Index & $I_{0}$ & Error & $\mathrm{C}$ & $\mathrm{N}$ & $\mathrm{O}$ & $\mathrm{Mg}$ & $\mathrm{Fe}$ & $\mathrm{Ca}$ & $\mathrm{Na}$ & $\mathrm{Si}$ & $\mathrm{Cr}$ & $\mathrm{Ti}$ & {$[\mathrm{Z} / \mathrm{H}]$} \\
\hline $\mathrm{CN}_{1}$ & -0.090 & 0.021 & -0.002 & 0.000 & 0.000 & 0.000 & 0.002 & 0.000 & 0.000 & 0.000 & 0.000 & 0.001 & -0.001 \\
\hline $\mathrm{CN}_{2}$ & -0.066 & 0.023 & -0.002 & 0.000 & 0.000 & 0.000 & 0.003 & 0.000 & 0.000 & 0.000 & 0.000 & 0.001 & 0.000 \\
\hline $\mathrm{Ca} 4227$ & 0.134 & 0.270 & -0.001 & 0.000 & 0.000 & 0.000 & 0.006 & 0.040 & 0.000 & 0.000 & -0.005 & 0.005 & 0.038 \\
\hline G4300 & -0.227 & 0.390 & 0.314 & 0.000 & 0.000 & -0.011 & 0.024 & 0.050 & -0.001 & -0.004 & -0.010 & 0.113 & 0.412 \\
\hline $\mathrm{Fe} 4383$ & 0.232 & 0.530 & 0.017 & 0.000 & -0.001 & -0.004 & 0.085 & -0.028 & 0.001 & 0.000 & -0.018 & 0.068 & 0.175 \\
\hline $\mathrm{Ca} 4455$ & 0.089 & 0.250 & -0.001 & 0.000 & 0.000 & -0.009 & -0.010 & -0.005 & 0.000 & 0.000 & 0.000 & 0.007 & 0.012 \\
\hline $\mathrm{Fe} 4531$ & 0.404 & 0.420 & 0.001 & 0.000 & 0.000 & -0.011 & 0.071 & -0.015 & 0.000 & 0.000 & 0.027 & 0.126 & 0.207 \\
\hline$C_{2} 4668$ & 0.126 & 0.640 & 0.001 & 0.000 & 0.000 & -0.057 & -0.056 & -0.070 & -0.001 & -0.010 & -0.126 & -0.072 & -0.069 \\
\hline $\mathrm{H} \beta$ & 3.647 & 0.220 & -0.001 & 0.000 & 0.000 & 0.003 & -0.015 & -0.003 & 0.000 & 0.002 & 0.002 & 0.008 & 0.058 \\
\hline $\mathrm{Fe} 5015$ & 0.605 & 0.460 & 0.001 & 0.000 & -0.016 & -0.002 & 0.133 & 0.013 & 0.006 & 0.003 & -0.018 & 0.112 & 0.299 \\
\hline $\mathrm{Mg}_{1}$ & -0.004 & 0.007 & 0.000 & 0.000 & 0.000 & 0.000 & 0.000 & 0.000 & 0.000 & 0.000 & 0.000 & 0.000 & 0.001 \\
\hline $\mathrm{Mg}_{2}$ & 0.018 & 0.008 & 0.000 & 0.000 & 0.000 & 0.005 & 0.001 & 0.000 & 0.000 & 0.000 & 0.000 & 0.001 & 0.006 \\
\hline $\operatorname{Mg} b$ & 0.546 & 0.230 & 0.000 & 0.000 & 0.000 & 0.172 & -0.050 & 0.000 & -0.001 & -0.001 & -0.021 & 0.011 & 0.098 \\
\hline $\mathrm{Fe} 5270$ & 0.366 & 0.280 & 0.000 & 0.000 & 0.000 & 0.000 & 0.049 & 0.063 & 0.000 & 0.000 & 0.002 & 0.013 & 0.119 \\
\hline Fe5270(Sauron) & 0.375 & & 0.000 & 0.000 & 0.000 & 0.000 & 0.046 & 0.060 & 0.000 & 0.000 & 0.004 & 0.008 & 0.113 \\
\hline $\mathrm{Fe} 5335$ & 0.295 & 0.260 & -0.001 & 0.000 & 0.000 & 0.000 & 0.047 & 0.001 & 0.000 & 0.000 & 0.014 & 0.013 & 0.075 \\
\hline Fe5406 & 0.142 & 0.200 & -0.003 & 0.000 & 0.000 & 0.000 & 0.044 & 0.000 & 0.000 & 0.000 & 0.012 & -0.013 & 0.039 \\
\hline Fe5709 & 0.047 & 0.180 & 0.000 & 0.000 & 0.000 & 0.012 & 0.025 & 0.000 & -0.010 & 0.002 & 0.000 & 0.000 & 0.033 \\
\hline Fe5782 & 0.007 & 0.200 & 0.001 & 0.000 & 0.000 & 0.002 & -0.004 & 0.000 & 0.000 & 0.000 & 0.008 & 0.000 & 0.007 \\
\hline $\mathrm{NaD}$ & 0.257 & 0.240 & 0.000 & 0.000 & 0.000 & -0.001 & -0.011 & -0.009 & 0.057 & -0.003 & 0.000 & -0.001 & 0.035 \\
\hline $\mathrm{TiO}_{1}$ & 0.000 & 0.007 & 0.000 & 0.000 & 0.000 & 0.000 & 0.000 & 0.000 & 0.000 & 0.000 & 0.000 & 0.000 & 0.000 \\
\hline $\mathrm{TiO}_{2}$ & -0.001 & 0.006 & 0.000 & 0.000 & 0.000 & 0.000 & 0.000 & 0.000 & 0.000 & 0.000 & 0.000 & 0.000 & 0.000 \\
\hline $\mathrm{H} \gamma \mathrm{A}$ & 3.655 & 0.480 & -0.250 & 0.000 & 0.000 & 0.034 & -0.081 & -0.036 & 0.000 & 0.007 & 0.012 & -0.101 & -0.318 \\
\hline $\mathrm{H} \gamma \mathrm{F}$ & 3.410 & 0.330 & -0.104 & 0.000 & 0.000 & 0.016 & -0.023 & -0.013 & 0.000 & 0.004 & 0.010 & -0.010 & -0.067 \\
\hline $\mathrm{H} \delta \mathrm{A}$ & 4.268 & 0.640 & -0.017 & 0.000 & 0.000 & 0.008 & -0.125 & 0.000 & 0.000 & 0.013 & 0.004 & -0.019 & -0.058 \\
\hline $\mathrm{H} \delta \mathrm{F}$ & 3.495 & 0.400 & -0.004 & 0.000 & 0.000 & 0.006 & -0.067 & 0.002 & 0.000 & 0.010 & 0.002 & -0.010 & -0.029 \\
\hline
\end{tabular}


A. J. Korn et al.: The sensitivity of Lick indices to abundance variations, Online Material p 12

Table 26. Spectral index response: Cool giant (4662/1.83/-1.35/+0.30).

\begin{tabular}{|c|c|c|c|c|c|c|c|c|c|c|c|c|c|}
\hline (1) & (2) & (3) & (4) & (5) & (6) & (7) & (8) & (9) & (10) & (11) & (12) & (13) & (14) \\
\hline Index & $I_{0}$ & Error & C & $\mathrm{N}$ & $\mathrm{O}$ & $\mathrm{Mg}$ & $\mathrm{Fe}$ & $\mathrm{Ca}$ & $\mathrm{Na}$ & $\mathrm{Si}$ & $\mathrm{Cr}$ & $\mathrm{Ti}$ & {$[\mathrm{Z} / \mathrm{H}]$} \\
\hline$\overline{\mathrm{CN}_{1}}$ & -0.010 & 0.021 & 0.030 & 0.034 & -0.007 & -0.005 & -0.005 & -0.003 & 0.000 & 0.002 & -0.002 & 0.002 & 0.028 \\
\hline $\mathrm{CN}_{2}$ & 0.008 & 0.023 & 0.030 & 0.036 & -0.006 & -0.006 & -0.006 & -0.003 & -0.001 & 0.006 & -0.001 & 0.002 & 0.033 \\
\hline Ca4227 & 0.085 & 0.270 & -0.391 & -0.224 & 0.119 & 0.081 & 0.049 & 0.205 & 0.006 & 0.027 & -0.027 & 0.003 & -0.032 \\
\hline G4300 & 7.885 & 0.390 & 0.333 & 0.000 & -0.326 & -0.128 & -0.157 & 0.040 & -0.010 & -0.071 & -0.033 & 0.071 & 0.115 \\
\hline $\mathrm{Fe} 4383$ & 3.316 & 0.530 & 0.670 & 0.000 & -0.148 & -0.209 & 0.284 & -0.067 & -0.007 & -0.129 & -0.005 & 0.165 & 0.607 \\
\hline Ca4455 & 0.346 & 0.250 & -0.037 & 0.000 & 0.008 & -0.001 & -0.041 & -0.003 & -0.002 & 0.002 & 0.014 & 0.005 & 0.121 \\
\hline $\mathrm{Fe} 4531$ & 2.586 & 0.420 & 0.043 & 0.000 & -0.010 & -0.039 & 0.115 & 0.002 & 0.000 & -0.014 & 0.115 & 0.247 & 0.531 \\
\hline$C_{2} 4668$ & 0.762 & 0.640 & 1.254 & 0.000 & -0.151 & -0.032 & 0.167 & 0.020 & 0.006 & -0.074 & -0.135 & 0.149 & 0.510 \\
\hline $\mathrm{H} \beta$ & 0.833 & 0.220 & 0.004 & 0.000 & -0.003 & -0.014 & -0.092 & -0.004 & -0.001 & -0.008 & 0.007 & 0.070 & 0.075 \\
\hline Fe5015 & 3.356 & 0.460 & -0.043 & 0.000 & 0.007 & -0.053 & 0.194 & 0.021 & 0.020 & 0.004 & -0.035 & 0.335 & 0.728 \\
\hline $\mathrm{Mg}_{1}$ & 0.011 & 0.007 & 0.021 & 0.000 & -0.003 & 0.005 & -0.001 & 0.000 & 0.000 & -0.001 & -0.001 & 0.000 & 0.012 \\
\hline $\mathrm{Mg}_{2}$ & 0.062 & 0.008 & 0.013 & 0.000 & -0.002 & 0.017 & -0.001 & 0.000 & 0.000 & -0.001 & -0.002 & 0.001 & 0.019 \\
\hline $\operatorname{Mg} b$ & 0.763 & 0.230 & -0.060 & 0.000 & 0.005 & 0.455 & -0.120 & -0.004 & -0.010 & -0.029 & -0.043 & -0.035 & 0.133 \\
\hline $\mathrm{Fe} 5270$ & 1.487 & 0.280 & 0.000 & 0.000 & 0.000 & -0.003 & 0.154 & 0.081 & 0.000 & -0.003 & 0.003 & 0.082 & 0.306 \\
\hline Fe5270(Sauron) & 1.185 & & 0.000 & 0.000 & 0.000 & -0.007 & 0.111 & 0.076 & 0.000 & -0.005 & 0.007 & 0.039 & 0.209 \\
\hline Fe5335 & 1.244 & 0.260 & 0.000 & 0.000 & 0.000 & -0.009 & 0.157 & 0.009 & -0.001 & -0.007 & 0.042 & 0.019 & 0.247 \\
\hline Fe5406 & 0.711 & 0.200 & -0.007 & 0.000 & 0.001 & 0.004 & 0.135 & 0.000 & 0.000 & 0.001 & 0.023 & 0.005 & 0.180 \\
\hline Fe5709 & 0.448 & 0.180 & 0.000 & 0.000 & 0.000 & 0.028 & 0.093 & 0.001 & -0.022 & 0.010 & 0.003 & 0.007 & 0.173 \\
\hline $\mathrm{Fe} 5782$ & 0.111 & 0.200 & 0.000 & 0.000 & 0.000 & 0.010 & -0.011 & -0.002 & 0.000 & 0.005 & 0.066 & -0.009 & 0.071 \\
\hline $\mathrm{Na} \mathrm{L}$ & & 0.240 & & & & -0.015 & & -0.029 & & -0.021 & 01 & -0.009 & 0.094 \\
\hline $\mathrm{TiO}_{1}$ & 0.001 & 0.007 & 0.000 & 0.000 & 0.000 & 0.000 & 0.000 & 0.000 & 0.000 & 0.000 & 0.000 & 0.001 & 0.001 \\
\hline $\mathrm{TiO}_{2}$ & 0.003 & 0.006 & 0.000 & 0.000 & 0.000 & 0.000 & 0.001 & 0.000 & 0.000 & 0.000 & 0.000 & 0.001 & 0.002 \\
\hline $\mathrm{H} \gamma \mathrm{A}$ & -8.063 & 0.480 & -0.079 & 0.000 & 0.286 & 0.155 & -0.219 & -0.039 & 0.004 & 0.066 & 0.073 & -0.205 & -0.561 \\
\hline $\mathrm{H} \gamma \mathrm{F}$ & -2.611 & 0.330 & -0.043 & 0.000 & 0.160 & 0.083 & -0.035 & -0.014 & 0.004 & 0.041 & 0.056 & 0.011 & -0.019 \\
\hline $\mathrm{H} \delta \mathrm{A}$ & -2.338 & 0.640 & -0.680 & -0.134 & 0.199 & 0.194 & -0.221 & 0.009 & 0.014 & 0.146 & 0.021 & -0.105 & -0.519 \\
\hline $\mathrm{H} \delta \mathrm{F}$ & -0.904 & 0.400 & -0.165 & -0.034 & 0.049 & 0.063 & -0.131 & 0.029 & 0.005 & 0.065 & 0.001 & -0.080 & -0.314 \\
\hline
\end{tabular}

Table 27. Spectral index response: Cool dwarf (5124/4.70/-2.25).

\begin{tabular}{|c|c|c|c|c|c|c|c|c|c|c|c|c|c|}
\hline (1) & (2) & (3) & (4) & (5) & (6) & (7) & (8) & (9) & (10) & (11) & (12) & (13) & (14) \\
\hline Index & $I_{0}$ & Error & C & $\mathrm{N}$ & $\mathrm{O}$ & $\mathrm{Mg}$ & $\mathrm{Fe}$ & $\mathrm{Ca}$ & $\mathrm{Na}$ & $\mathrm{Si}$ & $\mathrm{Cr}$ & $\mathrm{Ti}$ & {$[\mathrm{Z} / \mathrm{H}]$} \\
\hline $\mathrm{CN}_{1}$ & -0.038 & 0.021 & -0.009 & 0.001 & 0.003 & 0.000 & 0.001 & 0.000 & 0.000 & 0.002 & -0.002 & 0.000 & -0.005 \\
\hline $\mathrm{CN}_{2}$ & -0.032 & 0.023 & -0.011 & 0.001 & 0.003 & 0.001 & 0.002 & 0.000 & 0.000 & 0.004 & -0.002 & 0.001 & -0.004 \\
\hline $\mathrm{Ca} 4227$ & 0.301 & 0.270 & -0.056 & -0.005 & 0.011 & 0.004 & 0.014 & 0.163 & 0.000 & -0.008 & -0.018 & 0.001 & 0.095 \\
\hline G4300 & 4.313 & 0.390 & 1.148 & 0.000 & -0.408 & -0.107 & -0.224 & 0.046 & -0.007 & -0.052 & -0.032 & 0.096 & 0.559 \\
\hline $\mathrm{Fe} 4383$ & 1.702 & 0.530 & 0.231 & 0.000 & -0.023 & -0.048 & 0.562 & -0.062 & -0.003 & -0.022 & -0.015 & 0.041 & 0.649 \\
\hline $\mathrm{Ca} 4455$ & 0.099 & 0.250 & -0.010 & 0.000 & 0.002 & -0.001 & 0.009 & -0.012 & 0.000 & 0.000 & 0.000 & 0.010 & 0.037 \\
\hline $\mathrm{Fe} 4531$ & 0.530 & 0.420 & 0.015 & 0.000 & -0.003 & -0.027 & 0.106 & -0.018 & 0.000 & -0.002 & 0.025 & 0.137 & 0.246 \\
\hline$C_{2} 4668$ & 0.094 & 0.640 & 0.019 & 0.000 & -0.001 & 0.050 & 0.096 & 0.004 & 0.001 & -0.002 & -0.041 & 0.011 & 0.060 \\
\hline $\mathrm{H} \beta$ & 1.062 & 0.220 & 0.000 & 0.000 & 0.000 & 0.004 & -0.006 & -0.004 & 0.000 & 0.002 & -0.001 & 0.000 & 0.029 \\
\hline Fe5015 & 0.549 & 0.460 & -0.002 & 0.000 & 0.000 & -0.038 & 0.142 & 0.005 & 0.003 & 0.004 & -0.004 & 0.143 & 0.330 \\
\hline $\mathrm{Mg}_{1}$ & -0.004 & 0.007 & 0.000 & 0.000 & 0.000 & 0.004 & -0.002 & 0.000 & 0.000 & 0.000 & -0.001 & 0.000 & 0.001 \\
\hline $\mathrm{Mg}_{2}$ & 0.046 & 0.008 & 0.000 & 0.000 & 0.000 & 0.021 & -0.001 & 0.000 & 0.000 & 0.000 & -0.001 & 0.001 & 0.018 \\
\hline $\operatorname{Mg} b$ & 1.393 & 0.230 & -0.001 & 0.000 & 0.000 & 0.590 & -0.064 & -0.002 & -0.002 & -0.012 & -0.048 & 0.010 & 0.449 \\
\hline $\mathrm{Fe} 5270$ & 0.639 & 0.280 & 0.000 & 0.000 & 0.000 & 0.002 & 0.200 & 0.061 & 0.000 & -0.002 & 0.015 & 0.004 & 0.268 \\
\hline Fe5270(Sauron) & 0.605 & & 0.000 & 0.000 & 0.000 & 0.000 & 0.175 & 0.059 & -0.001 & -0.003 & 0.010 & 0.002 & 0.234 \\
\hline Fe5335 & 0.641 & 0.260 & 0.000 & 0.000 & 0.000 & -0.003 & 0.204 & 0.000 & -0.001 & -0.004 & 0.028 & 0.005 & 0.215 \\
\hline $\mathrm{Fe} 5406$ & 0.312 & 0.200 & 0.000 & 0.000 & 0.000 & 0.000 & 0.095 & 0.000 & 0.000 & -0.002 & 0.017 & -0.003 & 0.111 \\
\hline $\mathrm{Fe} 5709$ & 0.070 & 0.180 & 0.000 & 0.000 & 0.000 & 0.008 & 0.036 & 0.000 & -0.006 & 0.001 & 0.000 & 0.000 & 0.051 \\
\hline $\mathrm{Fe} 5782$ & 0.010 & 0.200 & 0.000 & 0.000 & 0.000 & 0.001 & -0.003 & 0.000 & 0.000 & 0.000 & 0.009 & 0.000 & 0.010 \\
\hline $\mathrm{NaD}$ & 0.584 & 0.240 & 0.000 & 0.000 & 0.000 & -0.002 & -0.015 & -0.006 & 0.226 & -0.004 & 0.000 & -0.002 & 0.192 \\
\hline $\mathrm{TiO}_{1}$ & & 0.007 & 0.000 & 0.000 & & & 0.000 & 0.000 & 0.000 & 0.000 & 0.000 & 0.000 & 0.000 \\
\hline $\mathrm{TiO}_{2}$ & -0.001 & 0.006 & 0.000 & 0.000 & 0.000 & 0.000 & 0.000 & 0.000 & 0.000 & 0.000 & 0.000 & 0.000 & 0.000 \\
\hline $\mathrm{H} \gamma \mathrm{A}$ & -4.280 & 0.480 & -1.150 & 0.000 & 0.390 & 0.170 & -0.214 & -0.041 & 0.008 & 0.061 & 0.033 & -0.099 & -0.948 \\
\hline $\mathrm{H} \gamma \mathrm{F}$ & -1.464 & 0.330 & -0.594 & 0.000 & 0.198 & 0.084 & -0.077 & -0.015 & 0.004 & 0.032 & 0.033 & -0.006 & -0.373 \\
\hline $\mathrm{H} \delta \mathrm{A}$ & -1.119 & 0.640 & -0.263 & -0.003 & 0.053 & 0.061 & -0.543 & 0.000 & 0.003 & 0.042 & 0.001 & -0.010 & -0.546 \\
\hline $\mathrm{H} \delta \mathrm{F}$ & -0.046 & 0.400 & -0.068 & -0.001 & 0.014 & 0.029 & -0.208 & 0.003 & 0.002 & 0.034 & 0.000 & -0.008 & -0.199 \\
\hline
\end{tabular}


A. J. Korn et al.: The sensitivity of Lick indices to abundance variations, Online Material p 13

Table 28. Spectral index response: Turnoff star (6724/4.15/-2.25).

\begin{tabular}{|c|c|c|c|c|c|c|c|c|c|c|c|c|c|}
\hline (1) & (2) & (3) & (4) & (5) & (6) & (7) & (8) & (9) & (10) & (11) & (12) & (13) & (14) \\
\hline Index & $I_{0}$ & Error & $\mathrm{C}$ & $\mathrm{N}$ & $\mathrm{O}$ & $\mathrm{Mg}$ & $\mathrm{Fe}$ & $\mathrm{Ca}$ & $\mathrm{Na}$ & $\mathrm{Si}$ & $\mathrm{Cr}$ & $\mathrm{Ti}$ & {$[\mathrm{Z} / \mathrm{H}]$} \\
\hline $\mathrm{CN}_{1}$ & -0.124 & 0.021 & 0.000 & 0.000 & 0.000 & 0.000 & 0.001 & 0.000 & 0.000 & 0.000 & 0.000 & 0.000 & 0.000 \\
\hline $\mathrm{CN}_{2}$ & -0.097 & 0.023 & 0.000 & 0.000 & 0.000 & 0.000 & 0.002 & 0.000 & 0.000 & 0.000 & 0.000 & 0.000 & 0.001 \\
\hline Ca4227 & 0.069 & 0.270 & 0.000 & 0.000 & 0.000 & 0.000 & 0.015 & 0.009 & 0.000 & 0.000 & -0.003 & 0.001 & 0.011 \\
\hline G4300 & -1.475 & 0.390 & 0.016 & 0.000 & 0.000 & 0.000 & 0.017 & 0.037 & 0.000 & 0.000 & -0.004 & 0.060 & 0.109 \\
\hline $\mathrm{Fe} 4383$ & -0.330 & 0.530 & 0.001 & 0.000 & 0.000 & -0.001 & 0.043 & -0.020 & 0.000 & 0.000 & -0.001 & 0.031 & 0.059 \\
\hline $\mathrm{Ca} 4455$ & 0.035 & 0.250 & 0.000 & 0.000 & 0.000 & -0.004 & 0.010 & -0.005 & 0.000 & 0.000 & 0.000 & 0.009 & 0.017 \\
\hline $\mathrm{Fe} 4531$ & 0.098 & 0.420 & 0.000 & 0.000 & 0.000 & -0.001 & 0.037 & -0.006 & 0.000 & 0.000 & 0.007 & 0.018 & 0.063 \\
\hline $\mathrm{C}_{2} 4668$ & -0.014 & 0.640 & 0.000 & 0.000 & 0.000 & 0.016 & -0.007 & 0.001 & 0.000 & -0.001 & 0.014 & 0.030 & -0.001 \\
\hline $\mathrm{H} \beta$ & 4.485 & 0.220 & 0.000 & 0.000 & 0.000 & 0.000 & 0.001 & -0.001 & 0.000 & 0.000 & 0.000 & 0.001 & 0.035 \\
\hline Fe5015 & 0.102 & 0.460 & 0.000 & 0.000 & 0.000 & 0.000 & 0.063 & 0.002 & 0.001 & 0.000 & 0.000 & 0.016 & 0.095 \\
\hline $\mathrm{Mg}_{1}$ & -0.006 & 0.007 & 0.000 & 0.000 & 0.000 & 0.000 & -0.001 & 0.000 & 0.000 & 0.000 & 0.000 & 0.000 & -0.001 \\
\hline $\mathrm{Mg}_{2}$ & 0.006 & 0.008 & 0.000 & 0.000 & 0.000 & 0.001 & 0.000 & 0.000 & 0.000 & 0.000 & 0.000 & 0.000 & 0.002 \\
\hline $\operatorname{Mg} b$ & 0.298 & 0.230 & 0.000 & 0.000 & 0.000 & 0.050 & 0.001 & 0.000 & 0.000 & 0.000 & -0.019 & 0.005 & 0.036 \\
\hline Fe5270 & 0.110 & 0.280 & 0.000 & 0.000 & 0.000 & 0.000 & 0.034 & 0.019 & 0.000 & 0.000 & 0.000 & 0.001 & 0.052 \\
\hline Fe5270(Sauron) & 0.125 & & 0.000 & 0.000 & 0.000 & 0.000 & 0.038 & 0.019 & 0.000 & 0.000 & 0.001 & 0.001 & 0.057 \\
\hline Fe5335 & 0.112 & 0.260 & 0.000 & 0.000 & 0.000 & 0.000 & 0.045 & 0.000 & 0.000 & 0.000 & 0.003 & 0.003 & 0.050 \\
\hline $\mathrm{Fe} 5406$ & 0.052 & 0.200 & -0.001 & 0.000 & 0.000 & 0.000 & 0.029 & 0.000 & 0.000 & 0.000 & 0.004 & -0.002 & 0.029 \\
\hline $\mathrm{Fe} 5709$ & 0.007 & 0.180 & 0.000 & 0.000 & 0.000 & 0.002 & 0.006 & 0.000 & -0.002 & 0.001 & 0.000 & 0.000 & 0.007 \\
\hline $\mathrm{Fe} 5782$ & 0.001 & 0.200 & 0.000 & 0.000 & 0.000 & 0.000 & -0.001 & 0.000 & 0.000 & 0.000 & 0.001 & 0.000 & 0.001 \\
\hline $\mathrm{NaD}$ & & 0.240 & & & & & -0 . & & & & 0.000 & 0.000 & 0.026 \\
\hline $\mathrm{TiO}_{1}$ & 0.000 & 0.007 & 0.000 & 0.000 & 0.000 & 0.000 & 0.000 & 0.000 & 0.000 & 0.000 & 0.000 & 0.000 & 0.000 \\
\hline $\mathrm{TiO}_{2}$ & 0.000 & 0.006 & 0.000 & 0.000 & 0.000 & 0.000 & 0.000 & 0.000 & 0.000 & 0.000 & 0.000 & 0.000 & 0.000 \\
\hline $\mathrm{H} \gamma \mathrm{A}$ & 5.781 & 0.480 & -0.011 & 0.000 & 0.000 & 0.011 & -0.035 & -0.024 & 0.000 & 0.001 & -0.004 & -0.044 & -0.063 \\
\hline $\mathrm{H} \gamma \mathrm{F}$ & 4.539 & 0.330 & -0.005 & 0.000 & 0.000 & 0.005 & -0.011 & -0.009 & 0.000 & 0.000 & 0.000 & -0.005 & 0.003 \\
\hline $\mathrm{H} \delta \mathrm{A}$ & 5.984 & 0.640 & -0.001 & 0.000 & 0.000 & 0.001 & -0.069 & 0.000 & 0.000 & 0.002 & -0.003 & -0.003 & -0.022 \\
\hline $\mathrm{H} \delta \mathrm{F}$ & 4.548 & 0.400 & 0.000 & 0.000 & 0.000 & 0.000 & -0.034 & 0.000 & 0.000 & 0.001 & 0.001 & -0.001 & -0.010 \\
\hline
\end{tabular}

Table 29. Spectral index response: Cool giant (4822/1.83/-2.25).

\begin{tabular}{|c|c|c|c|c|c|c|c|c|c|c|c|c|c|}
\hline (1) & (2) & (3) & (4) & (5) & (6) & (7) & (8) & (9) & (10) & (11) & (12) & (13) & (14) \\
\hline Index & $I_{0}$ & Error & $\mathrm{C}$ & $\mathrm{N}$ & $\mathrm{O}$ & $\mathrm{Mg}$ & $\mathrm{Fe}$ & $\mathrm{Ca}$ & $\mathrm{Na}$ & $\mathrm{Si}$ & $\mathrm{Cr}$ & $\mathrm{Ti}$ & {$[\mathrm{Z} / \mathrm{H}]$} \\
\hline $\mathrm{CN}_{1}$ & -0.027 & 0.021 & -0.010 & 0.001 & 0.001 & 0.001 & 0.002 & 0.000 & 0.000 & 0.001 & -0.001 & 0.002 & -0.005 \\
\hline $\mathrm{CN}_{2}$ & -0.017 & 0.023 & -0.012 & 0.001 & 0.001 & 0.001 & 0.003 & 0.000 & 0.000 & 0.001 & 0.000 & 0.002 & -0.003 \\
\hline $\mathrm{Ca} 4227$ & 0.107 & 0.270 & -0.053 & -0.008 & 0.003 & 0.004 & 0.023 & 0.051 & 0.000 & 0.001 & -0.010 & 0.009 & 0.026 \\
\hline G4300 & 5.319 & 0.390 & 1.200 & 0.000 & -0.101 & -0.092 & -0.078 & 0.049 & -0.005 & -0.073 & -0.022 & 0.127 & 1.069 \\
\hline $\mathrm{Fe} 4383$ & 1.480 & 0.530 & 0.164 & 0.000 & -0.003 & -0.013 & 0.175 & -0.036 & 0.000 & -0.008 & -0.020 & 0.146 & 0.519 \\
\hline $\mathrm{Ca} 4455$ & 0.198 & 0.250 & -0.008 & 0.000 & 0.000 & -0.001 & -0.024 & -0.004 & 0.000 & 0.000 & 0.001 & 0.012 & 0.053 \\
\hline $\mathrm{Fe} 4531$ & 1.078 & 0.420 & 0.011 & 0.000 & -0.001 & -0.021 & 0.120 & -0.020 & 0.000 & 0.003 & 0.048 & 0.257 & 0.426 \\
\hline $\mathrm{C}_{2} 4668$ & 0.106 & 0.640 & 0.037 & 0.000 & -0.001 & 0.095 & 0.068 & 0.006 & 0.001 & -0.005 & -0.112 & 0.061 & 0.082 \\
\hline $\mathrm{H} \beta$ & 0.916 & 0.220 & 0.002 & 0.000 & 0.000 & 0.000 & -0.038 & -0.004 & 0.000 & 0.000 & 0.007 & 0.019 & 0.023 \\
\hline $\mathrm{Fe} 5015$ & 1.391 & 0.460 & -0.003 & 0.000 & 0.000 & 0.003 & 0.145 & 0.008 & 0.004 & 0.008 & -0.008 & 0.233 & 0.561 \\
\hline $\mathrm{Mg}_{1}$ & -0.005 & 0.007 & 0.000 & 0.000 & 0.000 & 0.001 & 0.000 & 0.000 & 0.000 & 0.000 & -0.001 & 0.000 & 0.001 \\
\hline $\mathrm{Mg}_{2}$ & 0.023 & 0.008 & 0.000 & 0.000 & 0.000 & 0.004 & 0.000 & 0.000 & 0.000 & 0.000 & -0.001 & 0.002 & 0.005 \\
\hline $\operatorname{Mg} b$ & 0.410 & 0.230 & -0.002 & 0.000 & 0.000 & 0.124 & -0.120 & 0.000 & -0.001 & -0.002 & -0.025 & 0.016 & -0.022 \\
\hline $\mathrm{Fe} 5270$ & 0.690 & 0.280 & 0.000 & 0.000 & 0.000 & 0.004 & 0.114 & 0.068 & 0.000 & 0.004 & 0.004 & 0.026 & 0.204 \\
\hline Fe5270(Sauron) & 0.617 & & 0.000 & 0.000 & 0.000 & 0.002 & 0.071 & 0.066 & 0.000 & 0.002 & 0.005 & 0.016 & 0.156 \\
\hline $\mathrm{Fe} 5335$ & 0.709 & 0.260 & 0.000 & 0.000 & 0.000 & 0.002 & 0.075 & 0.002 & 0.000 & 0.002 & 0.034 & 0.023 & 0.152 \\
\hline $\mathrm{Fe} 5406$ & 0.378 & 0.200 & -0.001 & 0.000 & 0.000 & 0.003 & 0.076 & 0.000 & 0.000 & 0.002 & 0.018 & -0.028 & 0.092 \\
\hline $\mathrm{Fe} 5709$ & 0.134 & 0.180 & 0.000 & 0.000 & 0.000 & 0.012 & 0.050 & 0.000 & -0.007 & 0.003 & 0.000 & 0.001 & 0.080 \\
\hline $\mathrm{Fe} 5782$ & 0.022 & 0.200 & 0.000 & 0.000 & 0.000 & 0.001 & -0.004 & 0.000 & 0.000 & 0.000 & 0.015 & -0.001 & 0.020 \\
\hline $\mathrm{NaD}$ & 0.357 & 0.240 & 0.000 & 0.000 & 0.000 & 0.000 & -0.021 & -0.008 & 0.053 & -0.002 & 0.000 & -0.003 & 0.042 \\
\hline $\mathrm{TiO}_{1}$ & 0.000 & 0.007 & 0.000 & 0.000 & 0.000 & 0.000 & 0.001 & 0.000 & 0.000 & 0.000 & 0.000 & 0.000 & 0.001 \\
\hline $\mathrm{TiO}_{2}$ & 0.000 & 0.006 & 0.000 & 0.000 & 0.000 & 0.000 & 0.001 & 0.000 & 0.000 & 0.000 & 0.000 & 0.000 & 0.001 \\
\hline $\mathrm{H} \gamma \mathrm{A}$ & -4.620 & 0.480 & -1.212 & 0.000 & 0.097 & 0.119 & -0.077 & -0.046 & 0.005 & 0.074 & 0.081 & -0.155 & -1.246 \\
\hline $\mathrm{H} \gamma \mathrm{F}$ & -1.334 & 0.330 & -0.637 & 0.000 & 0.049 & 0.059 & 0.004 & -0.016 & 0.003 & 0.039 & 0.055 & 0.013 & -0.468 \\
\hline $\mathrm{H} \delta \mathrm{A}$ & -0.508 & 0.640 & -0.260 & -0.005 & 0.012 & -0.017 & -0.231 & -0.002 & 0.001 & 0.027 & -0.018 & -0.070 & -0.428 \\
\hline $\mathrm{H} \delta \mathrm{F}$ & 0.080 & 0.400 & -0.059 & -0.001 & 0.003 & 0.005 & -0.113 & 0.003 & 0.000 & 0.022 & 0.005 & -0.024 & -0.234 \\
\hline
\end{tabular}


A. J. Korn et al.: The sensitivity of Lick indices to abundance variations, Online Material p 14

Table 30. Spectral index response: Cool dwarf (5124/4.70/-2.25/+0.30).

\begin{tabular}{|c|c|c|c|c|c|c|c|c|c|c|c|c|c|}
\hline (1) & (2) & (3) & (4) & (5) & (6) & (7) & (8) & (9) & (10) & (11) & (12) & (13) & (14) \\
\hline Index & $I_{0}$ & Error & $\mathrm{C}$ & $\mathrm{N}$ & $\mathrm{O}$ & $\mathrm{Mg}$ & $\mathrm{Fe}$ & $\mathrm{Ca}$ & $\mathrm{Na}$ & $\mathrm{Si}$ & $\mathrm{Cr}$ & $\mathrm{Ti}$ & {$[\mathrm{Z} / \mathrm{H}]$} \\
\hline $\mathrm{CN}_{1}$ & -0.037 & 0.021 & -0.009 & 0.001 & 0.003 & 0.001 & 0.001 & 0.000 & 0.000 & 0.003 & -0.001 & 0.000 & -0.004 \\
\hline $\mathrm{CN}_{2}$ & -0.032 & 0.023 & -0.011 & 0.001 & 0.004 & 0.001 & 0.002 & 0.000 & 0.000 & 0.005 & -0.001 & 0.001 & -0.002 \\
\hline $\mathrm{Ca} 4227$ & 0.327 & 0.270 & -0.058 & -0.006 & 0.012 & 0.005 & 0.009 & 0.172 & 0.000 & -0.009 & -0.013 & 0.001 & 0.100 \\
\hline G4300 & 4.526 & 0.390 & 1.128 & 0.000 & -0.439 & -0.120 & -0.163 & 0.048 & -0.007 & -0.057 & -0.024 & 0.099 & 0.581 \\
\hline $\mathrm{Fe} 4383$ & 1.303 & 0.530 & 0.240 & 0.000 & -0.027 & -0.053 & 0.434 & -0.065 & -0.002 & -0.024 & -0.009 & 0.043 & 0.488 \\
\hline Ca4455 & 0.072 & 0.250 & -0.010 & 0.000 & 0.002 & -0.001 & 0.008 & -0.012 & 0.000 & 0.000 & -0.001 & 0.008 & 0.018 \\
\hline $\mathrm{Fe} 4531$ & 0.442 & 0.420 & 0.018 & 0.000 & -0.004 & -0.026 & 0.083 & -0.018 & 0.000 & -0.001 & 0.018 & 0.142 & 0.206 \\
\hline $\mathrm{C}_{2} 4668$ & 0.093 & 0.640 & 0.019 & 0.000 & -0.001 & 0.057 & 0.047 & 0.005 & 0.001 & -0.001 & -0.019 & 0.011 & 0.075 \\
\hline $\mathrm{H} \beta$ & 1.040 & 0.220 & -0.001 & 0.000 & 0.000 & 0.004 & 0.005 & -0.004 & 0.001 & 0.002 & 0.000 & 0.000 & 0.028 \\
\hline Fe5015 & 0.438 & 0.460 & -0.003 & 0.000 & 0.000 & -0.050 & 0.098 & 0.006 & 0.003 & 0.003 & -0.002 & 0.149 & 0.258 \\
\hline $\mathrm{Mg}_{1}$ & -0.002 & 0.007 & 0.000 & 0.000 & 0.000 & 0.005 & -0.002 & 0.000 & 0.000 & 0.000 & 0.000 & 0.000 & 0.002 \\
\hline $\mathrm{Mg}_{2}$ & 0.049 & 0.008 & 0.000 & 0.000 & 0.000 & 0.021 & -0.001 & 0.000 & 0.000 & -0.001 & 0.000 & 0.001 & 0.020 \\
\hline $\operatorname{Mg} b$ & 1.546 & 0.230 & -0.001 & 0.000 & 0.000 & 0.585 & -0.053 & -0.002 & -0.002 & -0.019 & -0.038 & 0.009 & 0.482 \\
\hline $\mathrm{Fe} 5270$ & 0.509 & 0.280 & 0.000 & 0.000 & 0.000 & -0.008 & 0.152 & 0.065 & 0.000 & -0.003 & 0.010 & 0.004 & 0.220 \\
\hline Fe5270(Sauron) & 0.493 & & 0.000 & 0.000 & 0.000 & -0.009 & 0.133 & 0.063 & 0.000 & -0.004 & 0.008 & 0.002 & 0.192 \\
\hline Fe5335 & 0.495 & 0.260 & 0.000 & 0.000 & 0.000 & -0.011 & 0.151 & 0.001 & 0.000 & -0.005 & 0.022 & 0.006 & 0.163 \\
\hline Fe5406 & 0.242 & 0.200 & 0.000 & 0.000 & 0.000 & -0.005 & 0.067 & 0.000 & 0.000 & -0.002 & 0.016 & -0.003 & 0.075 \\
\hline Fe5709 & 0.045 & 0.180 & 0.000 & 0.000 & 0.000 & 0.006 & 0.024 & 0.000 & -0.006 & 0.000 & 0.000 & 0.000 & 0.033 \\
\hline $\mathrm{Fe} 5782$ & 0.006 & 0.200 & 0.000 & 0.000 & 0.000 & 0.000 & -0.002 & 0.000 & 0.000 & 0.000 & 0.005 & -0.001 & 0.005 \\
\hline $\mathrm{Na} D$ & & 0.240 & 0.000 & 0.000 & 0.000 & -0.012 & -0.013 & -0.007 & 0.238 & -0.007 & 0.000 & -0.002 & 0.198 \\
\hline $\mathrm{TiO}_{1}$ & 0.000 & 0.007 & 0.000 & 0.000 & 0.000 & 0.000 & 0.000 & 0.000 & 0.000 & 0.000 & 0.000 & 0.000 & 0.000 \\
\hline $\mathrm{TiO}_{2}$ & -0.001 & 0.006 & 0.000 & 0.000 & 0.000 & 0.000 & 0.000 & 0.000 & 0.000 & 0.000 & 0.000 & 0.000 & 0.000 \\
\hline $\mathrm{H} \gamma \mathrm{A}$ & -4.187 & 0.480 & -1.115 & 0.000 & 0.416 & 0.185 & -0.174 & -0.043 & 0.008 & 0.065 & 0.026 & -0.103 & -0.858 \\
\hline $\mathrm{H} \gamma \mathrm{F}$ & -1.448 & 0.330 & -0.579 & 0.000 & 0.211 & 0.092 & -0.066 & -0.015 & 0.005 & 0.035 & 0.027 & -0.006 & -0.327 \\
\hline $\mathrm{H} \delta \mathrm{A}$ & -0.781 & 0.640 & -0.268 & -0.003 & 0.059 & 0.053 & -0.432 & -0.002 & 0.003 & 0.043 & 0.001 & -0.011 & -0.438 \\
\hline $\mathrm{H} \delta \mathrm{F}$ & 0.104 & 0.400 & -0.070 & -0.001 & 0.016 & 0.026 & -0.162 & 0.003 & 0.001 & 0.034 & 0.000 & -0.008 & -0.144 \\
\hline
\end{tabular}

Table 31. Spectral index response: Turnoff star $(6724 / 4.15 /-2.25 /+0.30)$.

\begin{tabular}{|c|c|c|c|c|c|c|c|c|c|c|c|c|c|}
\hline (1) & (2) & (3) & (4) & (5) & (6) & (7) & (8) & (9) & (10) & (11) & (12) & (13) & (14) \\
\hline Index & $I_{0}$ & Error & $\mathrm{C}$ & $\mathrm{N}$ & $\mathrm{O}$ & $\mathrm{Mg}$ & $\mathrm{Fe}$ & $\mathrm{Ca}$ & $\mathrm{Na}$ & $\mathrm{Si}$ & $\mathrm{Cr}$ & $\mathrm{Ti}$ & {$[\mathrm{Z} / \mathrm{H}]$} \\
\hline $\mathrm{CN}_{1}$ & -0.123 & 0.021 & 0.000 & 0.000 & 0.000 & 0.000 & 0.001 & 0.000 & 0.000 & 0.000 & 0.000 & 0.000 & 0.000 \\
\hline $\mathrm{CN}_{2}$ & -0.097 & 0.023 & 0.000 & 0.000 & 0.000 & 0.000 & 0.001 & 0.000 & 0.000 & 0.000 & 0.000 & 0.000 & 0.000 \\
\hline $\mathrm{Ca} 4227$ & 0.067 & 0.270 & 0.000 & 0.000 & 0.000 & 0.000 & 0.017 & 0.009 & 0.000 & 0.000 & -0.003 & 0.001 & 0.013 \\
\hline G4300 & -1.460 & 0.390 & 0.016 & 0.000 & 0.000 & 0.000 & 0.007 & 0.038 & 0.000 & 0.000 & & 0.063 & 0.103 \\
\hline $\mathrm{Fe} 4383$ & -0.366 & 0.530 & 0.001 & 0.000 & 0.000 & -0.001 & 0.039 & -0.020 & 0.000 & 0.000 & -0.001 & 0.032 & 0.052 \\
\hline $\mathrm{Ca} 4455$ & 0.025 & 0.250 & 0.000 & 0.000 & 0.000 & -0.004 & 0.008 & -0.005 & 0.000 & 0.000 & 0.000 & 0.009 & 0.013 \\
\hline $\mathrm{Fe} 4531$ & 0.066 & 0.420 & 0.000 & 0.000 & 0.000 & -0.001 & 0.028 & -0.006 & 0.000 & 0.000 & 0.004 & 0.019 & 0.048 \\
\hline$C_{2} 4668$ & -0.002 & 0.640 & 0.000 & 0.000 & 0.000 & 0.016 & 0.025 & 0.001 & 0.000 & -0.001 & -0.007 & 0.001 & 0.006 \\
\hline $\mathrm{H} \beta$ & 4.462 & 0.220 & 0.000 & 0.000 & 0.000 & 0.000 & 0.001 & -0.001 & 0.000 & 0.000 & 0.000 & 0.001 & 0.026 \\
\hline $\mathrm{Fe} 5015$ & 0.060 & 0.460 & 0.000 & 0.000 & 0.000 & 0.000 & 0.040 & 0.002 & 0.001 & 0.000 & 0.000 & 0.017 & 0.066 \\
\hline $\mathrm{Mg}_{1}$ & -0.005 & 0.007 & 0.000 & 0.000 & 0.000 & 0.000 & -0.001 & 0.000 & 0.000 & 0.000 & 0.000 & 0.000 & -0.001 \\
\hline $\mathrm{Mg}_{2}$ & 0.006 & 0.008 & 0.000 & 0.000 & 0.000 & 0.001 & 0.000 & 0.000 & 0.000 & 0.000 & 0.000 & 0.000 & 0.002 \\
\hline $\operatorname{Mg} b$ & 0.307 & 0.230 & 0.000 & 0.000 & 0.000 & 0.050 & 0.008 & 0.000 & 0.000 & 0.000 & -0.014 & 0.005 & 0.049 \\
\hline $\mathrm{Fe} 5270$ & 0.087 & 0.280 & 0.000 & 0.000 & 0.000 & 0.000 & 0.027 & 0.020 & 0.000 & 0.000 & 0.000 & 0.001 & 0.047 \\
\hline Fe5270(Sauron) & 0.096 & & 0.000 & 0.000 & 0.000 & 0.000 & 0.032 & 0.020 & 0.000 & 0.000 & 0.001 & 0.001 & 0.052 \\
\hline $\mathrm{Fe} 5335$ & 0.076 & 0.260 & 0.000 & 0.000 & 0.000 & 0.000 & 0.038 & 0.000 & 0.000 & 0.000 & 0.002 & 0.003 & 0.042 \\
\hline $\mathrm{Fe} 5406$ & 0.030 & 0.200 & -0.001 & 0.000 & 0.000 & 0.000 & 0.022 & 0.000 & 0.000 & 0.000 & 0.002 & -0.002 & 0.021 \\
\hline $\mathrm{Fe} 5709$ & 0.004 & 0.180 & 0.000 & 0.000 & 0.000 & 0.002 & 0.003 & 0.000 & -0.002 & 0.000 & 0.000 & 0.000 & 0.004 \\
\hline $\mathrm{Fe} 5782$ & 0.001 & 0.200 & 0.000 & 0.000 & 0.000 & 0.000 & 0.000 & 0.000 & 0.000 & 0.000 & 0.001 & 0.000 & 0.001 \\
\hline $\mathrm{Na} D$ & 0.151 & 0.240 & 0.000 & 0.000 & 0.000 & 0.000 & -0.002 & -0.002 & 0.030 & 0.000 & 0.000 & 0.000 & 0.026 \\
\hline $\mathrm{TiO}_{1}$ & 0.000 & 0.007 & 0.000 & 0.000 & 0.000 & 0.000 & 0.000 & 0.000 & 0.000 & 0.000 & 0.000 & 0.000 & 0.000 \\
\hline $\mathrm{TiO}_{2}$ & 0.000 & 0.006 & 0.000 & 0.000 & 0.000 & 0.000 & 0.000 & 0.000 & 0.000 & 0.000 & 0.000 & 0.000 & 0.000 \\
\hline $\mathrm{H} \gamma \mathrm{A}$ & & 0.480 & & 0.000 & 0.000 & & & -0.025 & 0.000 & & & -0.046 & -0.067 \\
\hline $\mathrm{H} \gamma \mathrm{F}$ & 4.528 & 0.330 & & 0.000 & 0.000 & 0.005 & -0.008 & -0.009 & 0.000 & 0.000 & -0.001 & -0.005 & -0.001 \\
\hline $\mathrm{H} \delta \mathrm{A}$ & 5.999 & 0.640 & -0.001 & 0.000 & 0.000 & 0.001 & -0.052 & 0.000 & 0.000 & 0.002 & -0.002 & -0.003 & -0.018 \\
\hline $\mathrm{H} \delta \mathrm{F}$ & 4.555 & 0.400 & 0.000 & 0.000 & 0.000 & 0.001 & -0.025 & 0.000 & 0.000 & 0.001 & 0.000 & -0.001 & -0.006 \\
\hline
\end{tabular}


A. J. Korn et al.: The sensitivity of Lick indices to abundance variations, Online Material p 15

Table 32. Spectral index response: Cool giant $(4822 / 1.83 /-2.25 /+0.30)$.

\begin{tabular}{|c|c|c|c|c|c|c|c|c|c|c|c|c|c|}
\hline (1) & (2) & (3) & (4) & (5) & (6) & (7) & (8) & (9) & (10) & (11) & (12) & (13) & (14) \\
\hline Index & $I_{0}$ & Error & $\mathrm{C}$ & $\mathrm{N}$ & $\mathrm{O}$ & $\mathrm{Mg}$ & $\mathrm{Fe}$ & $\mathrm{Ca}$ & $\mathrm{Na}$ & $\mathrm{Si}$ & $\mathrm{Cr}$ & $\mathrm{Ti}$ & {$[\mathrm{Z} / \mathrm{H}]$} \\
\hline $\mathrm{CN}_{1}$ & -0.028 & 0.021 & -0.010 & 0.001 & 0.001 & 0.001 & 0.003 & 0.000 & 0.000 & 0.001 & -0.001 & 0.002 & -0.003 \\
\hline $\mathrm{CN}_{2}$ & -0.021 & 0.023 & -0.012 & 0.001 & 0.001 & 0.001 & 0.004 & 0.000 & 0.000 & 0.002 & 0.000 & 0.002 & -0.001 \\
\hline Ca4227 & 0.102 & 0.270 & -0.053 & -0.009 & 0.003 & 0.003 & 0.016 & 0.053 & 0.000 & 0.001 & -0.006 & 0.010 & 0.016 \\
\hline G4300 & 5.377 & 0.390 & 1.175 & 0.000 & -0.108 & -0.097 & -0.030 & 0.047 & -0.006 & -0.077 & -0.015 & 0.128 & 1.082 \\
\hline $\mathrm{Fe} 4383$ & 1.247 & 0.530 & 0.168 & 0.000 & -0.003 & -0.014 & 0.134 & -0.037 & 0.000 & -0.009 & -0.017 & 0.148 & 0.479 \\
\hline Ca4455 & 0.168 & 0.250 & -0.008 & 0.000 & 0.000 & -0.002 & -0.015 & -0.004 & 0.000 & 0.000 & -0.001 & 0.010 & 0.039 \\
\hline $\mathrm{Fe} 4531$ & 0.948 & 0.420 & 0.012 & 0.000 & -0.001 & -0.021 & 0.097 & -0.020 & 0.000 & 0.003 & 0.035 & 0.261 & 0.386 \\
\hline$C_{2} 4668$ & 0.128 & 0.640 & 0.039 & 0.000 & -0.001 & 0.022 & 0.119 & 0.006 & 0.001 & -0.005 & -0.073 & 0.061 & 0.097 \\
\hline $\mathrm{H} \beta$ & 0.905 & 0.220 & 0.002 & 0.000 & 0.000 & 0.000 & -0.013 & -0.005 & 0.000 & 0.000 & 0.004 & 0.020 & 0.027 \\
\hline Fe5015 & 1.175 & 0.460 & -0.003 & 0.000 & 0.000 & 0.003 & 0.161 & 0.009 & 0.004 & 0.009 & -0.005 & 0.238 & 0.508 \\
\hline $\mathrm{Mg}_{1}$ & -0.006 & 0.007 & 0.000 & 0.000 & 0.000 & 0.001 & 0.001 & 0.000 & 0.000 & 0.000 & -0.001 & 0.000 & 0.002 \\
\hline $\mathrm{Mg}_{2}$ & 0.023 & 0.008 & 0.000 & 0.000 & 0.000 & 0.004 & 0.001 & 0.000 & 0.000 & 0.000 & -0.001 & 0.002 & 0.006 \\
\hline $\operatorname{Mg} b$ & 0.542 & 0.230 & -0.002 & 0.000 & 0.000 & 0.128 & -0.102 & 0.000 & -0.001 & -0.002 & -0.024 & 0.016 & 0.003 \\
\hline Fe5270 & 0.605 & 0.280 & 0.000 & 0.000 & 0.000 & 0.004 & 0.103 & 0.071 & 0.000 & 0.003 & 0.005 & 0.028 & 0.202 \\
\hline Fe5270(Sauron) & 0.558 & & 0.000 & 0.000 & 0.000 & 0.002 & 0.067 & 0.069 & 0.000 & 0.002 & 0.005 & 0.017 & 0.155 \\
\hline Fe5335 & 0.615 & 0.260 & 0.000 & 0.000 & 0.000 & 0.002 & 0.065 & 0.002 & 0.000 & 0.002 & 0.032 & 0.022 & 0.132 \\
\hline Fe5406 & 0.293 & 0.200 & -0.001 & 0.000 & 0.000 & 0.003 & 0.060 & 0.000 & 0.000 & 0.002 & 0.019 & -0.029 & 0.068 \\
\hline Fe5709 & 0.087 & 0.180 & 0.000 & 0.000 & 0.000 & 0.012 & 0.039 & 0.000 & -0.008 & 0.003 & 0.000 & 0.001 & 0.060 \\
\hline Fe5782 & 0.012 & 0.200 & 0.000 & 0.000 & 0.000 & 0.001 & -0.003 & 0.000 & 0.000 & 0.000 & 0.008 & -0.001 & 0.011 \\
\hline $\mathrm{Na} D$ & 0.360 & 0.240 & 0.000 & 0.000 & 0.000 & 0.000 & -0.014 & -0.008 & 0.053 & -0.002 & 0.000 & -0.004 & 0.039 \\
\hline $\mathrm{TiO}_{1}$ & 0.000 & 0.007 & 0.000 & 0.000 & 0.000 & 0.000 & 0.000 & 0.000 & 0.000 & 0.000 & 0.000 & 0.000 & 0.000 \\
\hline $\mathrm{TiO}_{2}$ & -0.001 & 0.006 & 0.000 & 0.000 & 0.000 & 0.000 & 0.001 & 0.000 & 0.000 & 0.000 & 0.000 & 0.000 & 0.000 \\
\hline $\mathrm{H} \gamma \mathrm{A}$ & -4.572 & 0.480 & -1.172 & 0.000 & 0.104 & 0.124 & -0.084 & -0.044 & 0.005 & 0.077 & 0.069 & -0.159 & -1.218 \\
\hline $\mathrm{H} \gamma \mathrm{F}$ & -1.354 & 0.330 & -0.620 & 0.000 & 0.052 & 0.062 & -0.007 & -0.016 & 0.003 & 0.041 & 0.050 & 0.011 & -0.474 \\
\hline $\mathrm{H} \delta \mathrm{A}$ & -0.376 & 0.640 & -0.234 & -0.005 & 0.013 & 0.014 & -0.178 & -0.003 & 0.001 & 0.027 & 0.008 & -0.040 & -0.380 \\
\hline $\mathrm{H} \delta \mathrm{F}$ & 0.216 & 0.400 & -0.061 & -0.001 & 0.003 & 0.006 & -0.088 & 0.002 & 0.000 & 0.022 & 0.003 & -0.024 & -0.194 \\
\hline
\end{tabular}

